PNL-2869

UC-94b

\title{
The Effects of Water on Compressed Air Energy Storage in Porous Rock Reservoirs
}

L. E. Wiles

March 1979

Prepared for the U.S. Department of Energy under Contract EY-76-C-06-1830

Pacific Northwest Laboratory Operated for the U.S. Department of Energy by Battelle Memorial Institute 
This report was prepared as an account of work sponsored by the United States Government. Neither the United States nor the Department of Energy, nor any of their employees, nor any of their contractors, subcontractors, or their employees, makes any warranty, express or implied, or assumes any legal liability or responsibility for the accuracy, completeness or usefulness of any information, apparatus, product or process disclosed, or represents that its use would not infringe privately owned rights.

The views, opinions and conclusions contained in this report are those of the contractor and do not necessarily represent those of the United States Government or the United States Department of Energy.

\author{
PACIFIC NORTHWEST LABORATORY \\ operated by \\ BATTELLE \\ for the \\ UNITED STATES DEPARTMENT OF ENERGY \\ Under Contract EY-76-C-06-1830
}
Printed in the United States of America Available from
National Technical Information Service
United States Department of Commerce
5285 Port Royal Road
Springfield, Virginia 22151

Price: Printed Copy $\$$

*: Microfiche $\$ 3.00$

$\begin{array}{cc}\text { *Pages } & \begin{array}{c}\text { NTIS } \\ \text { Selling Price }\end{array} \\ 001-025 & \$ 4.00 \\ 026-050 & \$ 4.50 \\ 051-075 & \$ 5.25 \\ 076-100 & \$ 6.00 \\ 101-125 & \$ 6.50 \\ 126-150 & \$ 7.25 \\ 151-175 & \$ 8.00 \\ 176-200 & \$ 9.00 \\ 201-225 & \$ 9.25 \\ 226-250 & \$ 9.50 \\ 251-275 & \$ 10.75 \\ 276-300 & \$ 11.00\end{array}$


THE EFFECTS OF WATER ON COMPRESSED AIR ENERGY STORAGE IN POROUS ROCK RESERVOIRS

L.E. Wiles

March 1979

Prepared for

the U.S. Department of Energy

under Contract EY-76-C-06-1830

Pacific Northwest Laboratory

Richland, Washington 99352 
$\checkmark$

$\checkmark$

, 
FOREWORD

The Compressed Air Energy Storage Technology Program at the Pacific Northwest Laboratory is sponsored by the Department of Energy, Division of Energy Storage Systems. The program scope includes a group of studies directed at developing a new energy storage technology to improve the cost and efficiency of electrical power utilization and reducing the dependence on premium fuels such as oil and natural gas. The program has two major thrusts --- Reservoir Stability Criteria Studies and Advanced Concepts Studies. These have the following objectives:

Reservoir Stability Criteria Studies

- Develop design and stability criteria for long-term operation of underground reservoirs used for CAES in order to accelerate the commercialization of the concept.

Advanced Concepts Studies

- Develop and assess advanced CAES concepts that require little or no supplementary firing by premium fuels in order to elimjnate the dependence of CAES on premium fuels.

The ultimate objective of this program is to reduce the consumption of natural gas and oil, used for peak-power generation plants, by about $100,000,000$ barrels per year. This could be accomplished by replacing conventional gas turbine peaking plants currently being used by utilities with CAES plants.

The following documents have been issued by PNL or by subcontractors to PNL reporting the results of the work toward these objectives.

- Air Storage Peaking Power Plants Utilizing Modified Industrial Gas Turbines and Cavities with Nuclear Explosives, B.C. Fryer, BNWL-1748, May 1973.

- Technical and Economic Feasibility Analysis of the No-Fuel Compressed Air Energy Storage Concept, D.K. Kreid, BNWL-2065, May 1976. 
- FY-1977 Progress Report - Stability and Design Criteria Studies for Compressed Air Energy Storage Reservoirs, G.C. Smith, J.A. Stottlemyre, L.E. Wiles, W.V. Loscutoff and H.J. Pincus, PNL-2443, March 1978.

- FY-1977 Progress Report - Compressed Air Energy Storage Advanced Systems Analysis, D.K. Kreid and M.A. McKinnon, PNL-2464, March 1978.

- Preliminary Stability Criteria for Compressed Air Energy Storage in Porous Media Reservoirs, J.A. Stottlemyre, PNL-2685, June 1978.

- Preliminary Long-Term Stability Criteria For Compressed Air Energy Storage Caverns in Salt Domes, R.L. Thoms and J.D. Martinez, August 1978.

- Numerical Analysis of Temperature and Flow Effects in a Dry, OneDimensional Aquifer Used for Compressed Air Energy Storage, G.C. Smith, L.E. Wiles, and W.V. Loscutoff, PNL-2546, February 1979. 


\section{SUMMARY}

The analysis described in this report continues work initiated at PNL in FY-1977. A computer code was developed in FY-1977 to define the hydrodynamic and thermodynamic response to simulated air mass cycling in a CAES dry porous rock reservoir. The code was based on one-dimensional, radial transport of mass and energy through a homogeneous, rigid porous material. A parametric study of the behavior of a one-dimensional dry porous rock reservoir, based on the code was presented in Reference 1. The capability of the code was extended in FY-1978 to permit a onedimensional, radial flow analys is of the effects of water on reservoir performance. This code was also based on the assumption of transport through a homogeneous, rigis porous media. The analytical and numerical models and the analysis of the moisture parameters are presented in this report.

The effect of the presence of water on the performance of a CAES porous rock reservoir was analyzed. Reservoir geometry, material properties and operating conditions were given reference values that were fixed throughout the analysis. The operating conditions included specification of a weekly cycle for the injection and extraction of mass to and from the reservoir. An important assumed initial condition of the reservoir was that the residual water was uniformly distributed. The parameters that were investigated with respect to the moisture problem were injection temperature, injection humidity and residual water content. Significant results obtained from the numerical model were:

- For a broad range of conditions of the three parameters that were studied, comparatively rapid dehydration of the near wellbore region can be achieved.

- Dehydration of the near wellbore region can be achieved even though the injection of moist air results in an increase in the amount of liquid water in the reservoir.

- The presence of water has only a small effect, compared to a dry reservoir, on thermal cycling, thermal growth, and thermal energy recovery. 
- Significant increases in the storage volume of the reservoir should not be expected to occur due to the dehydration process.

- Evaporation due to dry air injection or condensation from moist air injection will not significantly affect the amount of working fluid or the thermal energy recovery.

- For dry air injection, pore plugging due to local accumulation of liquid phase water should not be a problem.

- For moist air injection, the potential exists for pore plugging to occur due to local accumulation of liquid phase water.

- Dry air injection minizes the potential for the occurrence of adverse geochemical reactions associated with the coexistence of high temperatures and liquid water. 


\section{CONTENTS}

FOREWORD . . . . . . . . . . . . . . . . . . . . . . . . . .

SUMMARY . . . . . . . . . . . . . . . . . . . . . V V

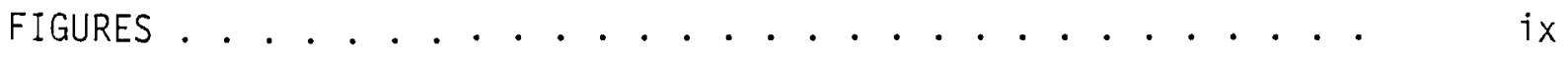

NOMENCLATURE . . . . . . . . . . . . . . . . . . . . $\quad x i$

T.O INTRODUCTION . . . . . . . . . . . . . . . . . . . . . . 1

2.0 ANALYTICAL MODEL . . . . . . . . . . . . . . . . 5

2.1 GOVERNING EQUATIONS . . . . . . . . . . . . . . 5

2.2 REDUCED EQUATIONS . . . . . . . . . . . . . . . . . . . 6

2.3 RATE OF EVAPORATION . . . . . . . . . . . . . 10

2.4 RELATIVE PERMEABILITY . . . . . . . . . . . . . 10

2.5 BOUNDARY CONDITIONS . . . . . . . . . . . . . . . . . . . . . . . 13

2.6 LIMITATIONS OF THE MODEL . . . . . . . . . . . 15

2.7 SUMMARY OF ASSUMPTIONS . . . . . . . . . . . . . 17

3.0 NUMERICAL MODEL ...................... . . . . . . 19

3.1 FINITE DIFFERENCE EQUATIONS . . . . . . . . . . . . . 19

3.2 SOLUTION METHOD: PRESSURE AND TEMPERATURE . . . . . . 23

3.3 SOLUTION METHOD: EVAPORATION RATE . . . . . . . . . 27

3.4 BOUNDARY CONDITIONS . . . . . . . . . . . . . . . . . 28

3.5 CODE VERIFICATION . . . . . . . . . . . . . . . . 29

4.0 ANALYSIS OF THE MOISTURE PARAMETERS . . . . . . . . . . . 31

4. 1 REFERENCE RESERVOIR . . . . . . . . . . . . . . 32

4.2 WEEKLY CAES CYCLE . . . . . . . . . . . . . . . . . . . 35

4.3 ANALYSIS OF THE REFERENCE RESERVOIR . . . . . . . . . 38

4.3.1 Dehydration ................ . . . 38

4.3.2 Thermal Cycling and Thermal Growth . . . . . . 43

4.3.3 Pressure Cycling . . . . . . . . . . . . 50

4.4 INJECTION TEMPERATURE . . . . . . . . . . . . . . . 54

4.5 INJECTION HUMIDITY . . . . . . . . . . . . . . . 61

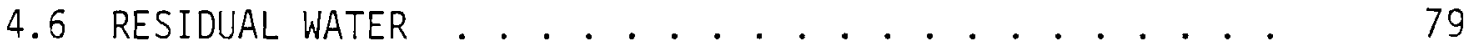

5.0 SUMMARY, CONCLUSIONS AND RECOMMENDATIONS FOR FURTHER STUDY . 82

5. 1 DELIVERABILITY . . . . . . . . . . . . . . . . . 82 
5.2 THERMAL ENERGY RECOVERY . . . . . . . . . . . 83

5.3 WORKING FLUID RECOVERY ............ 83

5.4 STORAGE VOLUME .................. 84

5.5 PRODUCED VAPOR ...................... 84

5.6 FURTHER STUDY . . . . . . . . . . . . 84

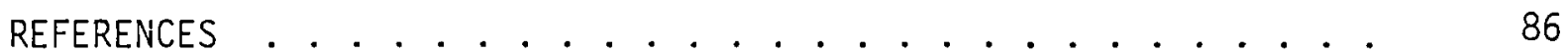




\section{FIGURES}

1 Relative Permeability to a Gas and a Liquid in Consolidated and Unconsolidated Sands . . . . . . . . . . . . . 11

2 Simplified Model for Relative Permeability . . . . . . . . 12

3 Single Well Reservoir Geometry ............. 13

4 Single Well Symmetry in a CAES Well Field . . . . . . . . . . . 14

5 Finite Difference Grid . . . . . . . . . . . . . . . . 19

6 Calculational Flow Chart............ 24

7 Percent of Mass Cycled for the Reference Conditions. . . . . . . 35

8 Weekly Variation of Average Reservoir Pressure . . . . . . . . 36

9 Reference Weekly Reservoir Pressure Cycle. . . . . . . . . . . 37

10 Dehydration for Three Locations (1-Year History). . . . . . . . 40

11 Dehydration for Three Locations (5-Year History) . . . . . . . . 41

12 Radius of the Dry Front for the Reference Reservoir. . . . . . . 42

13 Thermal Cycling During the First Week of Reservoir Operation . . 44

14 Therma1. Cycling During the 52nd Week of Reservoir Operation. . . 45

15 Effect of Thermal Growth on Extraction Temperatures. . . . . . . 46

16 Thermal Growth in the Reservoir. . . . . . . . . . . . . . 48

17 Effect of Residual Water on Thermal Growth........... 49

18 Effect of Percent of Mass Cycling on Thermal Growth. ...... 51

19 Weekly Pressure Cycle. . . . . . . . . . . . . . . 52

20 Effect of Residual Water and Thermal Growth on Pressure Cycling. . . . . . . . . . . . . . . . 53

21 Effect of Injection Temperature on Growth of the Dry Front . . . 55

22 Maximum Well Pressure During the First Week of Reservoir Operation as a Function of Injection Temperature ....... 56

23 Effect of Injection Temperature on the Net Reservoir Dehydration Rate................. 58

24 Effect of Injection Temperature on the Temperature at the Dry Front. ................... 59

25 Saturation Humidity Corresponding to Temperature and Pressure at the Dry Front. . . . . . . . . . . . . . . . . . 60

26 Saturated Absolute Humidity at $50 \mathrm{~atm}(5070 \mathrm{kPa})$. . . . . . 62 


\section{FIGURES (continued)}

27 Effect of Injection Humidity on the Dehydration of the Region Centered at a Radius of $14.0 \mathrm{ft}(4.27 \mathrm{~m})$. . . . . . 63

28 Effect of Injection Humidity on Thermal Growth. . . . . . . . 65

29 Effect of Injection Humidity on Extraction Temperature for Various Values of Residual Water. . . . . . . . . . . . 66

30 Effect of Injection Humidity on Initial Reservoir Dehydration Rates for Various Values of Residual Water. . . . . . . . . 67

31 Effect of Injection Humidity on Initial Reservoir Dehydration Rates for Various Values of Injection Temperature . . . . . . 68

32 Effect of Injection Humidity on Dehydration Rate: $100^{\circ} \mathrm{F}\left(38^{\circ} \mathrm{C}\right)$ Injection Temperature ................ 70

33 Effect of Injection Humidity on Dehydration Rate: $150^{\circ} \mathrm{F}\left(66^{\circ} \mathrm{C}\right)$ Injection Temperature . . . . . . . . . . . . . . 70

34 Effect of Injection Humidity on Dehydration Rate: $250^{\circ} \mathrm{F}$ $\left(121^{\circ} \mathrm{C}\right)$ Injection Temperature ............ . 71

35 Effect of Injection Humidity on Dehydration Rate: $350^{\circ} \mathrm{F}$ $\left(177^{\circ} \mathrm{C}\right.$ ) Injection Temperature ............. . . 72

36 Effect of Injection Humidity on Dehydration Rate: $450^{\circ} \mathrm{F}$ $\left(232^{\circ} \mathrm{C}\right.$ ) Injection Temperature .............. 73

37 Effect of Injection Humidity on Growth of the Dry Front: $100^{\circ} \mathrm{F}\left(38^{\circ} \mathrm{C}\right)$ Injection Temperature. . . . . . . . . . . . . . 74

38 Effect of Injection Humidity on Growth of the Dry Front: $150^{\circ} \mathrm{F}\left(66^{\circ} \mathrm{C}\right)$ Injection Temperature. . . . . . . . . . 75

39 Effect of Injection Humidity on Growth of the Dry Front: $250^{\circ} \mathrm{F}\left(121^{\circ} \mathrm{C}\right)$ Injection Temperature . . . . . . . . . . . 76

40 Effect of Iniection Humidity on Growth of the Dry Front: $350^{\circ} \mathrm{F}(1770 \mathrm{C})$ Injection Temperature . . . . . . . . . . . 77

41 Effect of Injection Humidity on Growth of the Dry Front: $450^{\circ} \mathrm{F}\left(232^{\circ} \mathrm{C}\right)$ Injection Temperature . . . . . . . . . . . 78

42 Effect of Residual Water on Dehydration Rate. . . . . . . . . . 80

43 Effect of Residual Water on Growth of the Dry Front . . . . . . 81 


\section{NOMENCLATURE}

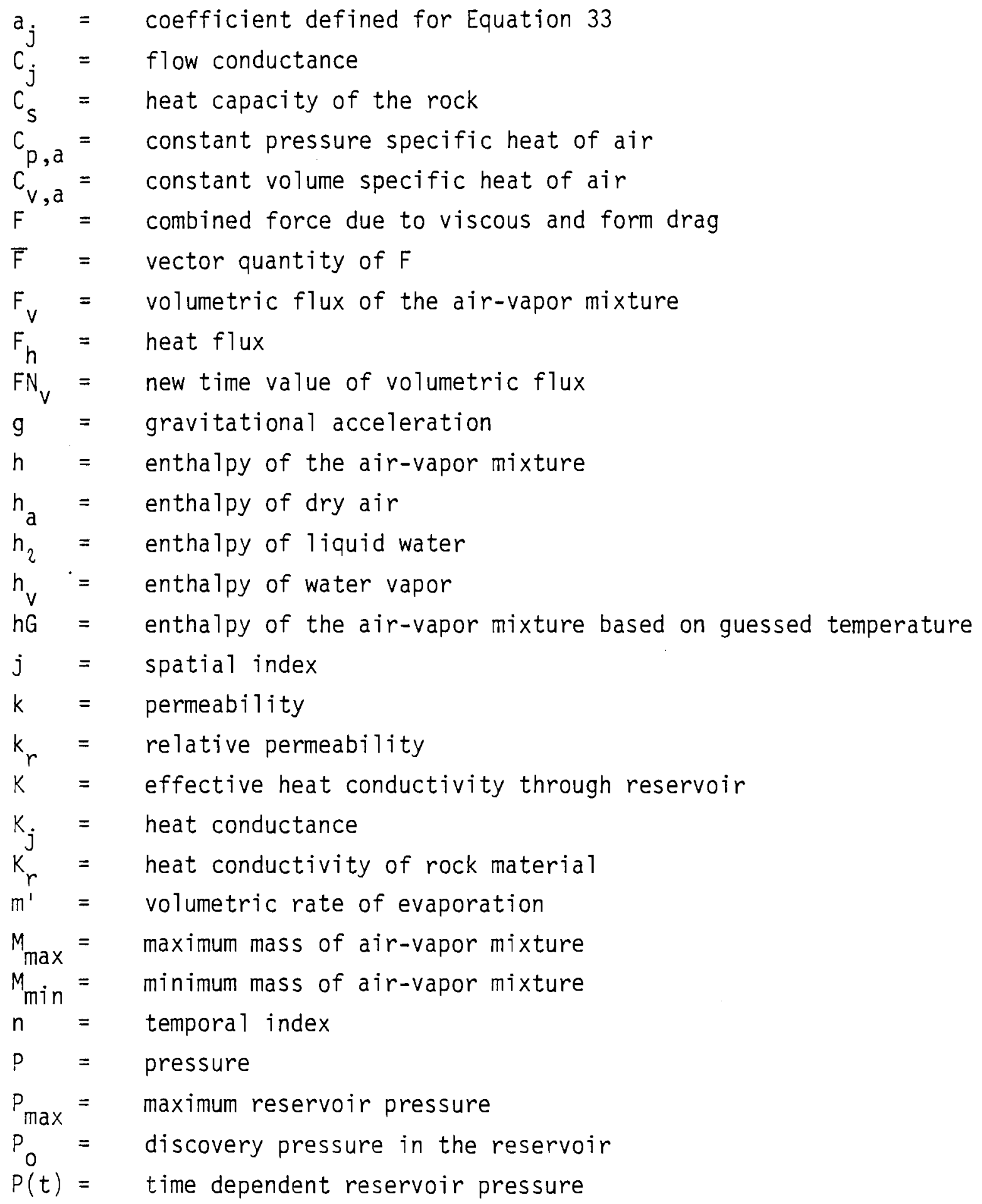




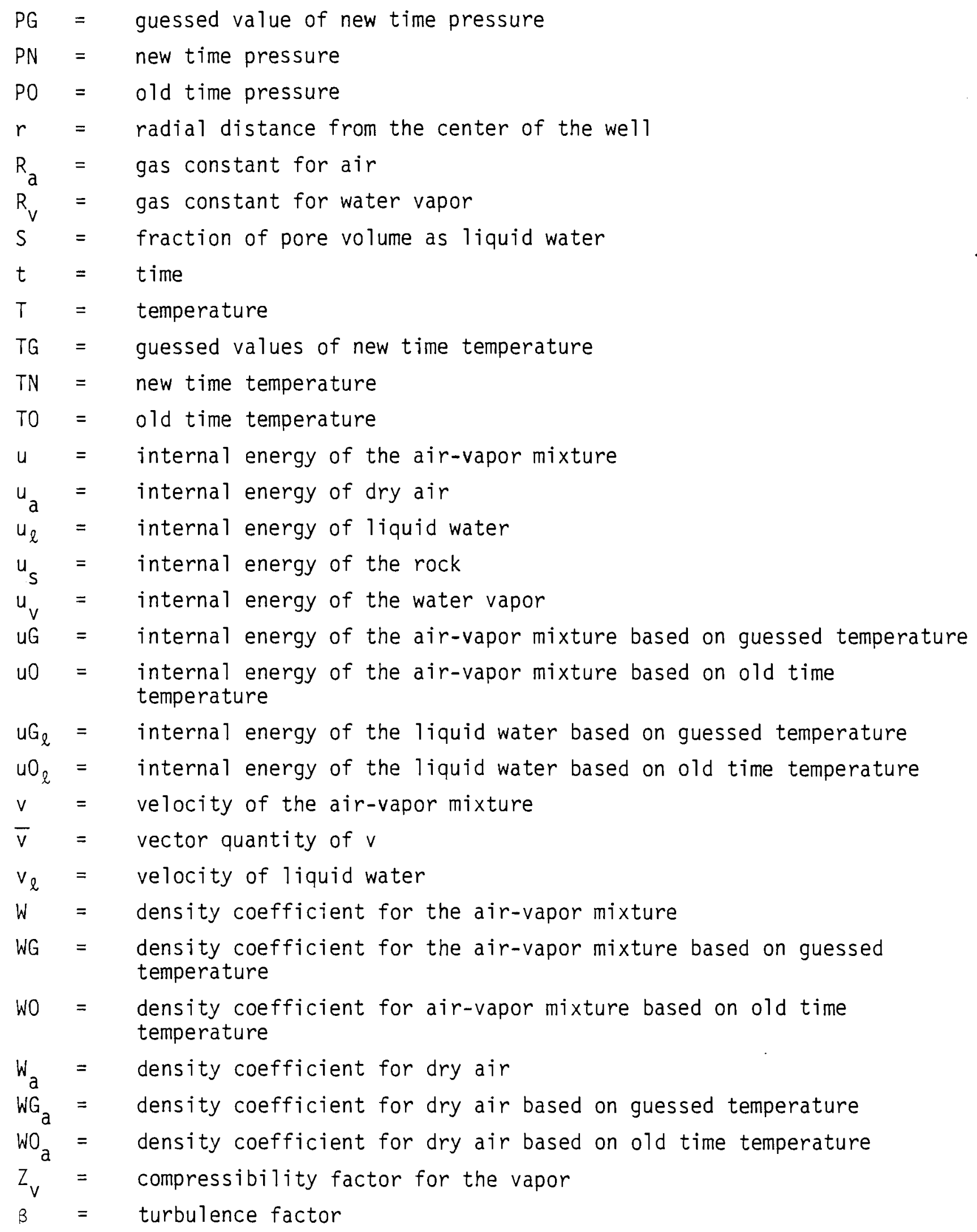




$$
\begin{aligned}
& \phi \quad=\text { porosity } \\
& \rho=\text { density of the air-vapor mixture } \\
& \rho_{a}=\text { density of dry air } \\
& \rho_{\ell}=\text { density of liquid water } \\
& \rho_{S}=\text { density of the rock } \\
& \rho_{V}=\text { density of water vapor } \\
& \rho G_{\ell}=\text { density of liquid water based on guessed temperature } \\
& \rho O_{\ell}=\text { density of liquid water based on old time temperature } \\
& \lambda=\text { maximum fractional change in stored mass over weekly cycle } \\
& \psi \quad=\text { fraction of weekly charge occurring on weekend } \\
& \omega \quad=\text { absolute humidity } \\
& \mu \quad=\text { viscosity of the air-vapor mixture }
\end{aligned}
$$


$\checkmark$

-

$+$ 
THE EFFECTS OF WATER ON COMPRESSED AIR ENERGY

STORAGE IN POROUS ROCK RESERVOIRS

\subsection{INTRODUCTION}

\subsection{BACKGROUND}

The analysis of the hydrodynamic and thermodynamic response to air cycling in CAES porous media reservoirs is intended to provide design guidelines for the efficient and stable operation of the air storage reservoir. The performance of the reservoir depends on reservoir material properties, reservoir geometry, and operating conditions. The influence of many of the important parameters was investigated at PNL in FY-1977. These parameters are:

- porosity

- permeability

- rock thermal conductivity

- rock thermal capacity

- reservoir diameter

- well diameter

- nominal pressure

- percent of mass cycling

- mass flow rate

- air injection temperature.

The analysis of these parameters made use of a computer code based on one-dimensional radial transport of mass and energy in a dry porous rock reservoir. (1)

In actual practice, the assumption that a reservoir is free of water may not be valid. Water from two general sources may be present in the reservoir. First, during the development of the cushion-air bubble, a significant amount of water will typically remain trapped in the air storage zone in dead-end pores and by capillary forces. This water is 
referred to as the residual water. Second, water may enter or exit the air storage zone as humidity in the air stream, by gravity drainage, or by coning. In view of this, the capability of the code was extended to permit the analysis of the effects of water on reservoir performance. Potential problems that could be evaluated with a one-dimensional model were identified. These did not include gravity drainage or coning. The problems related to the presence of residual water in the reservoir and humidity in the injected air stream, included the effect of water on the following parameters:

- deliverability

- thermal energy recovery

- working fluid recovery

- storage volume

- produced vapor.

A brief description of the effect of water on each of these parameters is given below.

Deliverability is a function of the pressure gradients required to maintain a prescribed mass flow rate to or from the reservoir. The presence of water near the wellbore can reduce the permeability of the porous material, thereby requiring a larger pressure gradient to maintain that flow rate. The permeability loss occurs by two general mechanisms. The water may stimulate geochemical responses such as clay swelling and particulate generation, both of which may constrict the flow passages. In the presence of water, the relative permeability to the flow of air may be reduced because water exists in the flow passages and/or there are viscous interactions between the water and air. In the limit, water may fill the pore space in a local region causing the relative permeability to go to zero. This would dramatically affect the stability of reservoir deliverability. Whether the permeability loss is due to geochemistry or reduced relative permeability, the reduced permeability will result in a corresponding reduction in the deliverability of the reservoir. 
If dry air is to be cycled into a reservoir initially containing residual water, the resultant net evaporation will diminish the thermal energy recovery because some of the injected energy will be lost as latent heat. On the other hand, if moist air is injected into the reservoir condensation may result. The addition of latent heat due to the condensation of water vapor would increase the recovery of thermal energy.

The recovery of thermal energy must be weighed against the recovery of the working fluid. Increasing thermal energy recovery by the condensation of water vapor from the injected air stream results in a loss in the mass of working fluid. Decreasing thermal energy recovery by the evaporation of residual water increases the mass of working fluid.

The air storage volume is diminished by the presence of residual water, thereby reducing the effectiveness of the reservoir. The injection of dry air may result in net dehydration of the reservoir, which would increase the storage volume.

If moist air is injected, vapor condensing out of the produced air stream may result in corrosion problems in the well casing and in the above ground equipment. Also, condensate falling to the bottom of the well has the potential for causing bottom hole piugging.

\subsection{OBJECTIVE}

The objective of this analysis is to quantify the magnitudes of the potential effects of residual water on the operation of an aquifer CAES facility. This has been done by numerically solving the conservation equations describing the transport of mass and energy in the reservoir. The results of the analysis provide reservoir behavior in terms of pressure, flow rate, temperature, humidity, and residual water conditions as functions of time. The change in response of the reservoir to variation of residual water content, injection air humidity and injection air temperature demonstrates the impact of these parameters. 


\subsection{ANALYTICAL MODEL}

The physical response of a porous material subjected to nonisothermal flow of moist air can be described by appropriate conservation equations and constitutive relations. Together, these form the analytical model described in this section.

\subsection{GOVERNING EQUATIONS}

The hydrodynamic and thermodynamic behavior of a CAES porous rock reservoir can be characterized by a set of conservation equations describing the flow of an air-vapor mixture and liquid water through a rigid porous material. Assumptions may be made that result in a set of equations which includes only terms relevant to air storage in porous rock reservoirs. These assumptions are:

- The air-vapor mixture is homogeneous.

- The rock porosity and density are constant.

- The rock is immobile.

- Binary diffusion in the air-vapor mixture is negligible.

- Inertial effects are negligible.

- The air-vapor mixture, liquid, and rock are in thermal equilibrium; i.e., only one temperature is required to characterize the thermal condition at a given location.

- Kinetic energy is negligible.

- Viscous dissipation of energy is negligible.

With these assumptions, the conservation equations that apply to the transport of mass, momentum and energy in a CAES porous rock reservoir are written as follows:

Conservation of mass in the reservoir

$$
\phi \frac{\partial}{\partial t}\left\{(1-S)_{\rho}+S_{\rho}\right\}+\nabla \cdot\left(\rho \bar{v}+\rho_{\ell} \bar{v}_{\ell}\right)=0
$$


Conservation of mass for the water vapor

$$
\phi \frac{\partial}{\partial t}\left\{(1-S) \rho_{v}\right\}+\nabla \cdot\left(\rho_{v} \bar{v}\right)=m^{\prime}
$$

Conservation of mass of the liquid water

$$
\phi \frac{\partial}{\partial t}\left(S \rho_{\ell}\right)+\nabla \cdot\left(\rho_{\ell} \bar{v}_{\ell}\right)=-m^{\prime}
$$

Conservation of momentum in the reservoir

$$
0=-\phi \nabla P-\bar{F}+\phi(1-S) \rho \bar{g}+\phi S_{\rho} \bar{g} ; \text { and }
$$

Conservation of energy in the reservoir

$$
\begin{gathered}
\phi \frac{\partial}{\partial t}\left\{(1-S) \rho u+S \rho_{\ell} u_{\ell}\right\}+(1-\phi) \rho_{S} \frac{\partial}{\partial t}\left(u_{s}\right) \\
=-\nabla \cdot\left(\rho h \bar{v}+\rho_{\ell} h_{\ell} \bar{v}_{\ell}\right)+\nabla \cdot(K \nabla T) .
\end{gathered}
$$

\subsection{REDUCED EQUATIONS}

Two important assumptions were made to reduce the governing equations to a form that would facilitate the initial analysis of the effects of water on reservoir behavior. These assumptions are:

- The transport of mass and energy is considered to occur only in the radial, (horizontal) direction.

- The liquid water is immobile.

The first assumption is justified for at least two reasons. First, the effective permeability in the horizontal direction is typically greater than in the vertical direction. As a result, mass flow will be

predominantly horizonta 1. Second, the reservoir thickness is large enough that the performance of most of the reservoir will not be significantly affected by the presence of the caprock and basement rock.

The second assumption is considered valid, provided the pore volume liquid water content never significantly exceeds the residual 
leve1. For such conditions the relative permeability to the flow of liquid would be low, thereby inhibiting the flow of liquid water. This condition can be satisfied if the absolute humidity of the air injected into the reservoir is relatively low.

Applying these two assumptions to the governing equations yields the following set of equations:

Conservation of mass in the reservoir

$$
\phi \frac{\partial}{\partial t}\left\{(1-S) \rho+S_{\rho}\right\}+\frac{1}{r} \frac{\partial}{\partial r}(\rho r v)=0
$$

Conservation of mass for the water vapor

$$
\phi \frac{\partial}{\partial t}\left\{(1-S)_{p_{v}}\right\}+\frac{1}{r} \frac{\partial}{\partial r}\left(\rho_{v} r v\right)=m^{\prime} ;
$$

Conservation of mass for the liquid water

$$
\phi \frac{\partial}{\partial t}\left(S \rho_{\ell}\right)=-m^{\prime} ;
$$

Conservation of momentum in the reservoir

$$
0=-\frac{\partial P}{\partial r}-\frac{F}{\phi}
$$

Conservation of energy in the reservoir

$$
\begin{aligned}
& \phi \frac{\partial}{\partial t}\left\{(1-s) \rho u+S_{\rho_{\ell}} u_{\ell}\right\}+(1-\phi) \rho_{s} \frac{\partial}{\partial t}\left(u_{s}\right) \\
& =-\frac{1}{r} \frac{\partial}{\partial r}(\rho h r v)+\frac{1}{r} \frac{\partial}{\partial r}\left(K r \frac{\partial T}{\partial r}\right)
\end{aligned}
$$

A simultaneous solution of Equations 6 and 10 yields pressure and temperature, respectively. Equations 7,8 , and 9 serve as constitutive relations.

A number of substitutions must be made to facilitate the solution of the above equations. 
The velocity can be written in terms of the pressure gradient by application of Darcy's law which is suitable for low velocity flows in porous media. The combined viscous and form drag force, $F / \phi$, is related to the fluid velocity by

$$
\frac{F}{\phi}=\frac{\mu}{k k_{r}} v
$$

Substitution of Equation 11 in Equation 9 allows the fluid velocity to be written in terms of pressure gradient as

$$
v=-\frac{k k_{r}}{\mu} \frac{\partial p}{\partial r}
$$

For high velocity flows the Forchheimer form of Equation 11 could be required, i.e.,

$$
\frac{F}{\phi}=\frac{\mu}{k k_{r}} v+\rho \beta|v| v .
$$

The Forchheimer form was not used because the FY-1977 results showed that for the conditions of this analysis (i.e., permeability of $500 \mathrm{md}$ and flow rates on the order of $0.101 \mathrm{bm} / \mathrm{sec} / \mathrm{ft}(0.15 \mathrm{~kg} / \mathrm{sec} / \mathrm{m}))$, effects of the second order term were not significant. Thus, Darcy's law was used in the study.

Various additional substitutions were made, which will now be outlined.

The density of the air-vapor mixture based on ideal gas behavior of air and vapor can be written as

$$
\rho=W P
$$

where

$$
W=\left(\frac{R_{a}}{Z_{v} R_{v}}+\omega Z_{v} R_{v} T\right)^{-1}(1+w)
$$

The internal energy of the air-vapor mixture is

$$
\rho u=\rho_{a} u_{a}+\rho_{v} u_{v}
$$


which becomes

$$
\rho u=W_{a} P\left(C_{v}, a T+w u_{v}\right)
$$

where the following substitutions have been made:

$$
\begin{aligned}
\rho_{v} & =w \rho_{a}, \\
\rho_{a} & =w_{a} P, \\
w_{a} & =\frac{w}{1+w}, \\
\text { and } & \\
u_{a} & =c_{v, a} T
\end{aligned}
$$

The enthalpy of the air-vapor mixture is

$$
\rho h=\rho_{a} h_{a}+\rho_{v} h_{v}
$$

Equations 17,18 , and 19 are used in addition to

$$
h_{a}=C_{p, a^{\top}}
$$

to convert Equation 21 to the following form

$$
\rho h=W_{a} P\left(C_{\left.p, a^{\top}+\omega h_{v}\right)}\right.
$$

The internal energy of the rock is

$$
u_{s}=C_{s} T
$$

By substitution of Equations 8, 11, 14, 16, 23, and 24, the set of equations that are solved to obtain the hydrodynamic and thermodynamic responses of the reservoir become: 
Conservation of mass

$$
\phi \frac{\partial}{\partial t}\{(1-S) W P\}-\frac{1}{r} \frac{\partial}{\partial r}\left\{W P r\left(\frac{k k r}{\mu} \frac{\partial P}{\partial r}\right)\right\}=m^{\prime}
$$

Conservation of energy

$$
\begin{aligned}
& =\frac{\partial}{\partial t}\left\{(1-S) W_{a} P\left(C_{v}, a T+w u_{v}\right)+S_{\rho_{l}} U_{l}\right\} \\
& +(1-\phi) \rho_{S} C_{S} \frac{\partial T}{\partial t} \\
& =-\frac{1}{r} \frac{\partial}{\partial r}\left\{W_{a} P\left(C_{p, a}{ }^{\top}+\omega h_{v}\right) r\left(\frac{k k_{r}}{\mu} \frac{\partial P}{\partial r}\right)\right\} \\
& +\frac{1}{r} \frac{\partial}{\partial r}\left(K r \frac{\partial T}{\partial r}\right)
\end{aligned}
$$

In Equation 26 the heat capacity of the rock, $C_{S}$, is assumed constant.

\subsection{RATE OF EVAPORATION}

The prediction of the rate of evaporation, $\mathrm{m}^{\prime}$, is based on the assumption that the air-vapor mixture will always be saturated according to the temperature and pressure at a location if liquid water is also present at that location. This assumption effectively states that saturation is achieved instantaneously. If insufficient water is available to achieve saturation, adjustments are made to the evaporation rate prediction.

The evaporation rate is modeled as a volumetric source term, having the units of $1 \mathrm{bm} / \mathrm{ft}^{3} / \mathrm{sec}\left(\mathrm{kg} / \mathrm{m}^{3} / \mathrm{sec}\right)$.

\subsection{RELATIVE PERMEABILITY}

If a pressure gradient is imposed on a porous material in which a liquid and gas coexist, the flow of each component will be less than what would be predicted by using the permeability of the material to a 
single component. The apparent reduced permeability is termed the relative permeability. The relative permeability as a function of percent of pore volume containing liquid is shown in Figure 1. The sum of the relative permeabilities is generally near unity except through the middle of the curve where viscous interaction of the two components becomes significant. When the percent of pore volume as a liquid approaches $100 \%$, the liquid displaces the gas from the flow paths which reduces the permeability to the flow of the gas. For low values of liquid content the permeability to the flow of liquid is reduced because liquid is held in dead-end pores and by capillary forces.

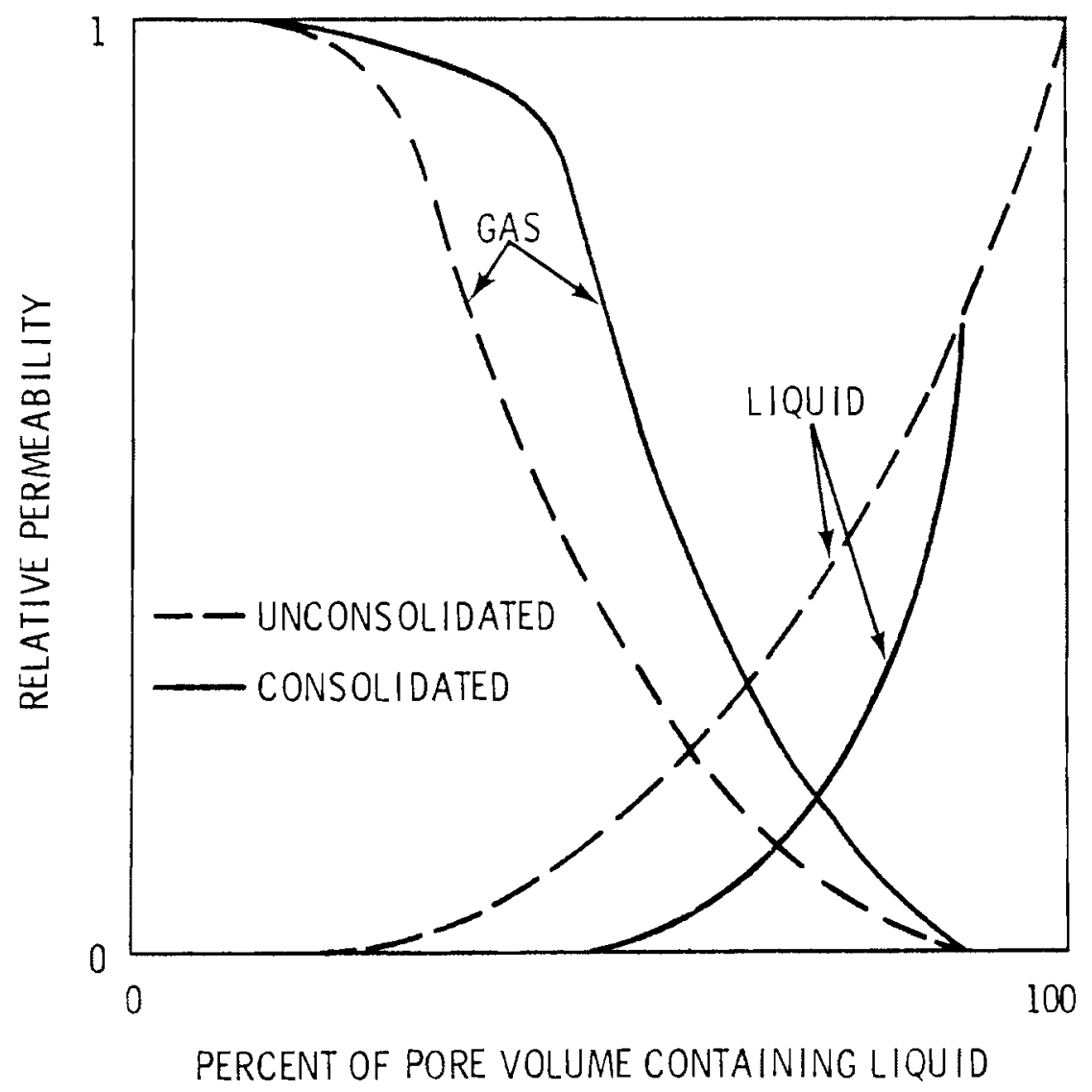

FIGURE 1. Relative Permeability to a Gas and a Liquid in Consolidated and Unconsolidated Sands 
In this analysis the relative permeability was modeled as shown in Figure 2. The relative permeability to the flow of the air-vapor mixture decreases linearly from unity at the residual liquid water content to zero for a material that is saturated with liquid water. The relative permeability to the flow of liquid water increases linearly from zero at the residual water content to unity for a liquid saturated material. (For the assumption of zero liquid mobility the effective permeability to the flow of liquid water is zero regardless of water content.) A more sophisticated model would have been warranted if the analysis of the moisture parameters had indicated that relative permeability caused a significant impact on the hydrodynamic response of an aquifer CAES reservoir subjected to flow cycling. This did not occur, however.

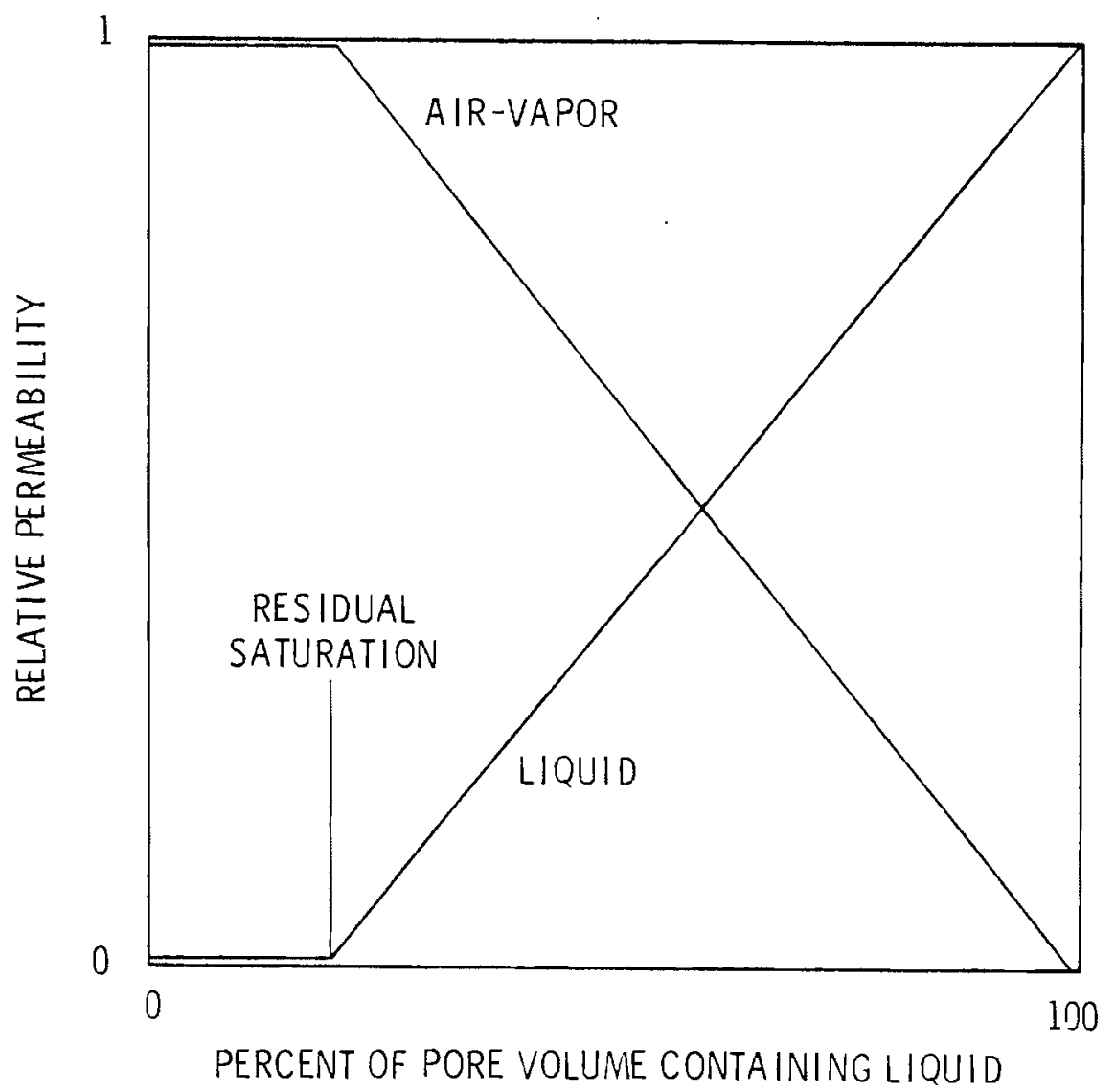

FIGURE 2. Simplified Model For Relative Permeability 


\subsection{BOUNDARY CONDITIONS}

The reservoir geometry adapted to this problem is shown in Figure 3. The region of influence of a single well is approximated as a radially symmetric cylindrical disc having unit vertical thickness.

The number of wells in an aquifer air storage field for a typical CAES application will be several hundred. The we11s will probably be arranged in a uniform pattern. In general, a single well can thus be characterized as being surrounded by other wells that are being charged or discharged at about the same rate. The symmetry involved, which is enhanced by the assumed homogeneous structure of the reservoir, would create a plane located halfway between adjacent wells through which there would be essentially no net flow of heat or mass. Consequently, the cylindrical outer boundary of the analytical reservoir model was defined as an insulated boundary. The symmetry of individual wells in a well field is shown in Figure 4.

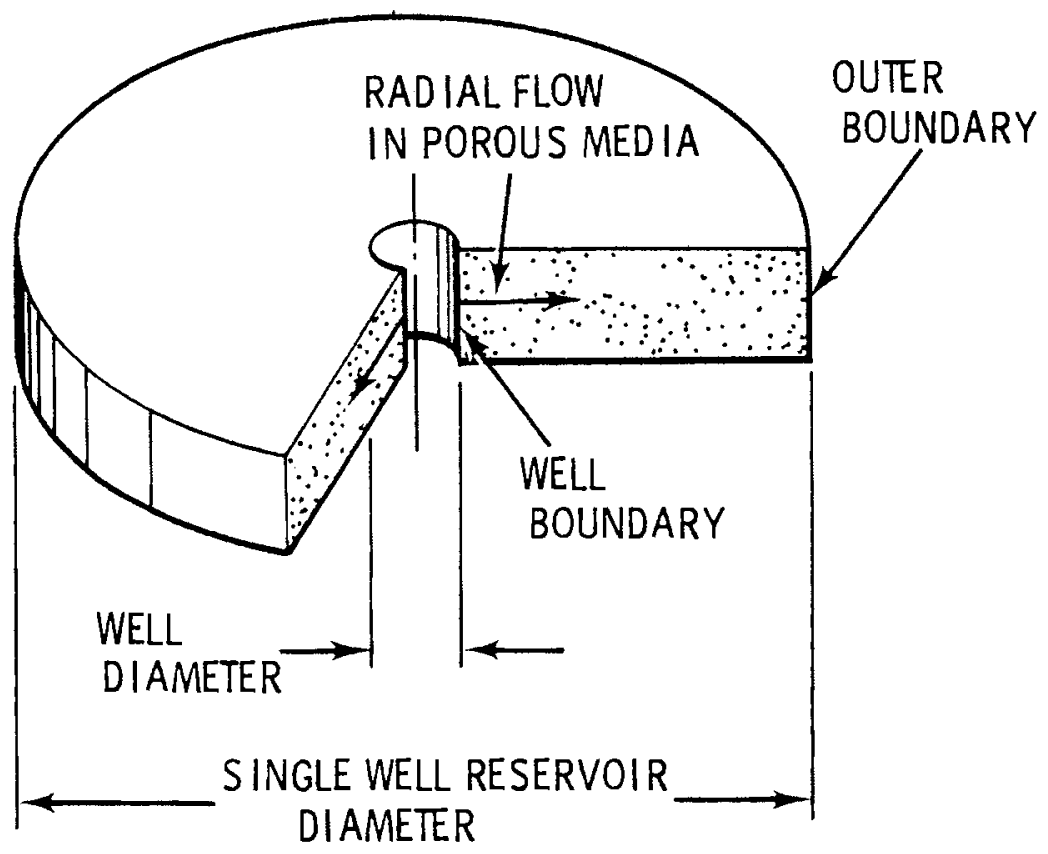

FIGURE 3. Single We11 Reservoir Geometry 

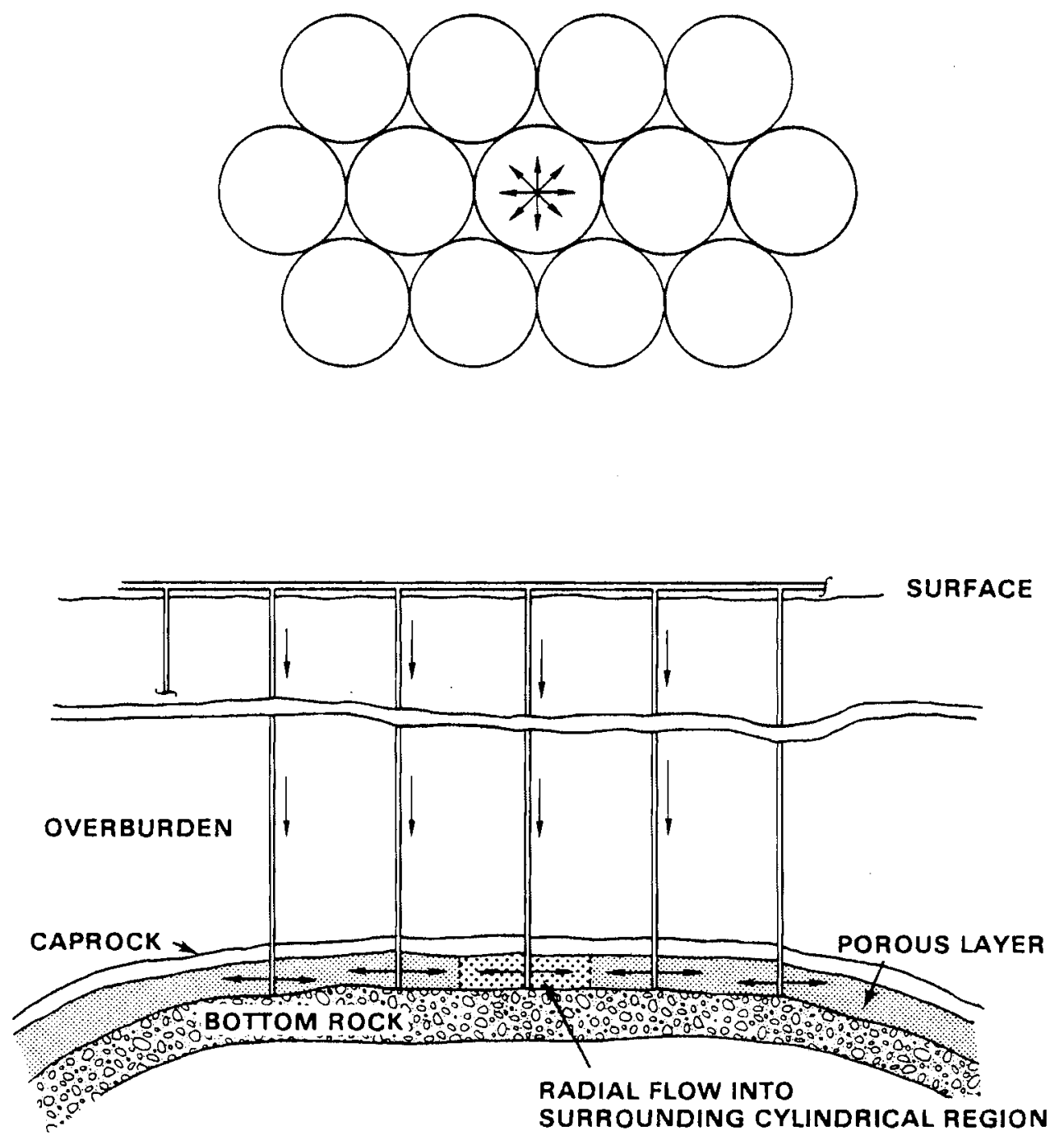

FIGURE 4. Single Well Symmetry in a CAES Well Field 
During the power generation cycle, the power produced is approximately proportional to the air mass flow rate delivered from the reservoir. Therefore, during reservoir discharge (power production cycle) a constant flow boundary condition at the well was simulated in the analytical mode 1 to approximate constant power generation. The temperature and humidity of the extracted air-vapor mixture was determined by the thermal condition and moisture distribution in the reservoir during the discharge cycle.

Anticipated CAES designs will be characterized by a large cushion air mass in the reservoir. The difference between the maximum and minimum stored mass wil1 be approximately 10\% of the average stored mass. Subject to these conditions, the total reservoir pressure swings will be small enough that a constant power input will result in a nearly constant airflow rate into the storage reservoir. The constant flow rate condition at the well boundary for the production cycle was, therefore, also applied to the well boundary for the reservoir charging cycle. In addition to the flow rate, the temperature and humidity of the air stream was specified for the charging cycle.

During the periods of CAES operation when the reservoir was idle, the boundary condition applied at the well was zero flow of heat or mass into or out of the reservoir.

Since the flow of heat and mass is assumed to occur only in the radial direction there was no need to specify boundary conditions above and below the air storage zone.

\subsection{LIMITATIONS OF THE MODEL}

The 1 imitations of the one-dimensional radially-symmetric model have been described previously in Reference 1. In this section, only the additional limitations pertaining to the moist air and liquid in the reservoir are discussed. 
Perhaps the most questionable aspects of the model are the assumptions that there is no liquid mobility and that saturation of the airvapor mixture is achieved instantaneously. As shown in Figure 1, the relative permeability to the flow of liquid through a porous material remains very low until the liquid water content is significantly above the residual level. Therefore, to achieve significant mobility of the liquid in excess of the residual water content, relatively large pressure gradients would be required. Since the highest pressure gradients occur near the wellbore, the assumption of zero liquid mobility will be valid throughout the reservoir if the percent of pore volume filled with liquid near the wellbore does not greatly exceed the residual levels. The assumption does limit the range of conditions for which the results will be valid. It is not difficult to violate the conditions of this assumption (this will be discussed in Section 3.0). For example, plugging can occur by injection of moist air. Inclusion of the liquid mobility terms adds another order of difficulty to the solution, so it would not have been justified without a quantification of the maximum expected liquid content. The results of this study show that in many circumstances the liquid mobility term may be ignored.

The assumption of instantaneous saturation of the air-vapor mixture dictates that the mixture will always be saturated at a particular location if liquid water is also present at that location. There are two points to be made regarding this assumption. First, the assumption is certainly optimistic from physical considerations, although it can be applied numerically to provide reasonable results. Second, as local dehydration proceeds, the water remaining will exist in increasingly more isolated pores, thus diminishing surface area interactions. This will tend to reduce the rate of evaporation as dehydration proceeds. Thus, the model of instantaneous saturation is possibly overly optimistic regarding the rate of evaporation and does not account for a probable decrease in evaporation rate as local dehydration progresses. This would suggest that the results obtained from this model would be biased by excessive evaporation rates. However, if flow velocities are low enough that residence time in a finite region is relatively large, 
saturation could possibly occur fast enough to satisfy the assumption. Calculations were done to compare a theoretical mass transfer coefficient to the mass transfer coefficient required to achieve mixture saturation within local residence time. The result of the comparison was favorable to the assumption of instantaneous saturation. In addition, this analysis provides insight to the behavior of the dehydration process. Even though a more accurate prediction of evaporation rate may be possible in the future, the conclusions provided in this report regarding the behavior of dehydration will likely be fundamentally correct. Thus, the assumption of instantaneous saturation of the air-vapor mixture is justified for an initial analysis of the moisture problem.

The assumption of an initially uniform distribution of residual water in the homogeneous reservoir is particularly significant to this study. Therefore, some justification is in order. While it is possible to achieve some dehydration of the wellbore region during bubble development, the actual distribution of residual water at the outset of reservoir operation will be very site specific and will depend upon the conditions of bubble development. As such, the assumption represents a good datum from which site specific data can be viewed and from which the characteristic behavior of the dehydration process can be described. To achieve any dehydration of the wellbore region during bubble development it would be necessary to develop the bubble with undersaturated air. This would not pose a significant problem for high temperature bubble development. However, for low temperature bubble development this would almost certainly require that special attention be given to the dehydration of the injected air stream. At any rate, the total amount of dehydration of the wellbore region achieved during bubble development is likely to be small. This results because the air mass of the bubble represents, less than the amount of air cycled into the reservoir during the first three weeks of operation. During continuous bubble development injected thermal energy will be almost totally retained in the reservoir, whereas for cyclic operation only a fraction of the injected thermal energy remains in the reservoir. Thus, the dehydration achieved during bubble development will, in general, exceed that predicted for cyclic injection of the same air mass. Results obtained from the computer model indicate that for continuous isothermal 
air injection at $1000 \mathrm{~F}$, the dehydrated zone approximates that achieved by cyclic injection of the same air mass. However, for continuous dry air injection at $450^{\circ} \mathrm{F}$ the dehydrated zone has a predicted radius of about 11 $\mathrm{ft}$ following continuous injection of the bubble air mass as compared to 5 ft for cyclic injection of the same air mass.

\subsection{SUMMARY OF ASSUMPTIONS}

In the development of the analytical mode1, a number of assumptions have been made. The assumptions used in the model are:

- The air-vapor mixture is homogeneous and behaves as an ideal gas.

- The rock porosity, density and heat capacity are constant.

- The rock is immobile.

- Binary diffusion in the air-vapor mixture is negligible.

- Inertial effects are negligible.

- The air-vapor mixture, liquid, and rock are in thermal equilibrium.

- Kinetic energy is negligible.

- Viscous dissipation of energy is negligible.

- Transport of mass and energy occurs only in the horizontal radial direction.

- Liquid water is immobile.

- Darcy's law for low velocity flows is applied.

- Saturation of the air-vapor mixture is instantaneous.

- The residual water is initially distributed uniformly throughout the reservoir.

- The rate of evaporation is independent of pore water content.

- Mass flow rate at the wellbore is specified.

- The reservoir geometry is modeled as a cylindrical disc.

- The effective thermal conductivity is calculated by

$$
K=(1-\phi) K_{r}
$$

- The viscosity of the air-vapor mixture is independent of the vapor content. 


\subsection{NUMERICAL MODEL}

A numerical model was developed to solve the governing equations that describe the transport of mass and energy in a porous rock reservoir. This extends the work done at PNL in FY-1977 to include the effects of moisture in the reservoir. The solution of Equations 25 and 26 is based on a fully implicit finite difference scheme employing total upwind differencing. A simultaneous solution of the equations has been used to facilitate the coupling of the equations by the pressure and temperature.

\section{1 FINITE DIFFERENCE EQUATIONS}

The grid system for the difference equations is presented in Figure 5. Pressures and temperatures are defined at the node points $j$. Node NR+1, located beyond the reservoir boundary, is a "mirror" of node NR. The result is that there are no gradients for the transport of either mass or energy across the outer reservoir boundary. A11 computations are based on a vertical grid thickness of one unit.

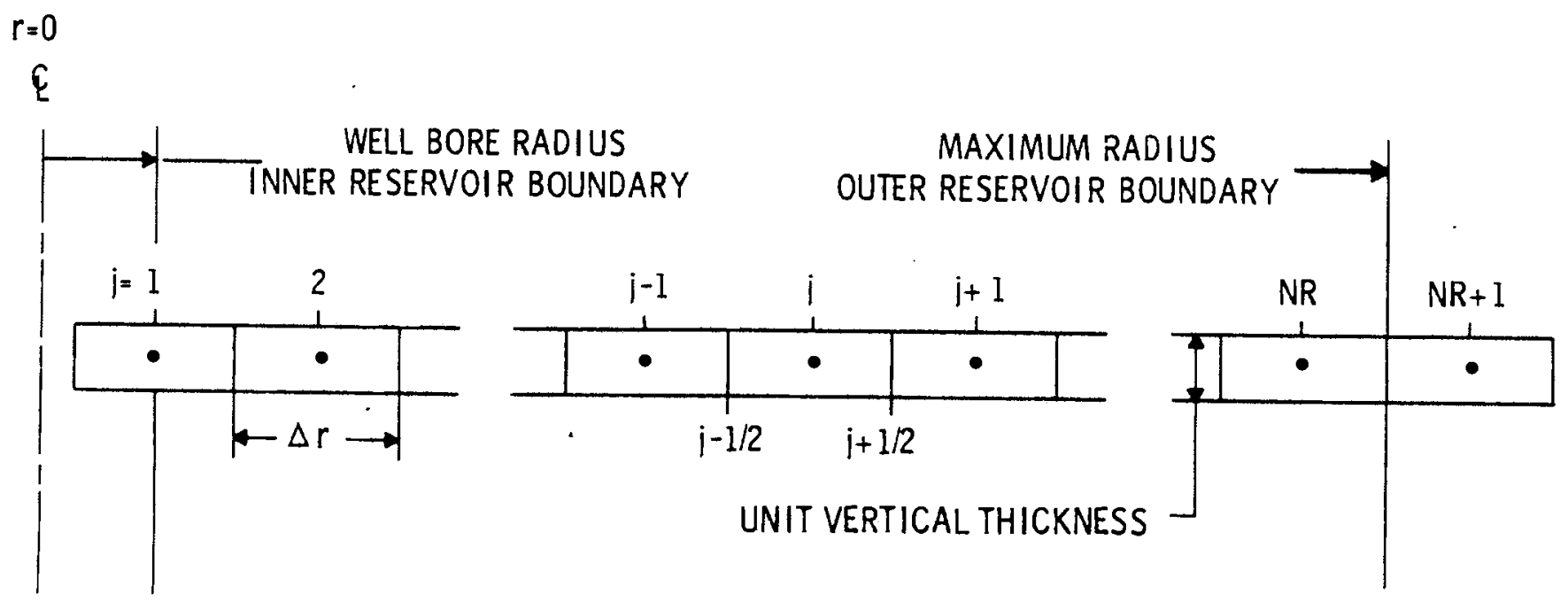

FIGURE 5. Finite Difference Grid 
The development of the difference equation for the mass transport begins from Equation 25.

$$
\phi \frac{\partial}{\partial t}\{(1-S) W P\}+\frac{1}{r} \frac{\partial}{\partial r}\left\{W \operatorname{Pr}\left(\frac{k k r}{\mu} \frac{\partial P}{\partial r}\right)\right\}=m^{\prime}
$$

A weighted volumetric flux, $F_{v}$, is defined from a product of the radius and velocity,

$$
F_{v}=r\left(\frac{k k_{r}}{\mu} \frac{\partial P}{\partial r}\right)
$$

The flux between nodes $j$ and $j+l$ is written as

$$
F_{v, j}=-C_{j}\left(P_{j+1}-P_{j}\right)
$$

The flow conductance, $C_{j}$, is based on the cell geometry, the viscosity of the air-vapor mixture, and the effective permeability of the porous material. If it were necessary to consider higher velocity flows. described by the Forchheimer equation. Equation 13, then the turbulence factor, $B$, would be included in the calculation of $C_{j}$.

Substitution of the flux term into Equation 26 yields

$$
\frac{\partial}{\partial t}\{(1-S) W P\}+\frac{1}{\phi r} \frac{\partial}{\partial r}\left(W P F_{v}\right)=m^{\prime}
$$

The percent of the pore volume that contains liquid water, $S$, is a dependent parameter that can be eliminated by considering the conservation of mass of the liquid. This is described by Equation 8 which includes the assumption of zero liquid mobility. For reasonable time steps the liquid density can be considered constant so that

$$
m^{\prime}=-\phi \rho_{\ell} \frac{\partial S}{\partial t}
$$

In difference form this becomes

$$
s^{n+1}=s^{n}-\frac{m^{1} \Delta t}{\phi \rho_{\ell}}
$$


The value of $S$ at the old time, $S^{n}$, is always known numerically. Therefore, the time dependence of $S$ is by-passed by writing $S^{n+1}$ in terms of the evaporation rate and $S^{n}$. This procedure eliminates $S^{n+1}$.

The implicit upstream difference form of Equation 25, with the inclusion of Equation 32 , is

$$
\begin{gathered}
-a_{j}\left\{(W P)_{j-1, F+}+(W P)_{j, F-}\right\}_{n+1} c_{j-1} P_{j-1, n+1} \\
+\left\{a_{j}\left[\left\{(W P)_{j-1, F+}+(W P)_{j, F-}\right\} c_{j-1}+\left\{(W P)_{j, F+}+(W P)_{j+1, F-}\right\} c_{j}\right]\right. \\
\left.+\left(1-S_{j, n}+\frac{m^{\prime}{ }_{j} \Delta t}{\phi P_{\ell}}\right) W_{j, n+1}\right\} P_{j, n+1} \\
-a_{j}\left\{(W P)_{j, F+}+(W P)_{j+1, F-}\right\} c_{j} P_{j+1, n+1}=m^{\prime} \Delta t+\{(1-S) W P\}_{j, n}
\end{gathered}
$$

where Equation 29 has been used for the flux, $F_{v}$, and $a_{j}=\Delta t /\left(\phi r_{j} \Delta r_{j}\right)$. If the volumetric flux at a cell interface is radially outward (i.e., a positive flux), the density terms, WP, designated with the subscript F+ are used while the terms having the subscript F-are zero. If the flux is negative, the inverse of this convention applies.

The convected property in Equation 33 is the density, WP. The pressure associated with the flux terms represent the driving force for the mass transport. For the solution to be conservative in mass and energy, it was necessary to distinguish between the two pressures in the mode 1 .

The development of the difference equation for the energy transport begins from Equation 26. With the mixture internal energy and enthalpy written as

$$
u=C_{v, a} T+w u_{v}
$$


and

$$
h=c_{p, a^{T}+\omega h_{v}}
$$

the energy equation is simplified to

$$
\begin{aligned}
\frac{\partial T}{\partial t}=\frac{1}{(1-\phi) \rho_{s} C_{s}} & {\left[-\frac{1}{r} \frac{\partial}{\partial r}\left(W_{a} P h r \frac{k k_{r}}{\mu} \frac{\partial P}{\partial r}\right)+\frac{1}{r}-\frac{\partial}{\partial r}\left(K r \frac{\partial T}{\partial r}\right)\right.} \\
& \left.-\phi \frac{\partial}{\partial t}\left\{(1-S) W_{a} P u+S \rho_{\ell} u_{\ell}\right\}\right]
\end{aligned}
$$

The first term on the right in Equation 36, the spatial derivative of ohrv, represents the convection of energy and is the dominant term for energy transport. The product of radius and velocity results in the same form as Equation 29. In this case, however, the transported quantity is thermal energy rather than mass.

Using a method similar to that for the development of the volumetric flux, Equation 29, a heat flux is defined from the conduction term. The heat flux between nodes $j$ and $j+1$ is written as

$$
F_{h, j}=K_{j}\left(T_{j+1}-T_{j}\right)
$$

The heat conductance, $k_{j}$, depends on the cell geometry and the effective thermal conductivity in the reservoir.

Substitution of the flux terms into Equation 36 yields

$$
\begin{gathered}
\frac{\partial T}{\partial t}=\frac{1}{(1-\phi) \rho_{s} C_{s}}\left\{-\frac{1}{r} \frac{\partial}{\partial r}\left(W_{a} P h F_{v}\right)+\frac{1}{r}-\frac{\partial}{\partial r}\left(F_{h}\right)\right. \\
\left.-\phi \frac{\partial}{\partial t}(1-S) W_{a} P u+S \rho_{\ell} u_{\ell}\right\}
\end{gathered}
$$


The implicit upstream difference form of Equation 38, with the inclusion of Equation 32 to eliminate $S^{n+1}$ is

$$
\begin{aligned}
& T_{j, n+1}=T_{j, n}+\frac{\Delta t}{(1-\phi) \rho_{s} C_{s}}\left[-\frac{1}{r_{j} \Delta r_{j}}\left\{-\left(W_{a} P h\right)_{j-1} F_{v, j-1, F+}\right.\right. \\
& \left.+\left(W_{a} P h\right)_{j} F_{v, j-1, F_{-}}+\left(W_{a} P h\right)_{j} F_{v, j, F_{+}}-\left(W_{a} P h\right)_{j+1} F_{v, j, F-}\right\}_{n+1} \\
& +\frac{1}{r_{j}\left\llcorner r_{j}\right.}\left\{k_{j-1} T_{j-1}-\left(k_{j-1}+k_{j}\right) T_{j}+k_{j} T_{j+1}\right\}_{n+1} \\
& -\frac{\phi}{\Delta t}\left\{\left(1-S+\frac{m^{\prime} \Delta t}{\phi \rho_{l}}\right)_{j} \quad\left(W_{a} P u\right)_{j, n+1}-\left(1-S_{j}\right)\left(W_{a} P u\right)_{j, n}\right\} \\
& \left.+\frac{\phi}{\Delta t}\left\{\begin{array}{lll}
\left(s-\frac{m^{\prime} \Delta t}{\phi \rho_{\ell}}\right)_{j} & \left(\rho_{\ell} u_{\ell}\right)_{j, n+1}-S_{j} & \left(\rho_{\ell} u_{\ell}\right)_{j, n}
\end{array}\right\}\right]
\end{aligned}
$$

In this form, $S_{j}$ implies the old time value of $S$ at node $j$.

\subsection{SOLUTION METHOD: PRESSURE AND TEMPERATURE}

The solution for the pressure, temperature and humidity conditions in the reservoir is obtained by a computer program. Figure 6 is a flow chart of the program.

The requirements of the solution method are dominated by the nonlinearity and the coupling of the mass and energy transport equations. The solution of the pressure from Equation 25 requires a certain knowledge of the pressure, temperature, and evaporation rate. The solution is obtained by guessing the pressure and temperature and by using an evaporation rate based on the pressure and temperature at the previous time step. Reasonably rapid convergence is obtained by using a linear extrapolation of the pressures and temperatures of the previous two time steps to obtain guesses for the new time solution of pressure and temperature. The convection term in Equation 25 has pressures associated 


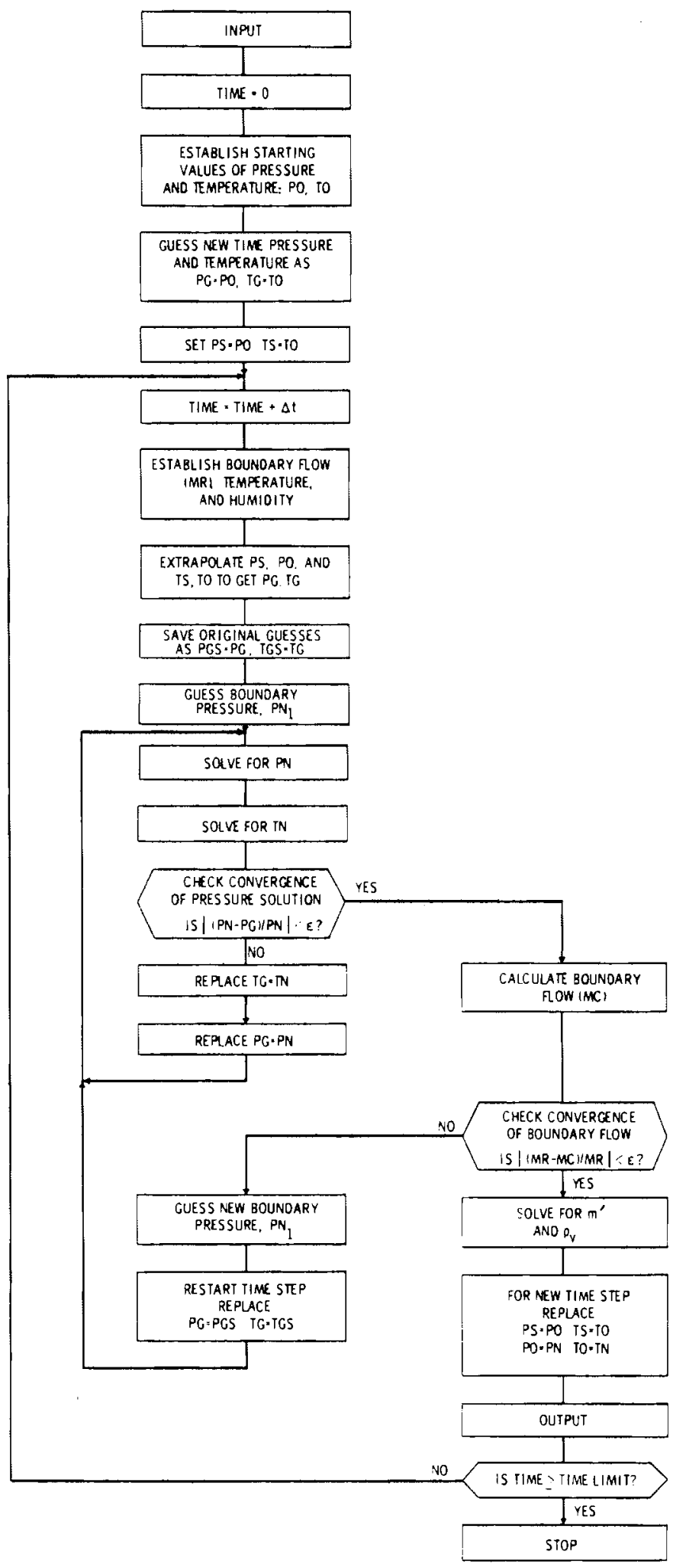

FIGURE 6. Calculational Flow Chart 
with the density and the volumetric flux. The pressures associated with the density are designated as the guessed pressures. The solution defines the pressures associated with the flux terms. The new time pressures obtained from the solution of Equation 25 are used to quantify the density and volumetric flux for the solution of Equation 26.

Defining pressure and temperature at the old time with PO and TO, guessed values with $P G$ and $T G$, and new time with $P N$ and $T N$, Equations 33 and 39 can be reconstructed as

$$
\begin{aligned}
& -a_{j}\left\{(W G P G)_{j-1, F+}+(W G P G)_{j, F-}\right\} c_{j-1} P N_{j-1}+\left\{a _ { j } \left[\left\{(W G P G)_{j-1, F+}\right.\right.\right. \\
& \left.\left.+(W G P G)_{j, F-}\right\} c_{j-1}+\left\{(W G P G)_{j, F+}+(W G P G)_{j+1, F-}\right\} C_{j}\right] \\
& \left.+\left(1-S+\frac{m^{\prime} \Delta t}{\phi \rho_{l}}\right)_{j} W G_{j}\right\}_{j N_{j}}-a_{j}\left\{(W G P G)_{j, F+}+(W G P G)_{j+1, F-}\right\} c_{j} P N_{j+1} \\
& =m_{j}^{\prime} \Delta t+\{(1-S) W O P O\}_{j}
\end{aligned}
$$

and

$T N_{j}=T O_{j}+\frac{\Delta t}{(1-\phi) \rho_{s} C_{s}}\left[-\frac{1}{r_{j} \Delta r_{j}}\left\{-\left(W G_{a} P N h G\right)_{j-1} F N_{v, j-1, F+}\right.\right.$

$+\left(W G_{a} P N h G\right)_{j} F N_{v, j-1, F-}+\left(N G_{a} P N h G\right)_{j} F N_{v, j, F+}$

- $\left.\left(W G_{a} P N h G\right)_{j+1} F N_{v, j, F-}\right\}+\frac{1}{r_{j} \Delta r_{j}}\left\{K_{j-1} T G_{j-1}\right.$

$\left.-\left(K_{j-1}+K_{j}\right) T G_{j}+K_{j} T G_{j+1}\right\}-\frac{\phi}{\Delta t}\left\{\left(1-S+\frac{m_{i}^{\prime} \Delta t}{\phi o}\right)_{l}\left(W G_{a} P N U G\right)_{j}\right.$

$\left.-(1-S)_{j}\left(W O_{a} P O u O\right)_{j}\right\}+\frac{\phi}{\Delta t}\left\{\left(S-\frac{m^{\prime} \Delta t}{\phi P_{\ell}}\right)_{j}\left(\rho G_{\ell} u G_{\ell}\right)_{j}\right.$

$\left.\left.-S_{j}\left(00_{\ell} 40_{\ell}\right) j\right\}\right]$ 
The moisture distribution from the previous time step and the guessed temperatures are used to obtain the additional guessed parameters, these being $W G, W G_{a}, H G, U G, \rho G_{\ell}$, and $U G_{\ell}$. The contribution of the vapor to the internal energy and enthalpy of the mixture, and the density and internal energy of the liquid are obtained from polynomial curve fits relating the properties to the temperature. The pressures obtained from the solution of Equation 40 are used to evaluate the new time volumetric flux, $F N_{v}$.

The structure of the solution is easier to understand by observing Equations 40 and 41 . The node equations defined by Equation 40 are solved simultaneously to obtain the new pressure distribution. The new pressures and the corresponding new values for the volumetric flux, FN are used to solve Equation 41 for the temperature. The new pressures are subsequently checked for convergence with the guessed pressures. The guessed pressures and temperatures are replaced by the new values and the calculations are repeated until satisfactory convergence is achieved.

This description of the solution may suggest that there is a lack of concern for the accuracy of the thermal solution. A simultaneous solution for temperature, which would be necessary if the guessed temperatures in Equation 41 were transposed to the left hand side of the equation, was not attempted. (a) Also, no convergence criterion is required for the temperature. In spite of this, the solution method is justified because the primary mode of energy transport is by convection of energy. Computationally, an accurate prediction of the convection of energy is dominated by the pressure solution. Thus, it is not necessary to use a simultaneous solution method to converge to an "exact" temperature distribution. Instead, the most accurate prediction of the mass and energy transport is gained by obtaining the best possible solution to Equation 40.

\footnotetext{
(a) We have recently concluded that, to achieve a stable solution for large time steps (i.e., on the order of the mass cycling schedule), it is necessary to use a fully implicit thermal solution. The results presented in this report were developed with relatively small time steps for which the discussion presented is still valid.
} 


\subsection{SOLUTION METHOD: EVAPORATION RATE}

The numerical model requires that the air-vapor mixture in a cell be saturated according to the "new time temperature" in the cell. This results in two distinct components of evaporation. A "thermal" component is due to the change of temperature in a cell with respect to time. A "convective" component is due to the difference of temperature between adjacent cells. The same components apply to condensation which is treated as negative evaporation.

The air-vapor mixture in a cell at the old time will be saturated according to the "old time temperature" of that cell. If the temperature of the cell changes in the next time step, the water carrying capacity of the air-vapor mixture will also change. Thus, the thermal component of the evaporation rate is determined by the net evaporation required to achieve saturation at the new time temperature divided by the time step size.

If a difference in temperature exists between adjacent cells, the transport of the air-vapor mixture between the cells will result in a net evaporation. An air-vapor mixture entering a cell will have the saturation water content corresponding to the temperature in the upstream ce11. The mixture will then saturate according to the temperature in the recipient cel1. The total flow into a cell during a time step determines the total convective evaporation in that time step. The convective component of the evaporation rate is the convective evaporation divided by the time step size.

Numerically, the prediction of the evaporation rate is delayed one time step. The new time solution of pressure and temperature is used to predict the evaporation rate. This evaporation rate feeds back into the pressure and temperature solution for the next time step. The time step delay was necessary to achieve convergence of the solution for pressure and temperature in a reasonable number of interations for reasonably large time steps. 
The rate of evaporation is determined simultaneously with the solution for the vapor distribution in the reservoir. The vapor distribution is determined by solution of the continuity equation for the vapor, Equation 7. An iterative solution is required because the rate of evaporation depends on the vapor distribution. The solution method requires a guess of the vapor distribution to predict the evaporation rate. Then Equation 7 is solved to obtain vapor density. A convergence criterion is used to determine when a satisfactory solution has been achieved.

\subsection{BOUNDARY CONDITIONS}

The boundary conditions are applied in a direct manner except for the mass flux specified at the wellbore.

The outer reservoir boundary is insulated to the passage of either mass or energy. During mass injection the temperature and humidity of the injected air is specified at the wellbore. During extraction, the wellbore node is given the temperature and humidity of the second node at the previous time step. When there is no flow, the wellbore node is disconnected from the solution by setting the mass conductance, $c_{1}$ from Equation 29, and the thermal conductance, $k_{1}$ from Equation 37, to zero. In this way there is no source or sink for mass or energy.

The forcing function for the convection of mass and energy is the pressure specified at the wellbore. Therefore, to apply a mass flux boundary condition it is necessary to specify a pressure. This presents difficulties because the new time pressure must be known. Since the pressure cannot be known until the solution is obtained, the application of the mass flux boundary condition is an iterative procedure. The boundary pressure is guessed and a pressure distribution is calculated. The pressure gradient at the wellbore determines the mass flow rate. If the mass flow rate is not satisfied, a new boundary pressure is defined. The iteration is repeated until convergence is achieved. The procedure is included in Figure 6 . 


\subsection{CODE VERIFICATION}

The validity of the solution method used in this analysis was documented in Reference 1. Results obtained from the computer code developed at PNL in FY-1977 for dry reservoirs were compared with analytic solutions of steady-state and transient heat conduction problems and with results from a code developed by Intercomp Resource and Development, Inc. The agreement obtained in these comparisons was excellent. Additionally, the results obtained in FY-1978 for the two-dimensional analysis of dry reservoirs verified that the thermal development and pressure cycling in the bulk of the reservoir could be determined with equal accuracy by the one-dimensional, radial flow model.

Adding the moisture problem to the analysis necessitated further comparisons to assure that consistency of the solution was maintained. Two comparisons were made to achieve this assurance. First, the program was used to analyze the reservoir operation for a case that set all the moisture parameters to zero. The agreement with the FY-1977 results was excellent. Second, a comparison was made between the temperature profiles in a dry reservoir and a reservoir containing residual water. The attenuation of the thermal growth in the wet reservoir was found to be consistent with the calculated heat of vaporization of the water. On the basis of these comparisons, it was concluded that the computer program is consistent with previous work and that the results pertaining to solution of the moisture problem are reliable, given the assumptions used. 


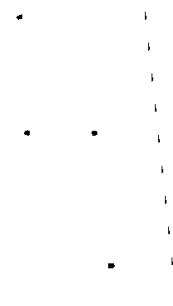




\subsection{ANALYSIS OF MOISTURE PARAMETERS}

The presence of residual water and the cycling of moist air to and from an aquifer CAES reservoir will have an impact on the performance of the reservoir. The parameters that are directly related to the presence of water in the air storage zone have been investigated to assess the concerns discussed in the problem description. These parameters are:

- air-vapor injection temperature

- air-vapor injection absolute humidity

- residual water content.

There are many additional parameters that can affect the performance of a CAES reservoir. These include reservoir material properties, reservoir geometry, and operating conditions. The effect of many of the important parameters was investigated at PNL in FY-1977. These are:

- porosity

- permeability

- rock thermal conductivity

- rock thermal capacity

- reservoir diameter

- well diameter

- nominal pressure

- percent of mass cycling

- mass flow rate

- air injection temperature.

Although the model used at PNL in $\mathrm{FY}-1977^{(1)}$ did not include the effects of water in the reservoir, the conclusions of the parametric study are believed to be valid. For example, it was concluded that moderately high permeabilities (on the order of $500 \mathrm{md}$ ) would typically be required for economic reservoir operation. It was assumed that addition of water to the reservoir problem would not significantly affect this conclusion. Thus, the parameters investigated for the dry reservoir have not been reconsidered here. The injection temperature was included in both studies. Air injection temperature was studied previously to determine 
the effect of viscosity and density changes on the pressure response of the reservoir. It was studied here to evaluate its effect on the dehydration of the near wellbore region.

The analysis of the moisture parameters was performed with the computer program described in the previous section. The results obtained from the program were unexpectedly affected by the finite size of the numerical cells. The rate of dehydration at a given location depends primarily on the temperature at that location. When a numerical cell becomes completely dry, the dehydration process suddenly advances to the next outward cel1 where the temperature is lower. Thus, the dehydration rate decreases. As this cell gains sensible heat, the dehydration rate increases. When the cel1 becomes completely dry, the dehydration again becomes dominated by the lower temperature in the next radially outward ce11. When reservoir dehydration rate, temperature at the dry front, humidity at the dry front, and so on, are plotted against time the results show a sawtooth pattern. Reporting the results in this fashion would lead to unnecessary confusion and has, therefore, been avoided. Instead, in situations where confusion might otherwise occur, the results are presented as smoothed averages of the numerical results.

\section{1 REFERENCE RESERVOIR}

To facilitate the analysis of the moisture parameters, a reference reservoir was established. The reference values of the reservoir parameters, given in Table 1, are identical to those used for the analysis of the dry reservoir in FY-1977. (1) These parameters were never varied in this analysis.

The reference values for the moisture parameters are given in Table 2 . The range of conditions investigated are also given in the table. The residual water content depends on the existence of dead-end pores and the capillary forces in the porous material. For reservoirs having permeabilities on the order of $500 \mathrm{md}$ and $20 \%$ porosity, $20 \%$ of the pore volume would typically be filled with residual water. (2) Because dehydration 
TABLE 1. Reservoir Parameters

Parameter

Geometry

Reservoir Diameter

Well Diameter
Reference Value

$400 \mathrm{ft}(122 \mathrm{~m})$

7 in $(18 \mathrm{~cm})$

Properties

Porosity

Permeability

Rock Thermal Conductivity

Rock Thermal Capacity $\left(\rho_{S} C_{S}\right)$

Operating Conditions

Nominal Pressure

Mass Flow Rate

Injection

Extraction

Initial Reservoir Temperature
$20 \%$

$500 \mathrm{md}$

$1.25 \frac{\mathrm{Btu}}{\mathrm{hr}-\mathrm{ft}-\mathrm{OF}} \quad\left(2.16 \frac{\mathrm{W}}{\mathrm{m}-\mathrm{OC}}\right)$

$39.1 \frac{\mathrm{Btu}}{\mathrm{hr}-\mathrm{ft}-\mathrm{OF}_{\mathrm{F}}}\left(2.62 \frac{\mathrm{MJ}}{\mathrm{m}^{3-O C}}\right)$

$50 \mathrm{~atm}(5070 \mathrm{kPa})$

$0.119 \frac{1 \mathrm{bm}}{\mathrm{sec}-\mathrm{ft}} \quad\left(0.177 \frac{\mathrm{kg}}{\mathrm{sec}-\mathrm{m}}\right)$

$0.158 \frac{1 \mathrm{bm}}{\mathrm{sec}-\mathrm{ft}} \quad\left(0.158 \frac{\mathrm{kg}}{\mathrm{sec}-\mathrm{m}}\right)$

$100^{\circ} \mathrm{F} \quad\left(38^{\circ} \mathrm{C}\right)$

is desirable, dry air injection was chosen as a reference condition. The injection of dry air, coupled with the evaporation model (which dictates the instantaneous saturation of the air-vapor mixture), produces the most rapid dehydration that could be expected in the reservoir. The problem is then bounded on the opposite extreme by the injection of saturated air, which may result in plugging of the flow path in the reservoir.

In the dry reservoir analysis of $F Y-1977$, the mass flow rates were determined such that the weekly maximum and minimum values of stored air mass varied by $12 \%(\lambda=0.12)$. The fraction of the total mass of airvapor mixture that is cycled, $\lambda$, is calculated by

$$
\lambda=\frac{M_{\max }-M_{\min }}{M_{\max }}
$$


TABLE 2. Moisture Parameters

\begin{tabular}{|c|c|c|}
\hline Parameter & Reference Value & Range of Values \\
\hline Injection Temperature & $450^{\circ} \mathrm{F}$ & $100-450$ \\
\hline & $\left(232^{\circ} \mathrm{C}\right)$ & $(38-232)$ \\
\hline $\begin{array}{l}\text { Residual Water as Percent of } \\
\text { Pore Volume }\end{array}$ & $20 \%$ & $0-40$ \\
\hline Injection Humidity & 0 1b/7b (dry air) & $\begin{array}{l}0-0.0429 \\
\text { (maximum water } \\
\text { vapor in ambient } \\
\text { air) }\end{array}$ \\
\hline
\end{tabular}

With $\lambda=0.12$ and with a reference nominal pressure of $50 \mathrm{~atm}(5070 \mathrm{kPa})$, the maximum average reservoir pressure was approximately $53 \mathrm{~atm}$ (5374 $\mathrm{kPa}$ ) and the minimum average reservoir pressure was approximately $47 \mathrm{~atm}$ $(4770 \mathrm{kPa})$. The moisture analysis was done to compare the thermal response and dehydration rates of reservoirs having different residual water contents. To make equitable comparisons it was necessary to input the same thermal energy into each of the reservoirs. This was done by maintaining constant mass flow rates to and from the reservoir, regardless of residual water content. Since the effective storage volume is reduced by the presence of liquid water, the weekly variation of average reservoir pressure was of greater magnitude. As shown in Figure 7 , for the reference residual water content of $20 \%$ of pore volume, the percent of mass cycled is $14.8 \%$. This curve is determined by the reference mass flow rates and 


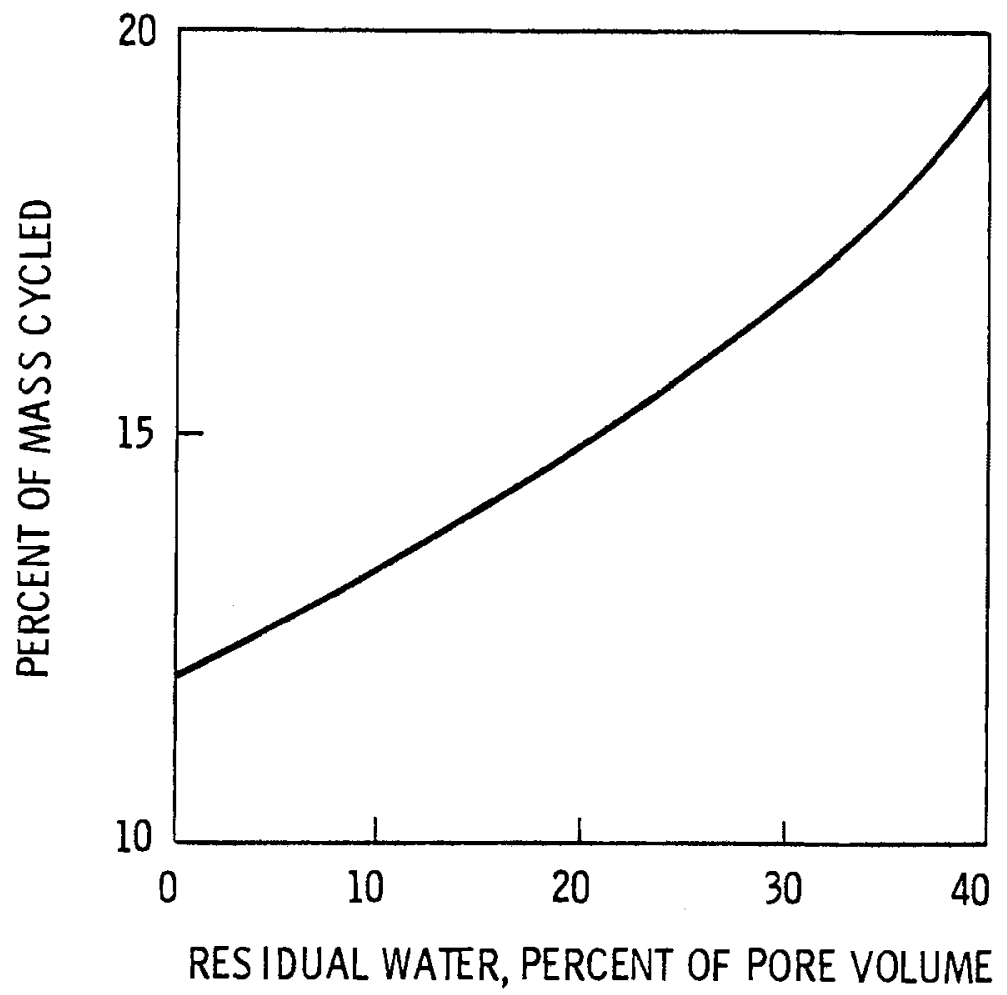

FIGURE 7. Percent of Mass Cycled for the Reference Conditions

the effective storage volume that takes into account the residual water. The weekly variation of average reservoir pressure increases with the percent of mass cycled as shown in Figure 8 . The average reservoir pressure varies from approximately $46 \mathrm{~atm}$ (4664 kPa) to approximately 54 $\operatorname{atm}(5476 \mathrm{kPa})$ for the reference conditions.

\subsection{WEEKLY CAES CYCLE}

In addition to the reference conditions given above, a weekly operating cycle was specified that defines when the reservoir is charged or discharged and when there is no flow to the reservoir. The operating cycle is similar to that used by PNL in FY-1977. (1) In this analysis, however, the percent of the air mass that is cycled is higher. Thus, the maximum and minimum pressures are more extreme. 


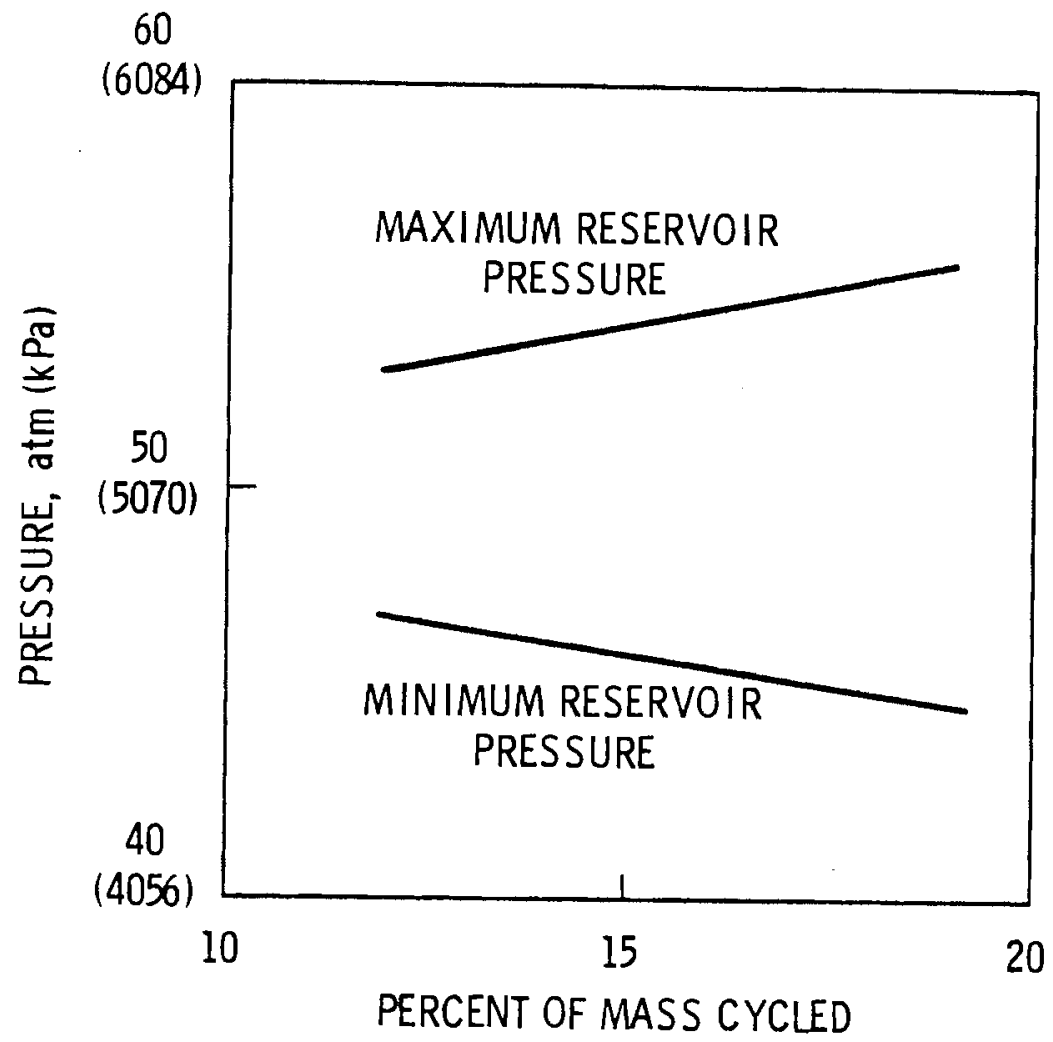

FIGURE 8. Weekly Variation of Average Reservoir Pressure

The development of the weekly operating cycle is described in detail in Reference 1. The same techniques have been applied to the conditions of this analysis. The resulting weekly reservoir pressure cycle applied to this analysis is shown in Figure 9. The weekly cycle begins and ends on Friday at 8:00 p.m. The fraction of the weekly stored mechanical energy supplied to the CAES plant on the weekend, $\psi$, is specified as 0.40 . The value of $\lambda$ is 0.148 . The duration of the daily charge and discharge cycles is $10 \mathrm{hrs}$ each. The reservoir is closed for $2 \mathrm{hrs}$ between each cycle. 


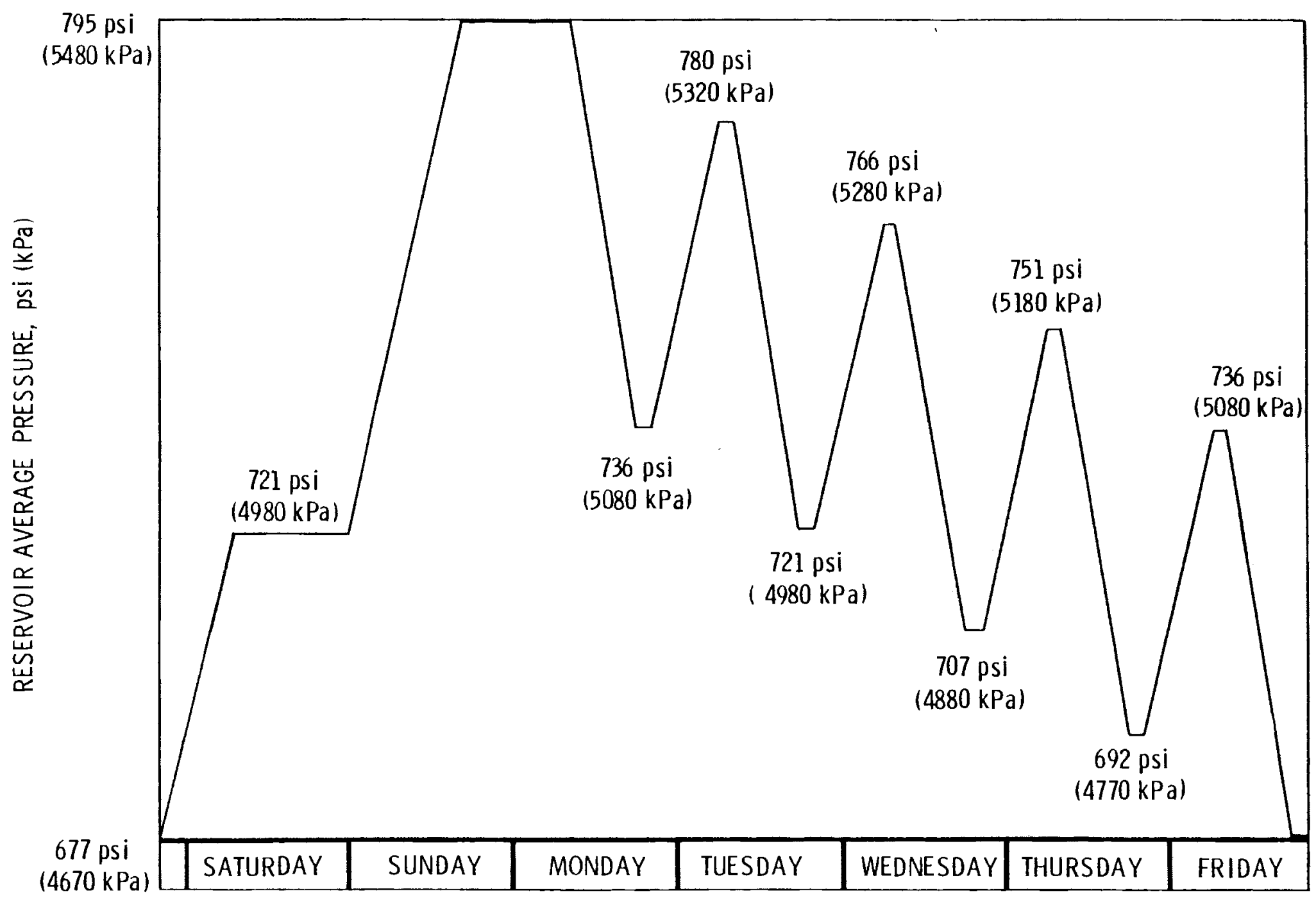

TIME OF WEEK, days

FIGURE 9. Reference Weekly Reservoir Pressure Cycle 
The amount of air-vapor mixture injected into the reservoir over the weekend was adjusted slightly from week to week. If net condensation during the week resulted in a reduction in working fluid, the subsequent weekend charging cycle would be extended such that the total working fluid would be brought up to the level of the previous week. Net evaporation resulting in an increase in working fluid would require a decrease in the weekend charging period. Maintaining a constant working fluid essentially conforms to the work of FY-1977, in which the only long term increase in reservoir pressure was due to growth of the heated region near the wellbore.

\subsection{ANALYSIS OF THE REFERENCE RESERVOIR}

The results of the analysis of the reference reservoir, as defined in Tables 1 and 2 and subject to the weekly cycle described in section 4.2, are presented in this section. Parametric changes to the reference parameters do not significantly impact the characteristic behavior of dehydration, thermal development, and pressure cycling in the reservoir. Thus, the descriptions of these processes presented in this section generally apply to all of the results of the parametric study of the moisture parameters.

The results presented in this and in subsequent sections are given with the units of per foot (per meter), wherever appropriate. This refers to the unit of vertical measurement in the reservoir.

\subsubsection{Dehydration}

When heated dry air is injected into the reservoir it will exchange heat with the surrounding material by sensible heating of the rock and liquid water and by evaporating some of the water. The result is that the air-vapor mixture wil1 be saturated and wil1 be in thermal equilibrium with the rock and liquid water. When the saturated air-vapor mixture moves radially outward it will continue to loose heat to the surroundings. The moisture carrying capacity of the mixture will be 
reduced and condensation will occur. Thus, a dehydrated region surrounding the wel1 will grow during mass injection. During reservoir discharge the mixture will gain heat as it nears the well, gaining moisture as it moves radially inward. Net dehydration of the reservoir occurs by the eventual extraction of this moisture. Net dehydration can generaliy be assured if the injected air is dry and is warmer than the discovery temperature in the reservoir. However, these restrictive conditions are not a Tways necessary for net dehydration or dehydration of the near wellbore region.

The process of dehydration for various radial locations is shown in Figures 10 and 11 . The model predicts that the percent of pore volume filled with liquid water, which is initialiy uniform at $20 \%$, never exceeds $25 \%$. This result for the reference reservoir satisfies the assumption of zero liquid mobility that required that the water content should never greatly exceed the residual level. The result is significant because it indicates that for dry air injection, pore plugging is not likely to adversely affect the deliverability of the reservoir. However, it is easy to visualize that injection of heated moist air could result in plugging of the available pore volume by cooling and subsequent condensation. In this event, liquid mobility would likely be significant.

Evaporation will occur near the wel1 until complete dehydration of this region is achieved. Gradually, the dry region expands. The model implies that a sharp interface exists between the dehydrated zone and the region still containing liquid water. The "dry front" is a term used to define the location of this hypothetical interface. When the water content reaches zero for a given radial location, the dry front is defined to exist at that location. By this definition the growth of the dry front is shown in Figure 12.

The results shown in Figure 12 are not totally conclusive. To make use of this result, criteria must first be established for the required size of the dehydrated zone that assure stable and efficient reservoir operation. Then, results such as those shown in Figure 12 can be used to determine if the criteria can be satisfied. 


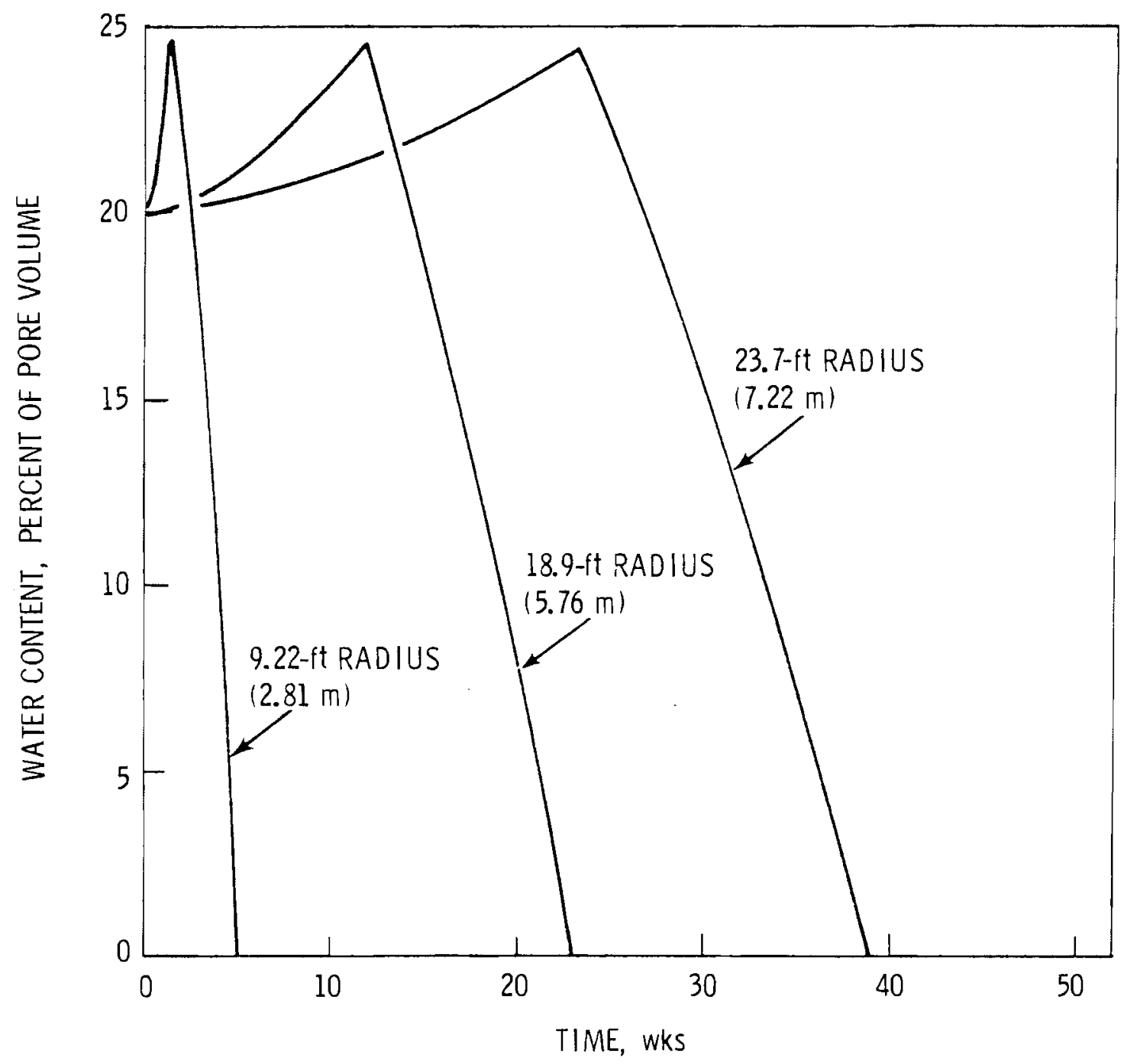

FIGURE 10. Dehydration for Three Locations (1-Year History) 


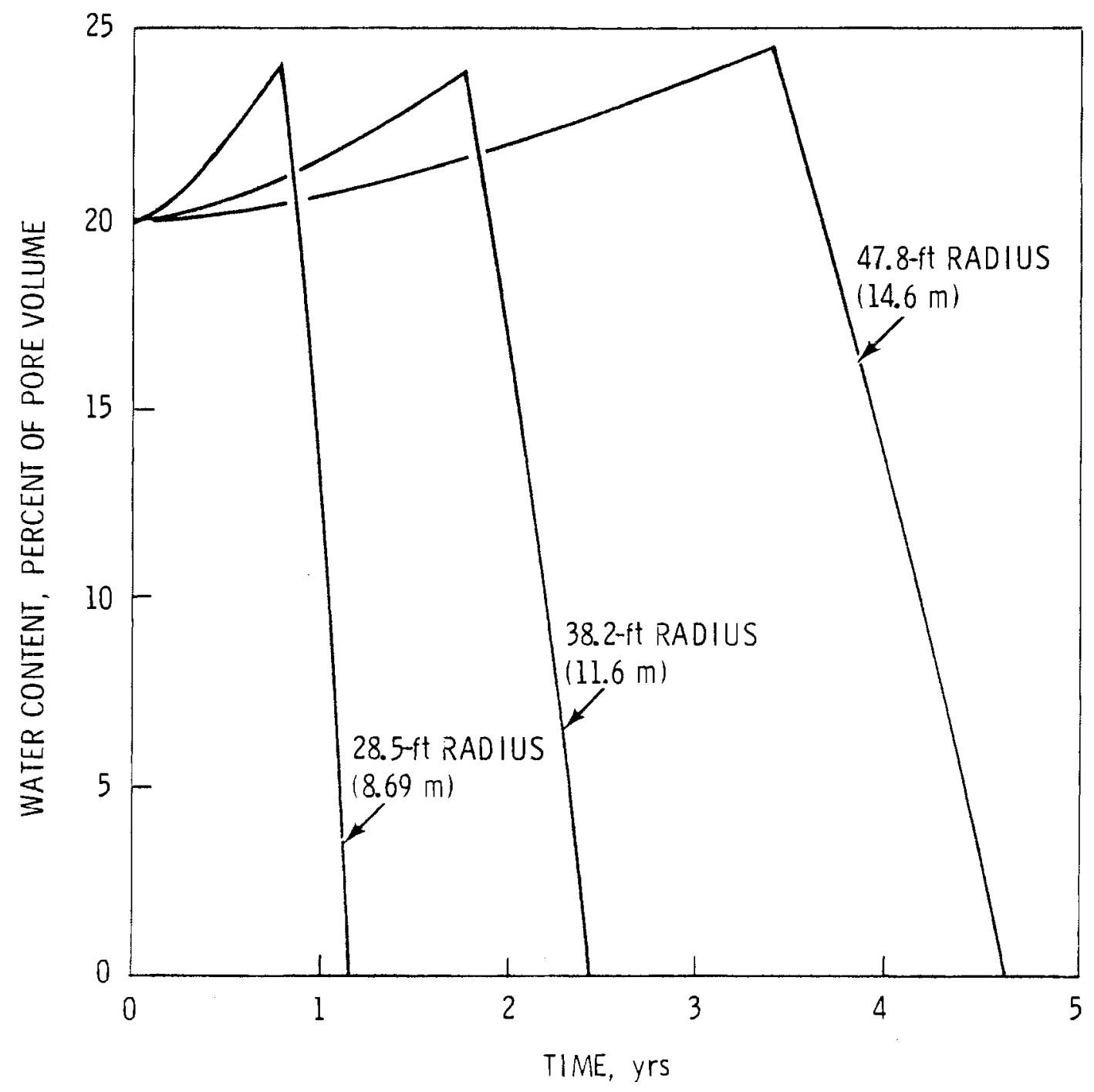

FIGURE 11. Dehydration for Three Locations (5-Year History) 


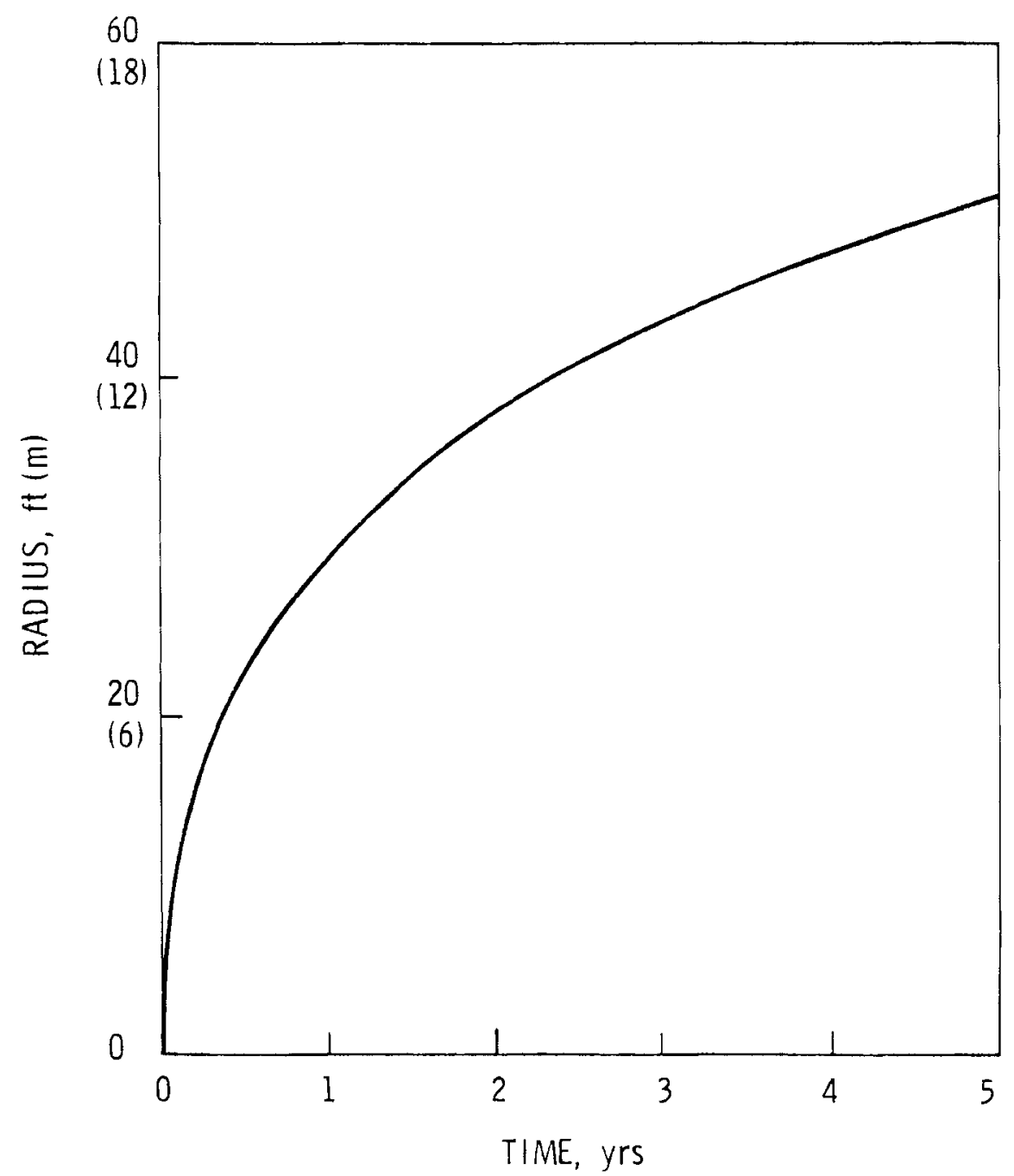

FIGURE 12. Radius of the Dry Front for the Reference Reservoir 
The analysis of the reference reservoir suggests the extent to which dehydration may be expected -to affect the storage volume of the reservoir. The initial mass of water in the reservoir is $3120001 \mathrm{bm} / \mathrm{ft}$ $(464000 \mathrm{~kg} / \mathrm{m})$. After 5 years of continuous reservoir operation the model shows that the radius to the dry front is approximately $51 \mathrm{ft}$ $(17 \mathrm{~m})$. The total water displaced from this region is $203001 \mathrm{bm} / \mathrm{ft}$ $(30200 \mathrm{~kg} / \mathrm{m})$. The net water removed from the reservoir is $171001 \mathrm{bm} / \mathrm{ft}$ $(25400 \mathrm{~kg} / \mathrm{m})$. The remaining water is deposited by condensation beyond the $51 \mathrm{-ft}$ radius (17-m radius). The total water removed from the reservoir represents on $1 y 5.5 \%$ of the original mass of water. The net increase in reservoir storage volume is a mere $1.1 \%$. Thus, the dehydration process is quite slow and should not, in general, be expected to significantly increase the potential storage volume.

\subsubsection{Thermal Cycling and Thermal Growth}

When the simulation of reservoir operation begins, the reservoir is at a uniform temperature of $100^{\circ} \mathrm{F}\left(38^{\circ} \mathrm{C}\right)$. Air is injected into the reservoir at $450^{\circ} \mathrm{F}\left(232^{\circ} \mathrm{C}\right)$ and is extracted at the equilibrium temperature adjacent to the wel1. Figure 13 shows the temperature variations occurring in the near wellbore region during the first week of reservoir operation. While large temperature swings occur at the well boundary, thermal cycling is observed to be nearly non-existent within $14.0 \mathrm{ft}$ $(4.28 \mathrm{~m})$ of the well center. The volumetric thermal capacity of the rock mass is large enough to contain the injected thermal energy very near the we11. Heating of the reservoir beyond $14.0 \mathrm{ft}(4.28 \mathrm{~m})$ occurs primarily by conduction. Figure 14 shows the temperature cycling occurring after 1 year of continuous reservoir operation. Temperature cycling at and near the well has decreased due to the thermal growth of the reservoir.

The development of thermal cycling predicted by the model is shown in Figure 15, where the maximum and minimum weekly extraction temperatures are plotted as functions of time. The solid lines represent the result for the reference reservoir, i.e., for a residual water content of $20 \%$ 


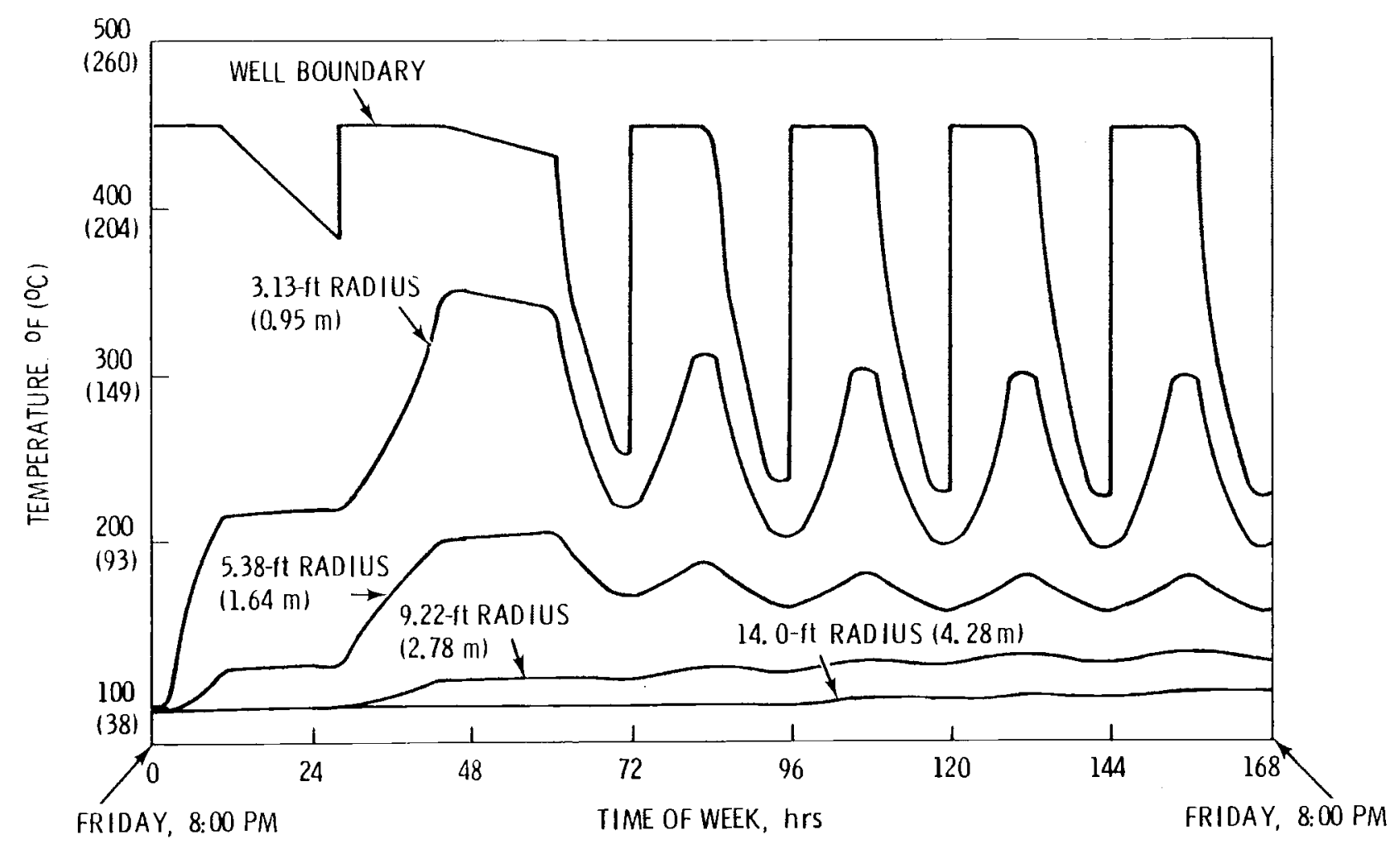

FIGURE 13. Thermal Cycling During the First week of Reservoir Operation 


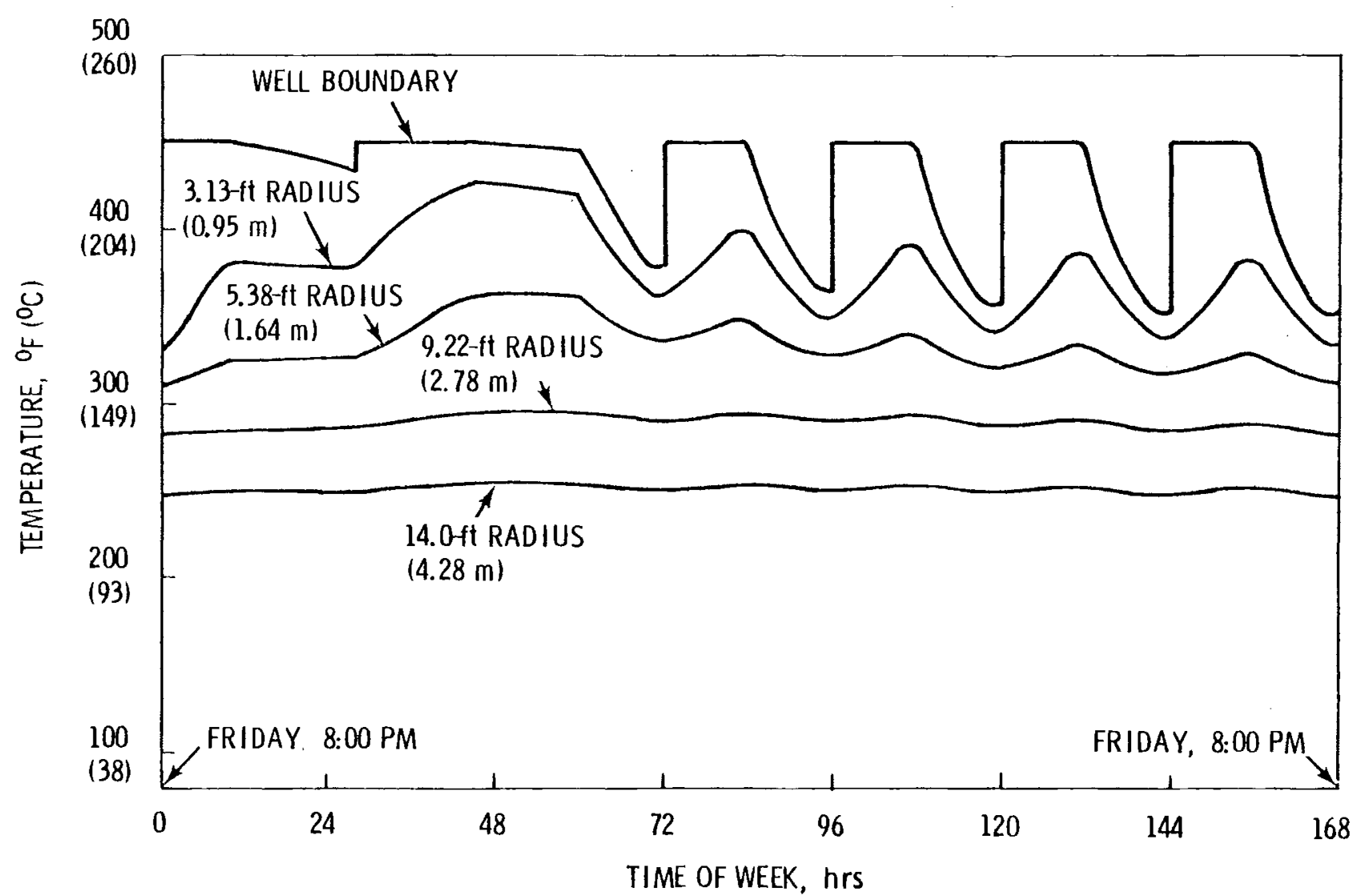

FIGURE 14. Thermal Cycling During the 52nd Week of Reservoir Operation 


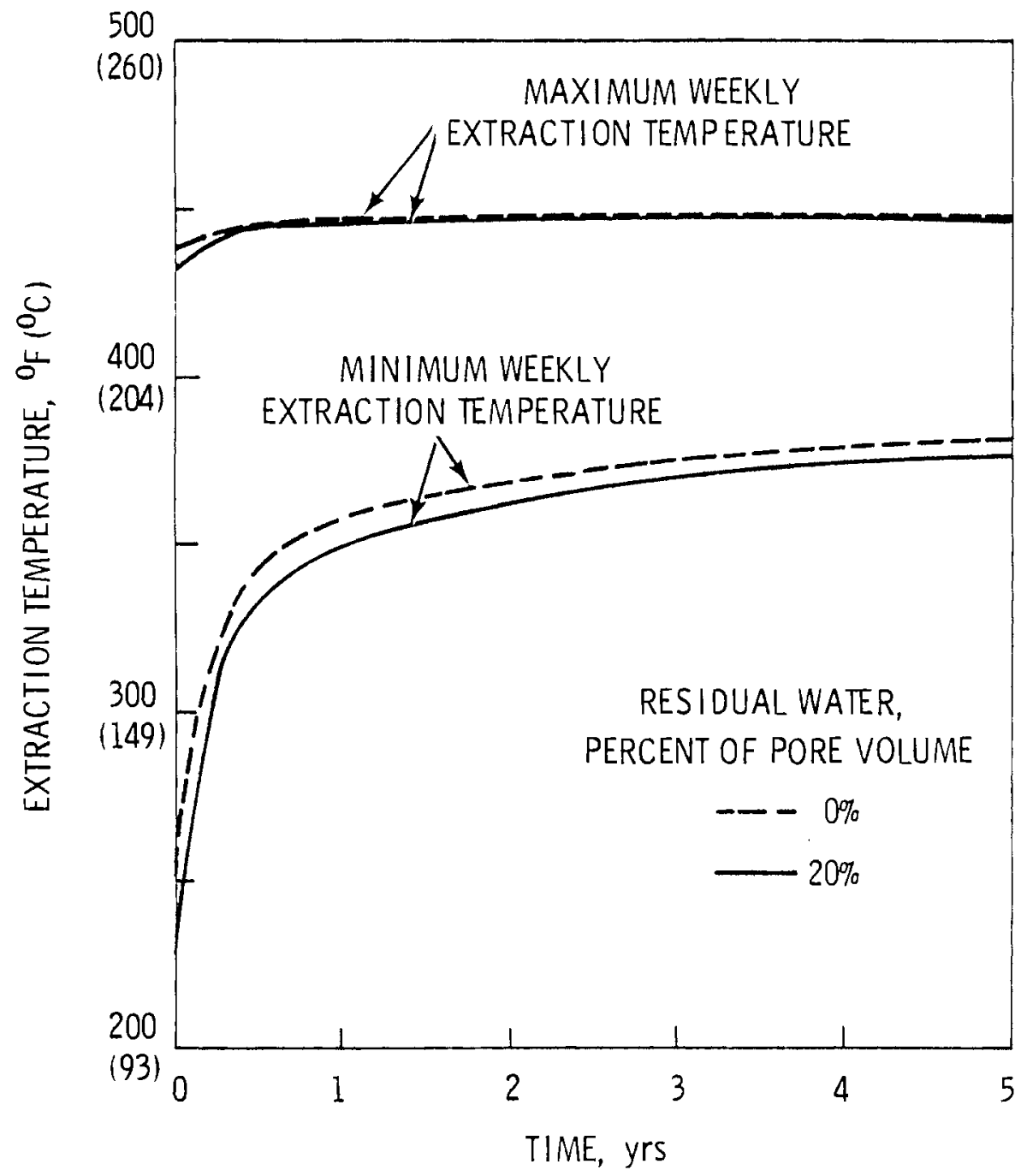

FIGURE 15. Effect of Therma1 Growth on Extraction Temperatures 
of pore volume. A significant reduction in thermal cycling at the well occurs in the first year of operation. Beyond one year the changes occur more gradually. Thus, the weekly cycling occurring after 5 years would not look significantly different than that shown in Figure 14 .

The growth of a heated region surrounding the well is depicted in Figure 16. These profiles were taken at the end of the weekly cycle, i.e., Friday at 8:00 p.m., for the periods indicated. The thermal pillar remains relatively confined within the well region even after 5 years of reservoir operation. Less than $10 \%$ of the rock mass of the 400-ft-diameter (122-m-diameter) reservoir exists within a 60-ft radius (18-m radius) of the wel1. After 5 years the temperature at the $60-\mathrm{ft}$ radius (18-m radius) has reached on 1 y $150^{\circ} \mathrm{F}\left(66^{\circ} \mathrm{C}\right)$.

Figures 15 and 16 show that a significant percentage of thermal energy injected into a reservoir can be recovered during reservoir discharge. The average thermal energy recovery over the first 5 years of reservoir operation is about $81 \%$.

The effect of residual water on thermal cycling and thermal growth is shown in Figures 15 and 17. The dashed 1 ines in Figures 15 and 17 represent the result for a dry reservoir. The comparison with the reference reservoir suggests that the presence of residual water will have only a small effect on temperature cycling and thermal growth. This becomes conclusive in view of the fact that $80 \%$ of the reservoir volume is rock, while initially only $4 \%$ of the volume is liquid water. The difference in the total thermal capacity between the dry reservoir and the reference reservoir is, therefore, relatively small. Since the reference reservoir has a slightly greater thermal capacity, the growth of the high temperature region surrounding the well will be slower. The slower rate of thermal growth can be partially attributed to the dehydration process. The average thermal energy recovery for the dry reservoir is about $82 \%$, which is only slightly better than the reference reservoir. (The same thermal energy is injected in both cases.) Thus, it can also be concluded that the effect of residual water on thermal energy recovery is small. 


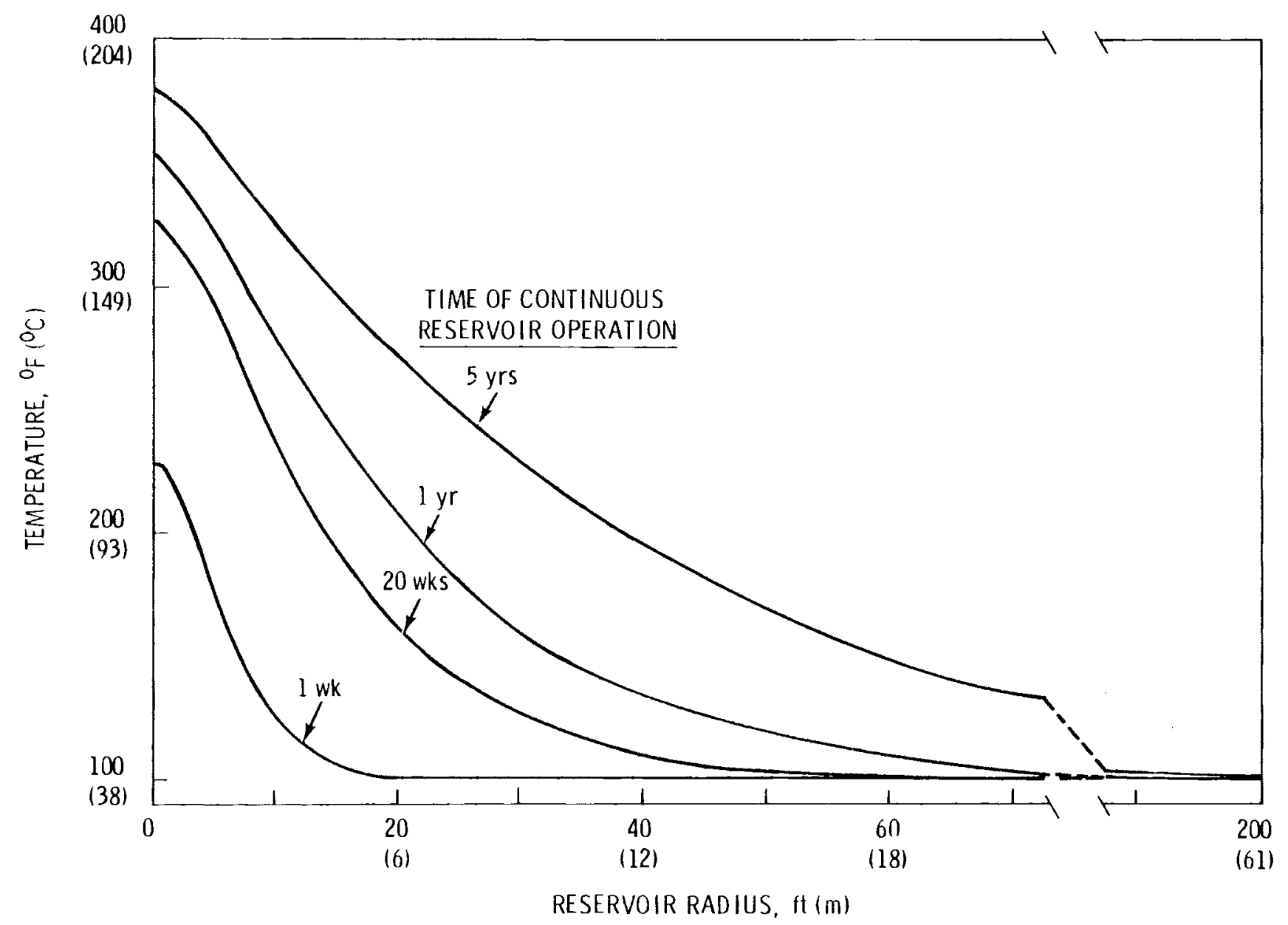

FIGURE 16. Thermal Growth in the Reservoir 


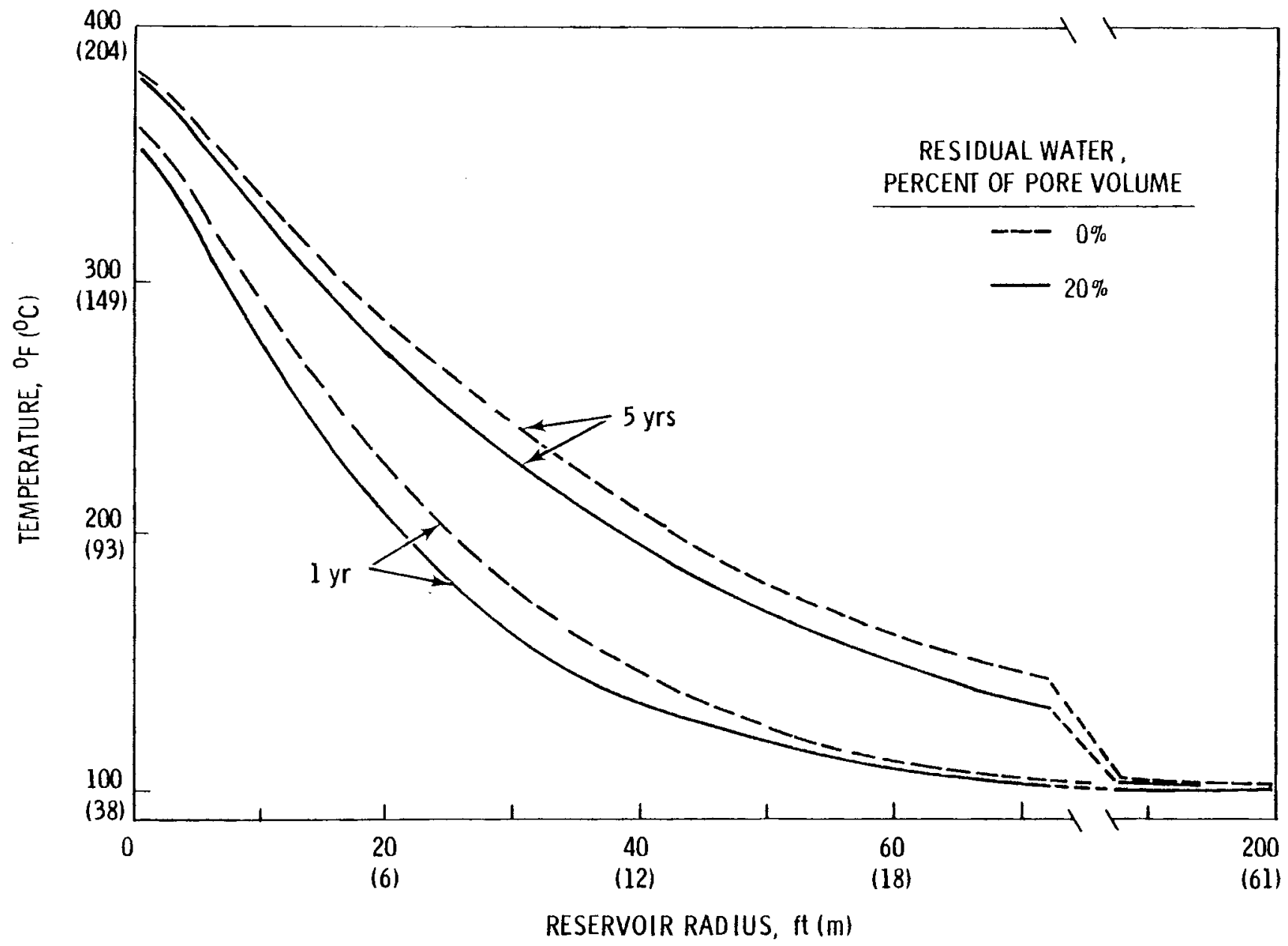

FIGURE 17. Effect of Residual Water on Thermal Growth 
The reference reservoir and weekly cycle for the moisture analysis were designed so that the thermal energy input would be the same as for the analysis of the dry reservoir. To maintain an equal thermal energy input with a residual water content of $20 \%$ of pore volume, the mass cycling had to be $14.8 \%$. This produces pressure cycling at the we 11 that may be excessive, since a literature survey conducted in FY-1977 indicated that mass cycling ranged from 7 to $12 \%$. To examine the effects of reduced mass cycling, an analysis of the reference reservoir was performed with $12 \%$ mass cycling. The thermal growth for these cases is compared in Figure 18. For a residual water content of $20 \%$ of pore volume and $12 \%$ mass cycling, significantly less thermal energy is input to the reservoir than for the two other cases shown on the figure. However, for all the cases a large portion of the input thermal energy is recovered during reservoir discharge. Therefore, the difference in the sizes of the remaining thermal pillars for each case is small.

\subsubsection{Pressure Cycling}

The weekly operating cycle will result in pressure cycling in the reservoir during the first week of operation as shown in Figure 19. The maximum we 11 pressure occurs on Sunday at 4:00 p.m. and reaches a value of 816 psi $(5630 \mathrm{kPa})$. The minimum well pressure occurs on Friday at 6:00 p.m. and has a value of $649 \mathrm{psi}(4480 \mathrm{kPa})$. Due to thermal growth in the reservoir the weekly extremes of well pressure change over time as shown in Figure 20. The comparison with the dry reservoir indicates the greater pressure cycling of the reference reservoir occurring in proportion to the percent of mass cycling. The pressures for the reservoir containing water do not increase as much as those of the dry reservoir. This is not only because average temperatures are slightly lower, but because as water is evaporated, the effective storage volume is increased. While the change in storage volume is small, this behavior will, nevertheless, have to be considered in the design of an aquifer CAES reservoir. 


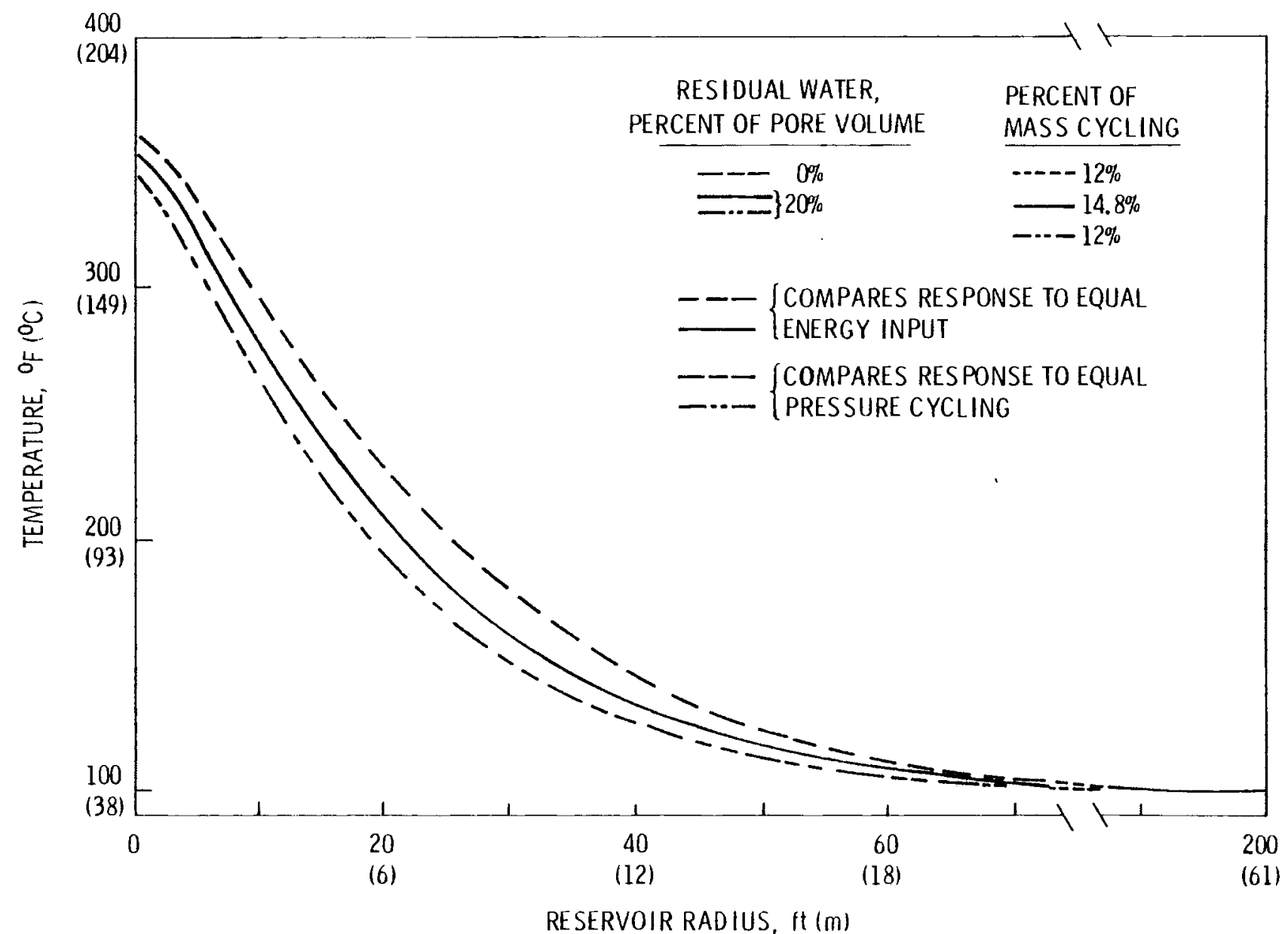

FIGURE 18. Effect of Percent of Mass Cycling on Thermal Growth 


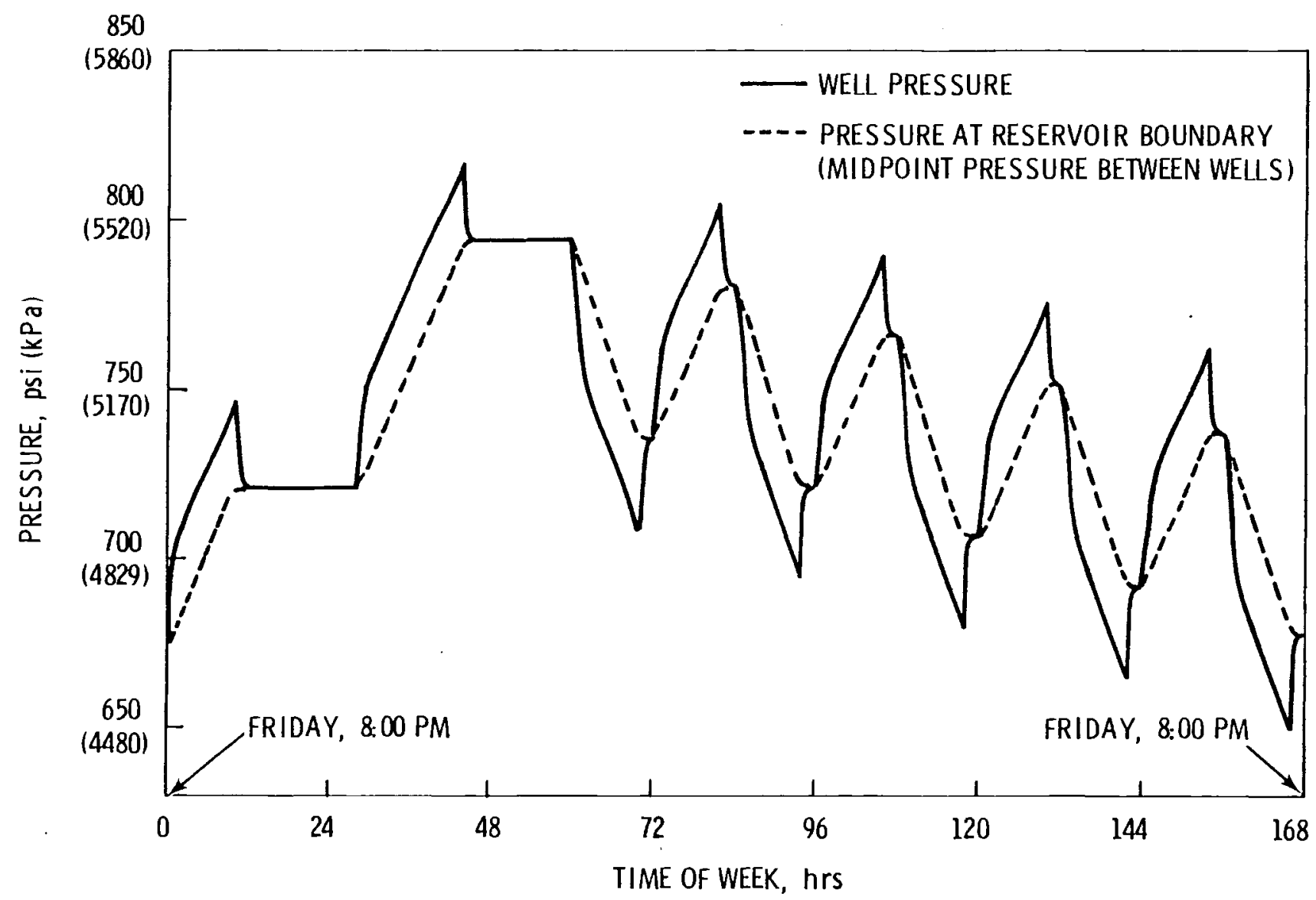

FIGURE 19. Weekly Pressure Cycle 


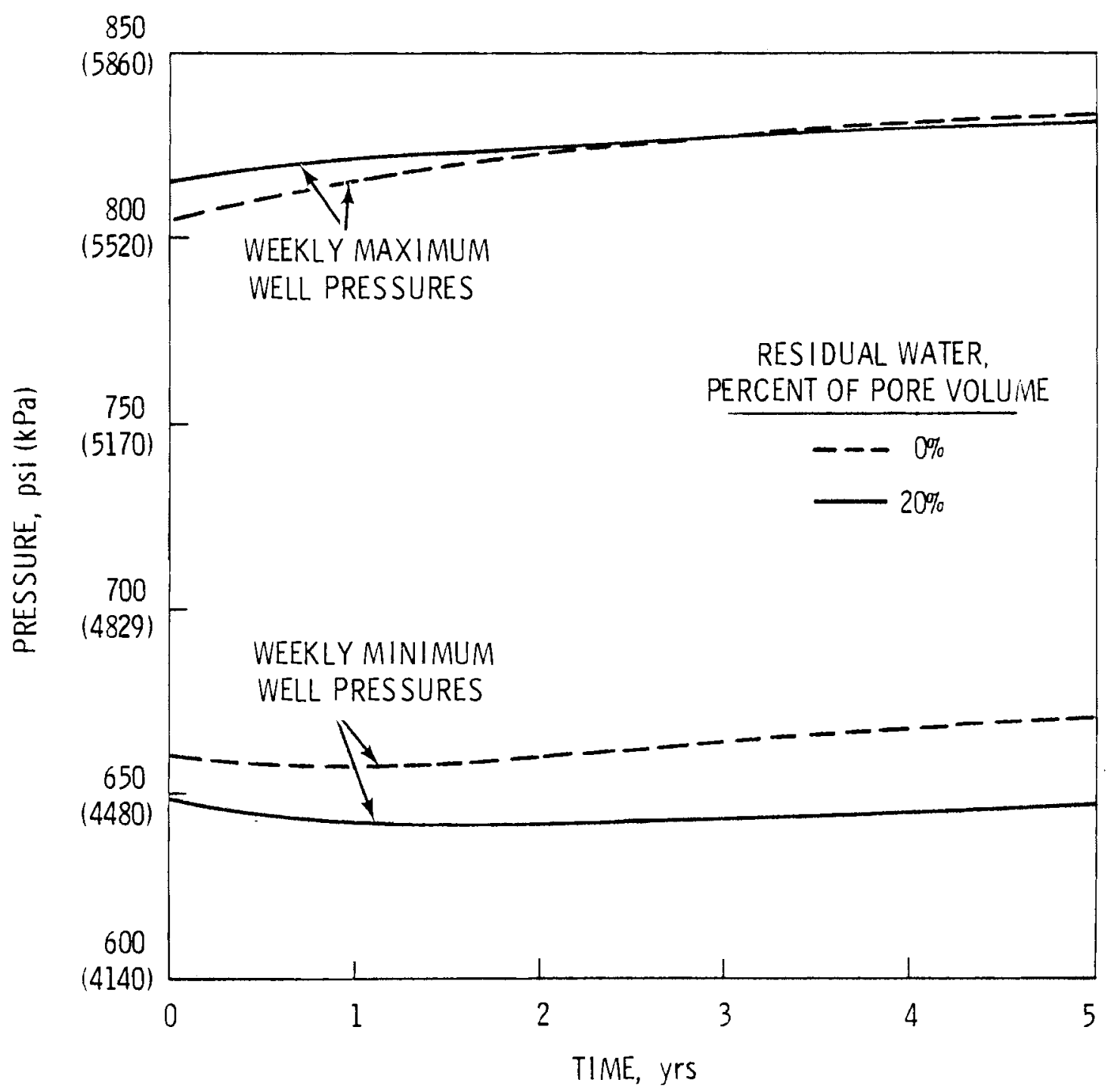

FIGURE 20. Effect of Residual Water and Thermal Growth on Pressure Cycling 


\subsection{INJECTION TEMPERATURE}

The study of injection temperature is essentially an extension of the analysis of the reference reservoir. The motive for performing this analysis was to establish the difference in the dehydration rates associated with the spectrum of possible injection temperatures. Also, the coexistence of high temperature and liquid water can dramatically increase the potential for adverse geochemical reactions. Thus, it is important to quantify when such conditions might occur. A reasonable lower limit of injection temperature was considered to be $100^{\circ} \mathrm{F}\left(38^{\circ} \mathrm{C}\right)$. This will depend on the costs associated with rejecting the heat of compression. An upper limit of $450^{\circ} \mathrm{F}\left(232^{\circ} \mathrm{C}\right)$ was chosen because this represents the approximate maximum outlet temperature that can be tolerated by currently available centrifugal compressors.

In Figure 21 the radius to the dry front is plotted as a function of time for each injection temperature. The results of the model indicate that the time required for dehydration to be achieved to a radius of $10 \mathrm{ft}(3 \mathrm{~m})$ varies from about 4 weeks for the highest injection temperature to about 32 weeks for the lowest injection temperature. Injection temperatures above $250^{\circ} \mathrm{F}\left(121^{\circ} \mathrm{C}\right)$ are necessary if dehydration to a $20-\mathrm{ft}$ radius (6-m radius) is to be achieved within one year. Conclusions regarding these results cannot be drawn until criteria have been established which define the size of the required dehydrated zone that assure stable and efficient reservoir operation. These criteria will have to consider the potential effects of water related to deliverability, i.e., reduced relative permeability and reduced permeability due to geochemical reactions. When such guidelines are established, the usefulness of the results suggested by Figure 21 will be more apparent.

Reduced deliverability due to the presence of liquid water in the vicinity of the well degrades the performance of the air storage system. To maintain a given flow rate to or from the reservoir, a greater difference between the reservoir pressure and the well pressure is required. In Figure 22 a surprising result is shown where the maximum 


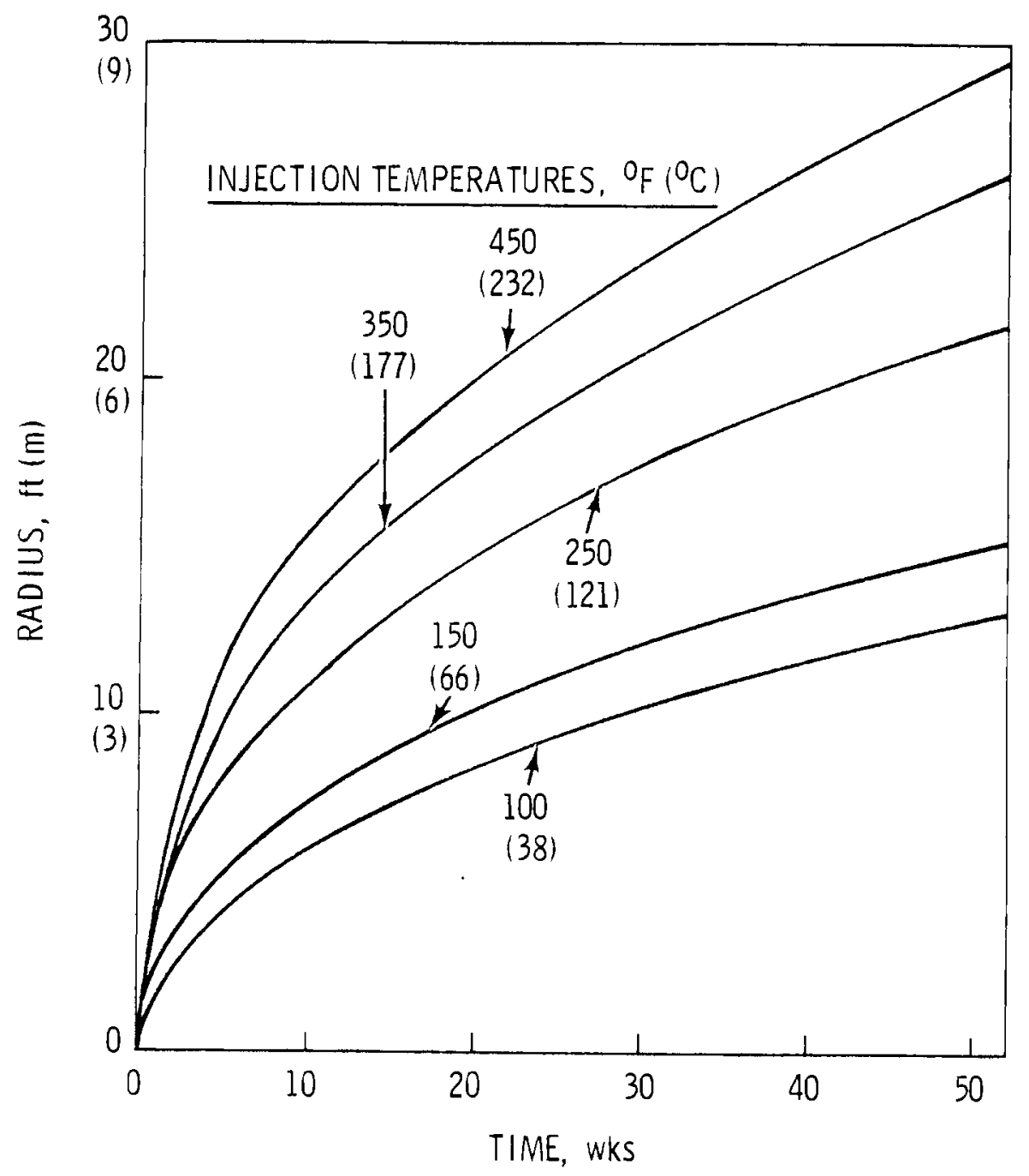

FIGURE 21. Effect of Injection Temperature on Growth of the Dry Front

wel1 pressure encountered during the first week of reservoir operation is plotted against the injection temperatures. In a11 cases, the reservoir pressures are the same (because each case begins with the same stored mass), the mass charging rates are identical, and the peak pressures are reached at the same time. While higher temperatures may 


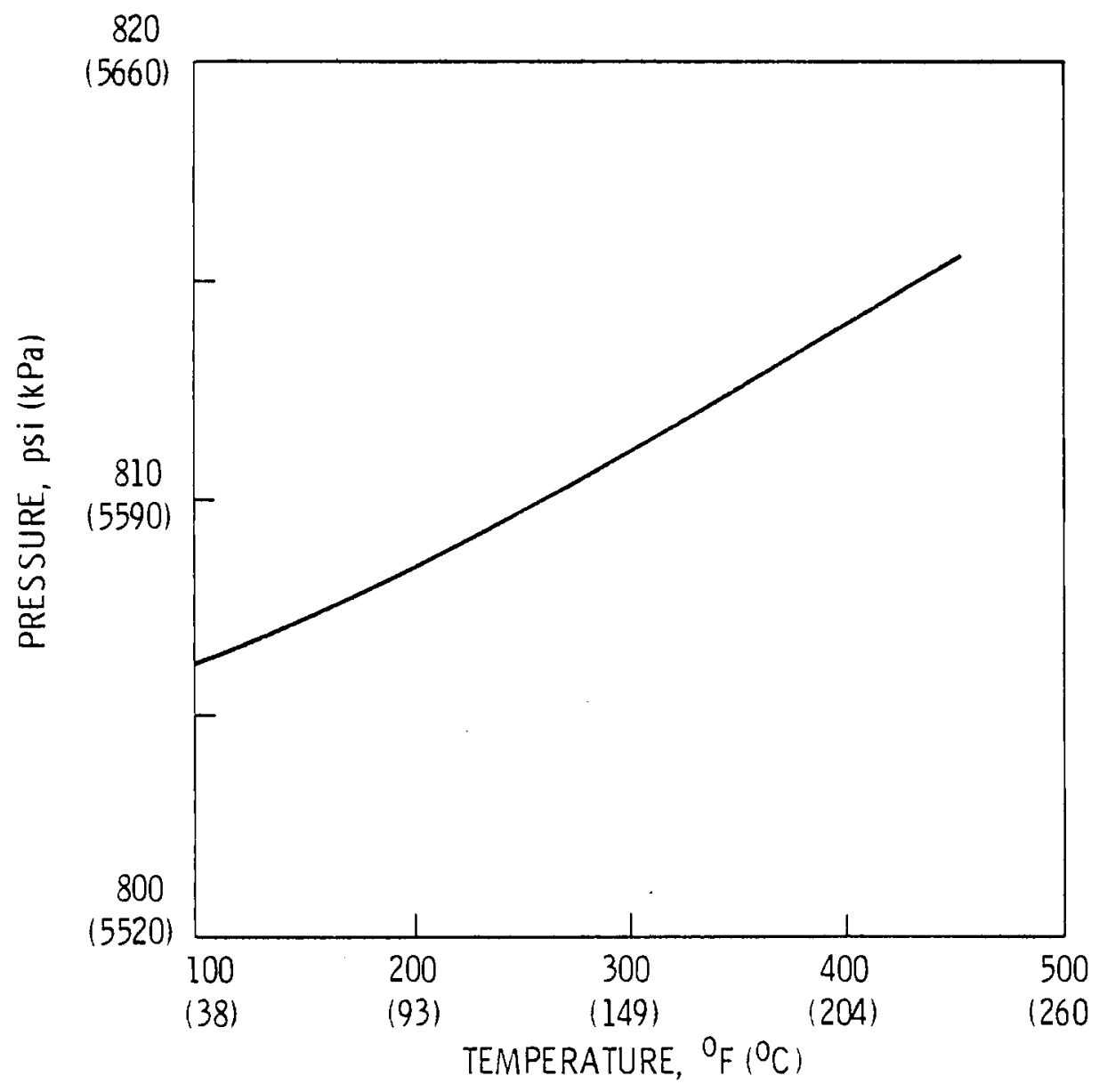

FIGURE 22. Maximum We11 Pressure During the First Week of Reservoir Operation as a Function of Injection Temperature

dehydrate the wellbore region faster, thereby increasing the relative permeability, the greater viscosity of the air-vapor mixture at higher temperatures dominates the required pressures. Indeed, the results suggest that high temperature is the prime contributor to the potential for reduced deliverability, rather than reduced relative permeability due to the residual water. 
Additional observations can be made with respect to behavior of the dehydration process for various injection temperatures. In Figure 23 the rates of net reservoir dehydration are shown. In the dehydration process the dry air entering the reservoir becomes saturated when it reaches the dry front and encounters liquid water. As it moves radially outward the air-vapor mixture gives up heat while maintaining thermal equilibrium with the surroundings. Condensation subsequently results. In this way the water is displaced from the wellbore region, although it is not necessarily removed from the reservoir. Reservoir dehydration takes place when air heats up and gains moisture as it maintains a saturated condition while flowing radially inward. The gain in moisture is experienced until the discharging air reaches the dry front. After 1 year of reservoir operation, the radius to the dry front for $450^{\circ} \mathrm{F}$ $\left(232^{\circ} \mathrm{C}\right)$ injection is about $29 \mathrm{ft}(9 \mathrm{~m})$. Approximately $6550 \mathrm{lbm} / \mathrm{ft}$ $(9750 \mathrm{~kg} / \mathrm{m})$ of water has been removed from this region. The net water removed from the reservoir was $5480 \mathrm{lbm} / \mathrm{ft}(8160 \mathrm{~kg} / \mathrm{m})$. The remaining water was deposited by condensation at a radius beyond that of the dry front.

A time dependent decrease in the dehydration rate, which is most apparent for high temperature injection, characterizes the results of Figure 23. During initial operation the dehydration in the near well region is influenced by periodically high temperatures due to thermal cycling. When the dry front moves beyond the region of thermal cycling, the dehydration rates slow as the heat necessary for evaporation is available primarily by conduction. Another cause of the decrease in dehydration rate with time is that an increasing portion of the injected air-vapor mixture is stored within the expanding dry region. That portion of the air is subsequently extracted without having encountered any liquid water.

The temperature at the dry front is important because it dictates the humidity of the extracted air. These temperatures are shown in Figure 24. The saturation humidity corresponding to these temperatures 


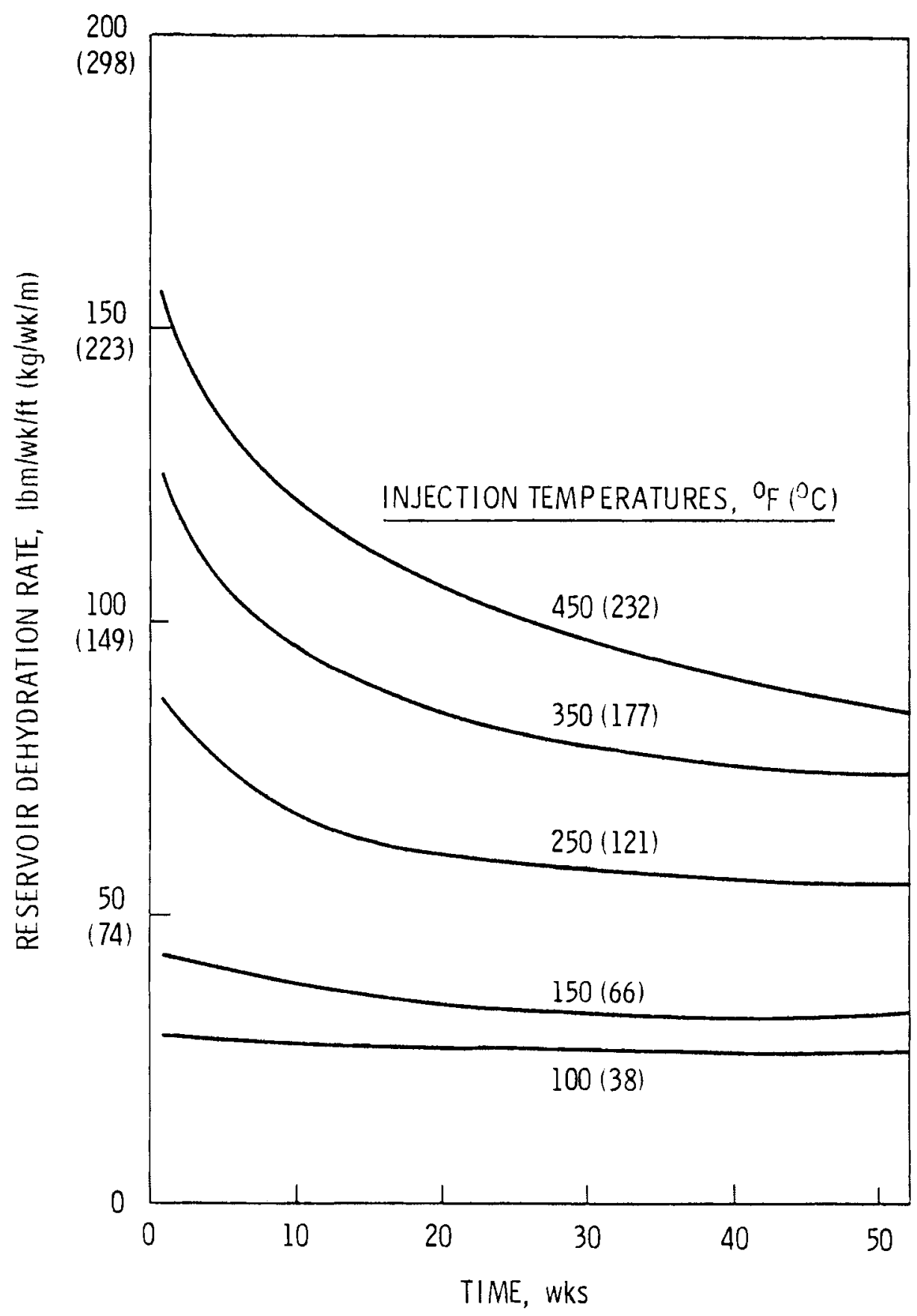

FIGURE 23. Effect of Injection Temperature on the Net Reservoir Dehydration Rate 


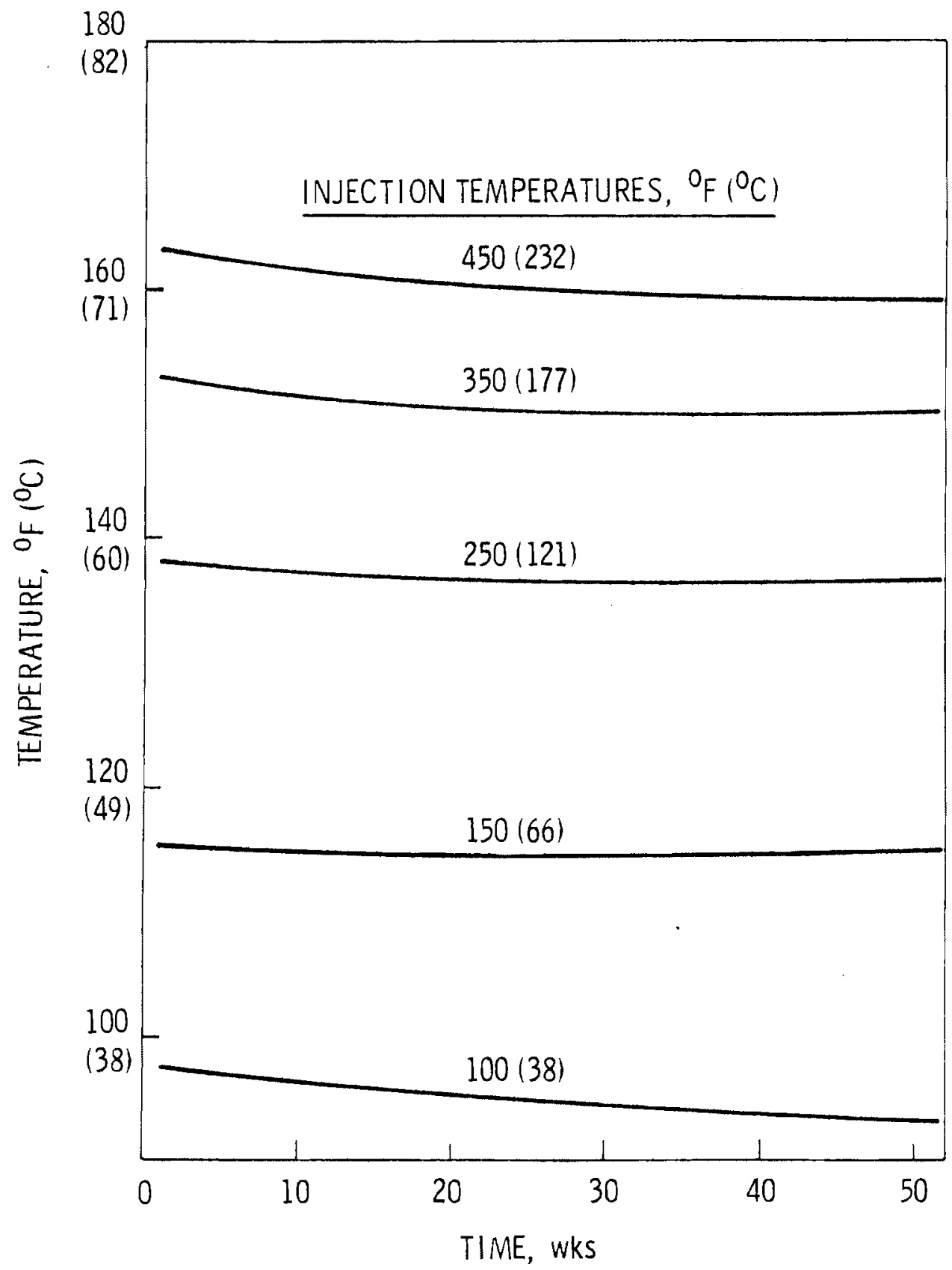

FIGURE 24. Effect of Injection Temperature on the Temperature at the Dry Front 
at the local pressure is shown in Figure 25. These values are obtained from the equilibrium conditions at the end of the weekly cycle and, thus, do not reflect the effects of thermal cycling occurring during initial reservoir operation. During reservoir discharge, air flowing radially inward will gain moisture until it reaches the dry front. At this point the air-vapor mixture wi $17^{\circ}$ be saturated at the temperature and pressure of the dry front. As the air is produced from the reservoir, condensation of the vapor will begin if this saturation condition is encountered. However, reasonable precautions against heat loss from the

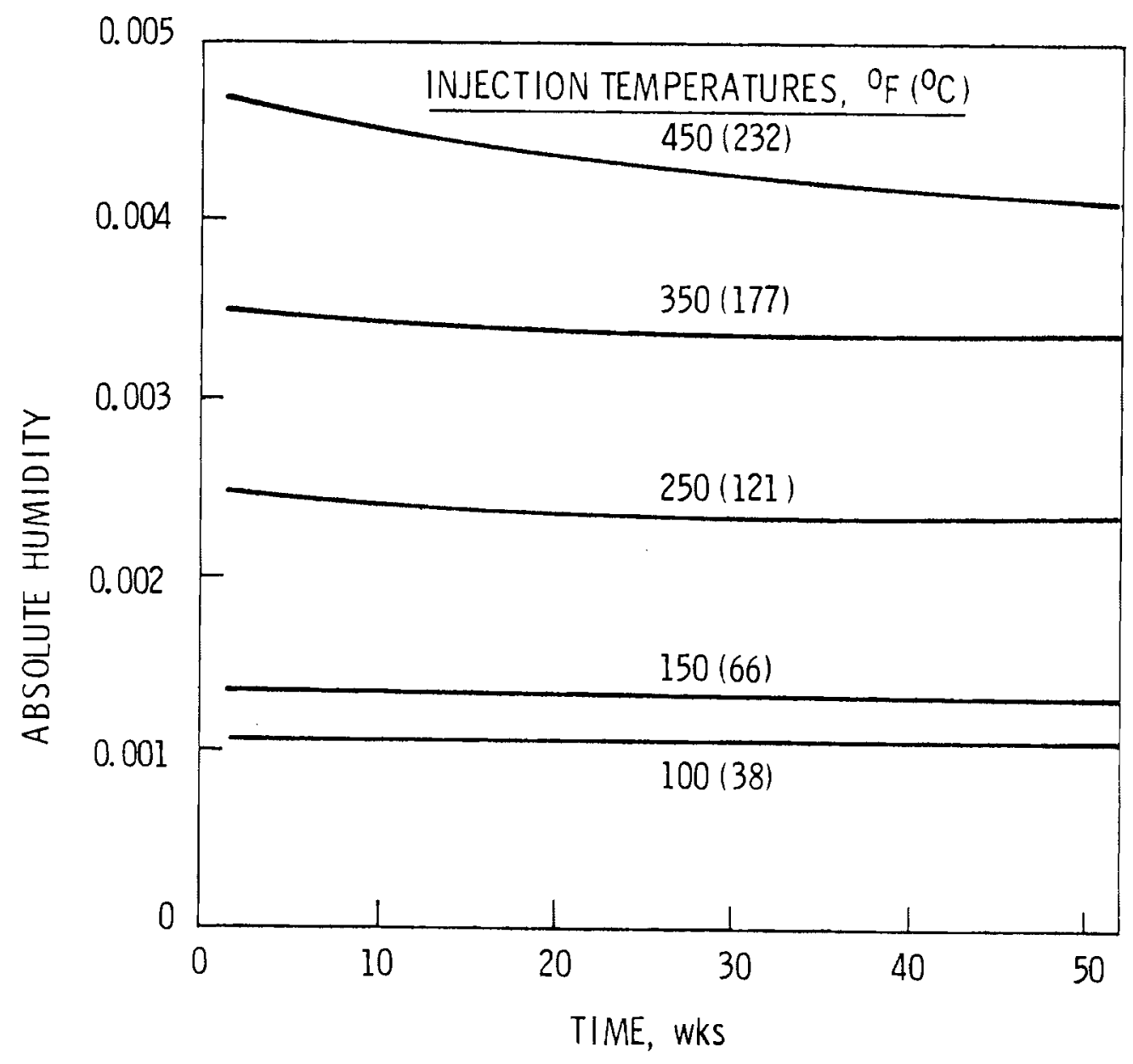

FIGURE 25. Saturation Humidity Corresponding to Temperature and Pressure at the Dry Front 
produced air stream should allow this problem to be avoided. Also, an inevitable drop in pressure will enhance the moisture carrying capacity of the mixture.

An important observation with regard to Figure 24 is that the coexistence of high temperatures and liquid water can be minimized by injection of dry air, even if the injection temperature is as high as $450^{\circ} \mathrm{F}\left(232^{\circ} \mathrm{C}\right)$. The equilibrium temperature at the end of the weekly cycle at the dry front is nearly a constant $160^{\circ} \mathrm{F}\left(71^{\circ} \mathrm{C}\right)$ for an injection temperature of $450^{\circ} \mathrm{F}\left(232^{\circ} \mathrm{C}\right)$. Until the dry front has moved beyond the region of thermal cycling, which requires about 8 weeks, the dry front will be periodically subjected to higher temperatures. Beyond this time the temperature at the dry front will remain nearly constant.

\subsection{INJECTION HUMIDITY}

If water vapor exists in the injected air stream to an aquifer CAES reservoir it can have a significant impact on the progression of the dry front, the rate of dehydration, and the thermal development of the reservoir.

Unless it is otherwise defined, the reference to humidity in this report is absolute humidity in which the units are mass of water vapor per unit mass of dry air.

The moisture content of the injected air is 1 imited by the humidity of the ambient air that is to be compressed. Saturated air at $100^{\circ} \mathrm{F}$ $\left(38^{\circ} \mathrm{C}\right)$ and $1 \mathrm{~atm}(101 \mathrm{kPa})$ of pressure will have an absolute humidity of 0.0429. When the air is compressed to the nominal reservoir pressure of $50 \mathrm{~atm}(5070 \mathrm{kPa})$, its ability to hold water vapor is reduced. At that pressure, an absolute humidity of 0.0429 can exist only if the temperature of the mixture is above $276^{\circ} \mathrm{F}\left(136^{\circ} \mathrm{C}\right)$. Below this temperature the humidity of the injected air-vapor mixture cannot exceed the saturation conditions dictated by the injection temperature and the reservoir pressure. This is shown in Figure 26. 


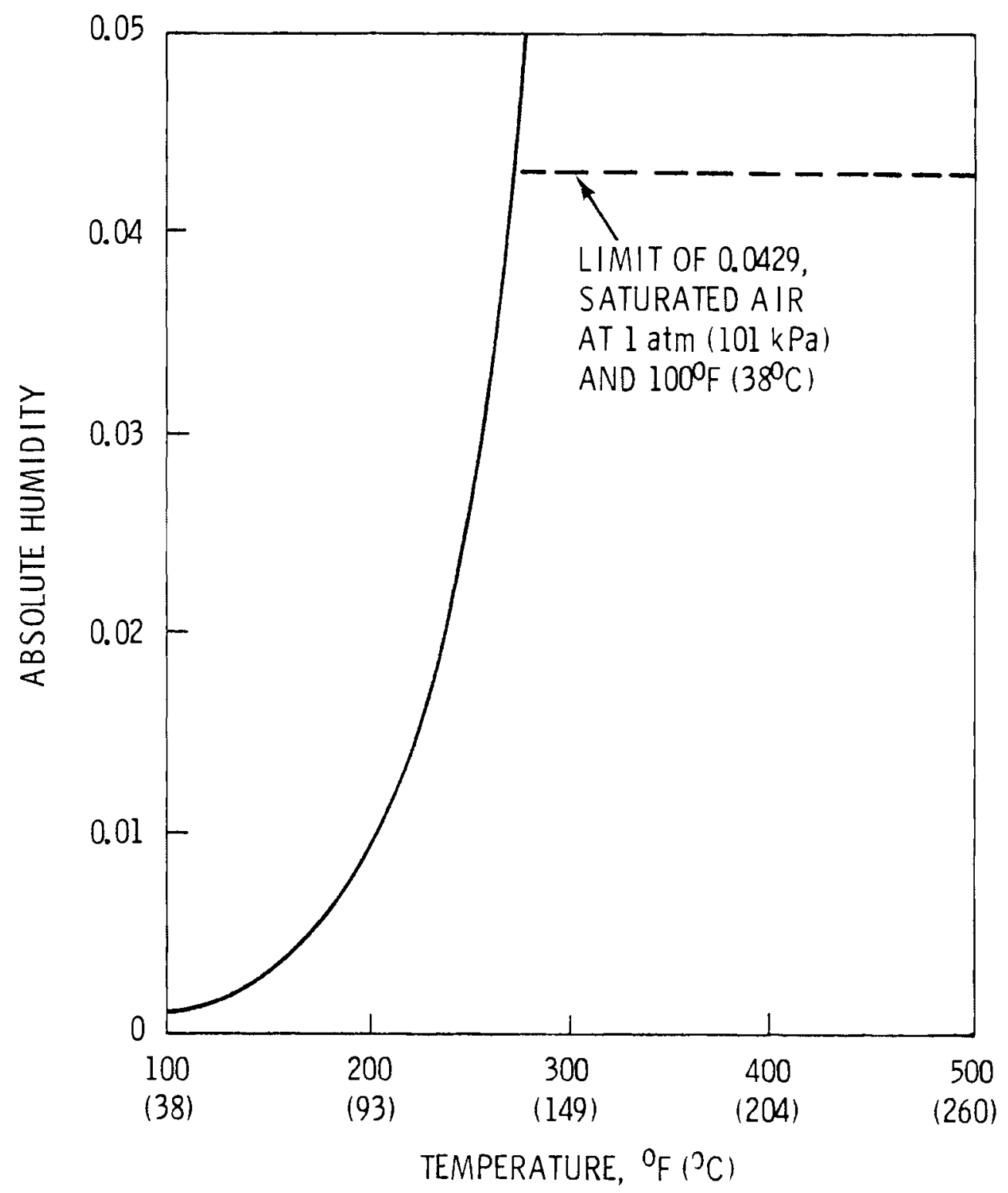

FIGURE 26. Saturated Absolute Humidity at $50 \mathrm{~atm}$ (5070 kPa)

The process of dehydration and the movement of the dry front depend largely on the amount of moisture in the injected air stream. The dehydration at a radius of $14.0 \mathrm{ft}(4.27 \mathrm{~m})$ is shown in Figure 27 for the reference reservoir, where the injection humidities are compared. The dehydration is obviously slowed by the inclusion of humidity in the injected air stream. The result that shows the pore water content to 


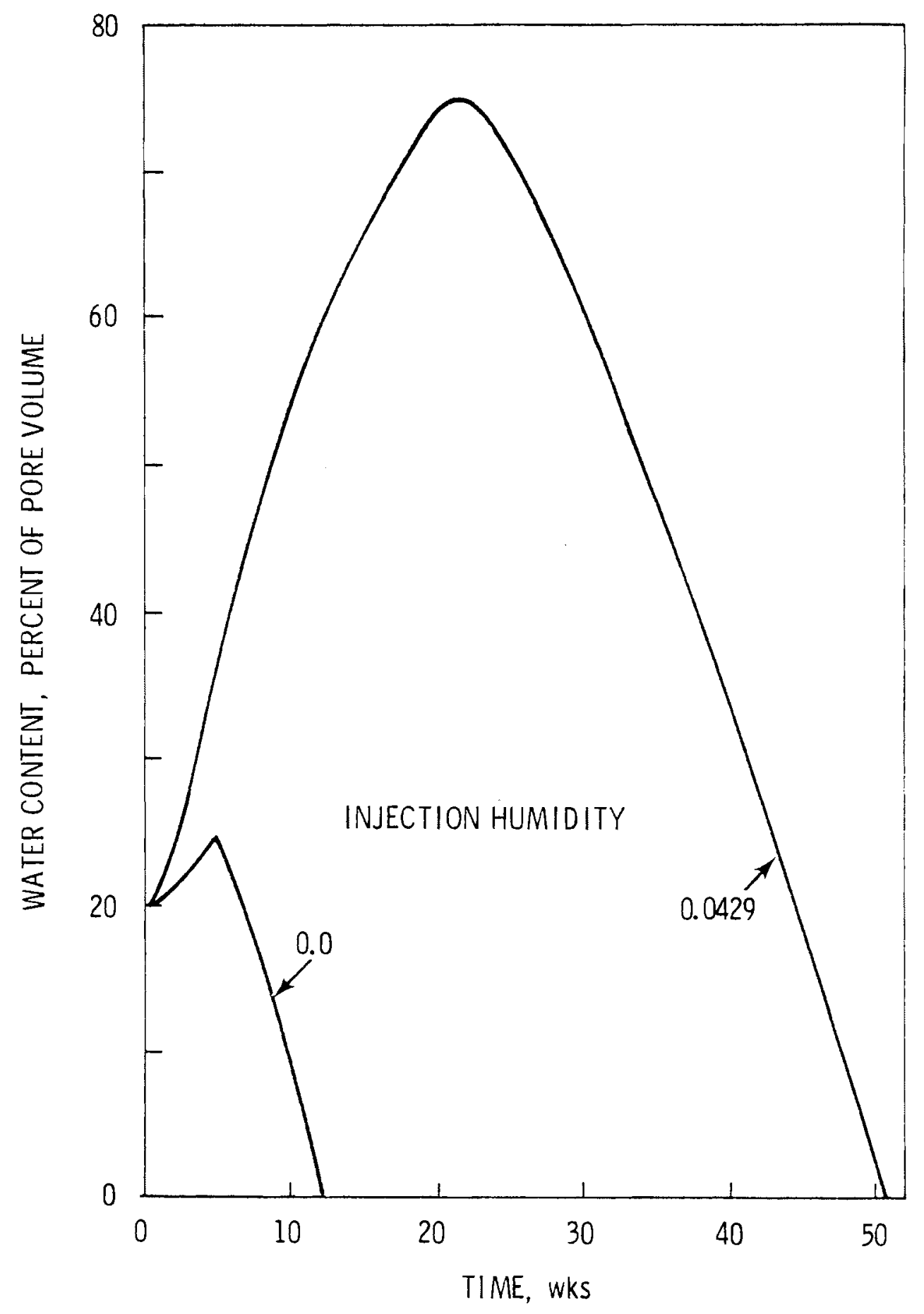

FIGURE 27. Effect of Injection Humidity on the Dehydration of the Region Centered at a Radius of $14.0 \mathrm{ft}$ $(4.27 \mathrm{~m})$ 
greatly exceed the initial value suggests the significant potential for pore plugging under some conditions of moist air injection. The potential effect on the stability of reservoir deliverability could be significant.

The effect of injected moisture on thermal growth in the reservoir is shown in Figure 28. When dry air enters the reservoir the subsequent evaporation wi11 inhibit the thermal growth. In contrast, the injection of moist air results in a net increase of liquid water in the reservoir due to condensation, and the thermal growth will be enhanced because of the deposition of latent heat.

The difference between the injection of dry air and the injection of moist air is observed in Figures 29 and 30, which apply to the injection of moist air at $450^{\circ} \mathrm{F}\left(232^{\circ} \mathrm{C}\right)$. The results were taken after completion of the first week of reservoir operation. In Figure 29 the injection of dry air into an initially dry reservoir results in an extraction temperature of $243^{\circ} \mathrm{F}\left(117^{\circ} \mathrm{C}\right)$ at the end of the week. If the reservoir has any liquid water the evaporation resulting from the injection of dry air will result in an extraction temperature below $243^{\circ} \mathrm{F}\left(117^{\circ} \mathrm{C}\right)$. However, as displayed in Figure 30 , the net dehydration will be positive. This indicates that there has been a net increase in the available working fluid in the reservoir. Injecting humid air into an initially dry reservoir can result in a decrease in working fluid, as indicated by the negative dehydration rates, and an increase in thermal energy recovery, as indicated by the increase in extraction temperature. For each injection temperature there will be a trade-off humidity, above which there will be a gain in extraction thermal energy and a loss of working fluid. Below the trade-off humidity, the opposite result will occur.

Long-term thermal development will have an effect on the trade-off humidity. As the thermal pillar and region encompassed by the dry front increase in size, a portion of the injected moist air will be stored inside this region where the moisture will not condense. Thus, the rate 


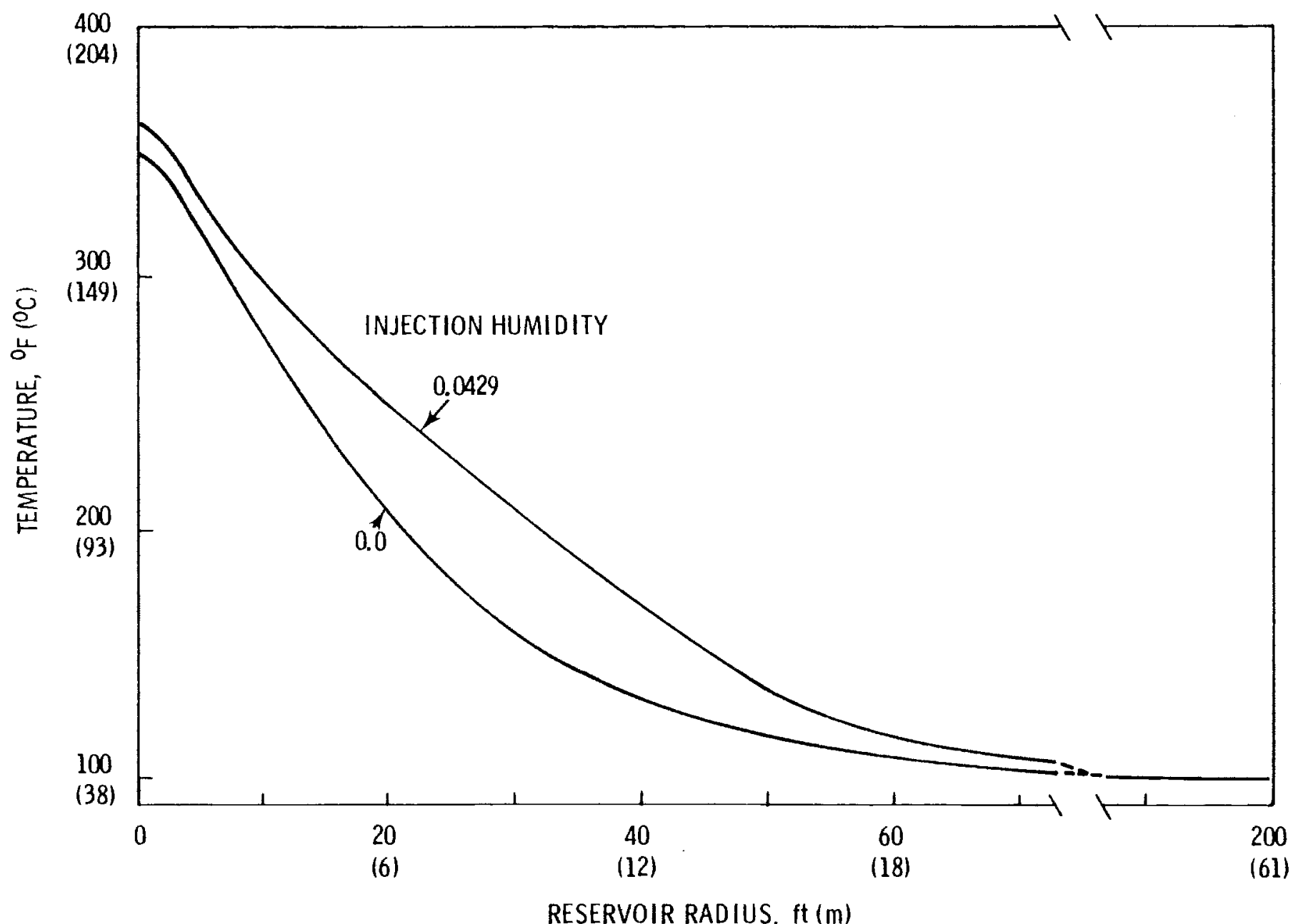

FIGURE 28. Effect of Injection Humidity on Thermal Growth 


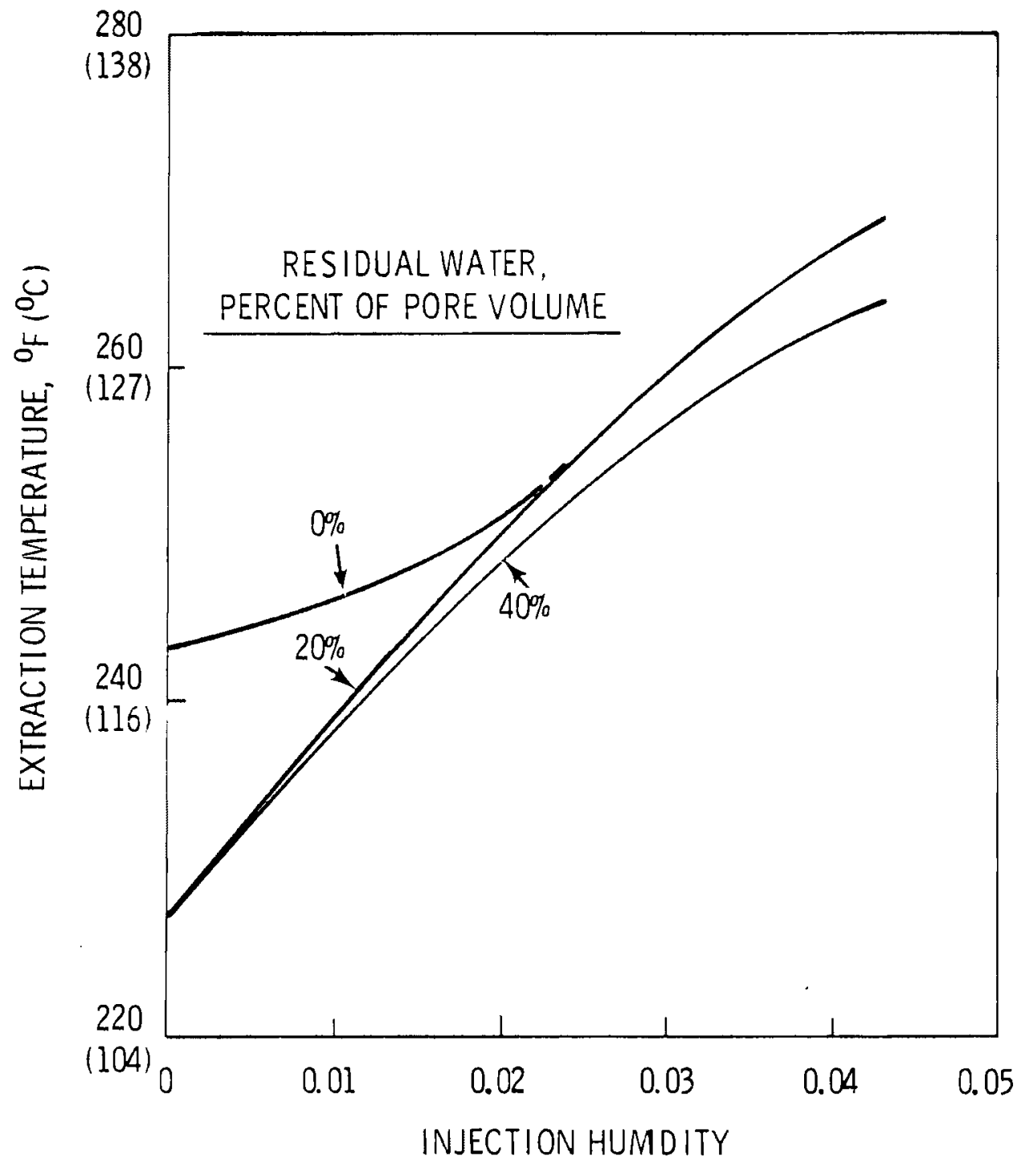

FIGURE 29. Effect of Injection Humidity on Extraction Temperatures for Various Values of Residual Water

of addition of moisture to the reservoir will decrease. This will tend to move the trade-off humidity to a somewhat higher value.

The effect of injection humidity on initial dehydration rates for various injection temperatures is shown in Figure 31. These results were also taken after completion of one week of simulated reservoir operation. The results apply to a residual water content of $20 \%$ of pore 


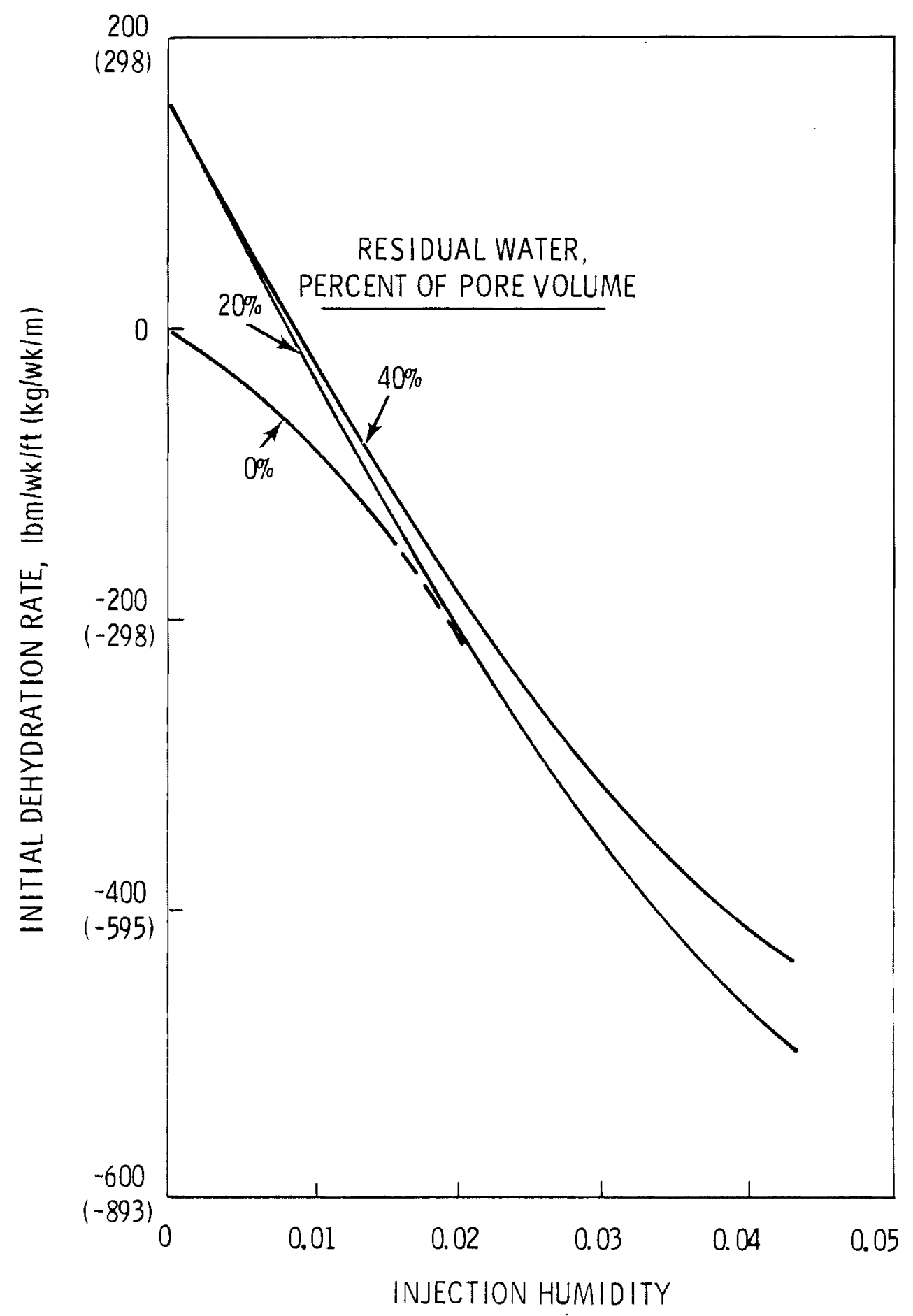

FIGURE 30. Effect of Injection Humidity on Initial Reservoir Dehydration Rates for Various Values of Residual Water 


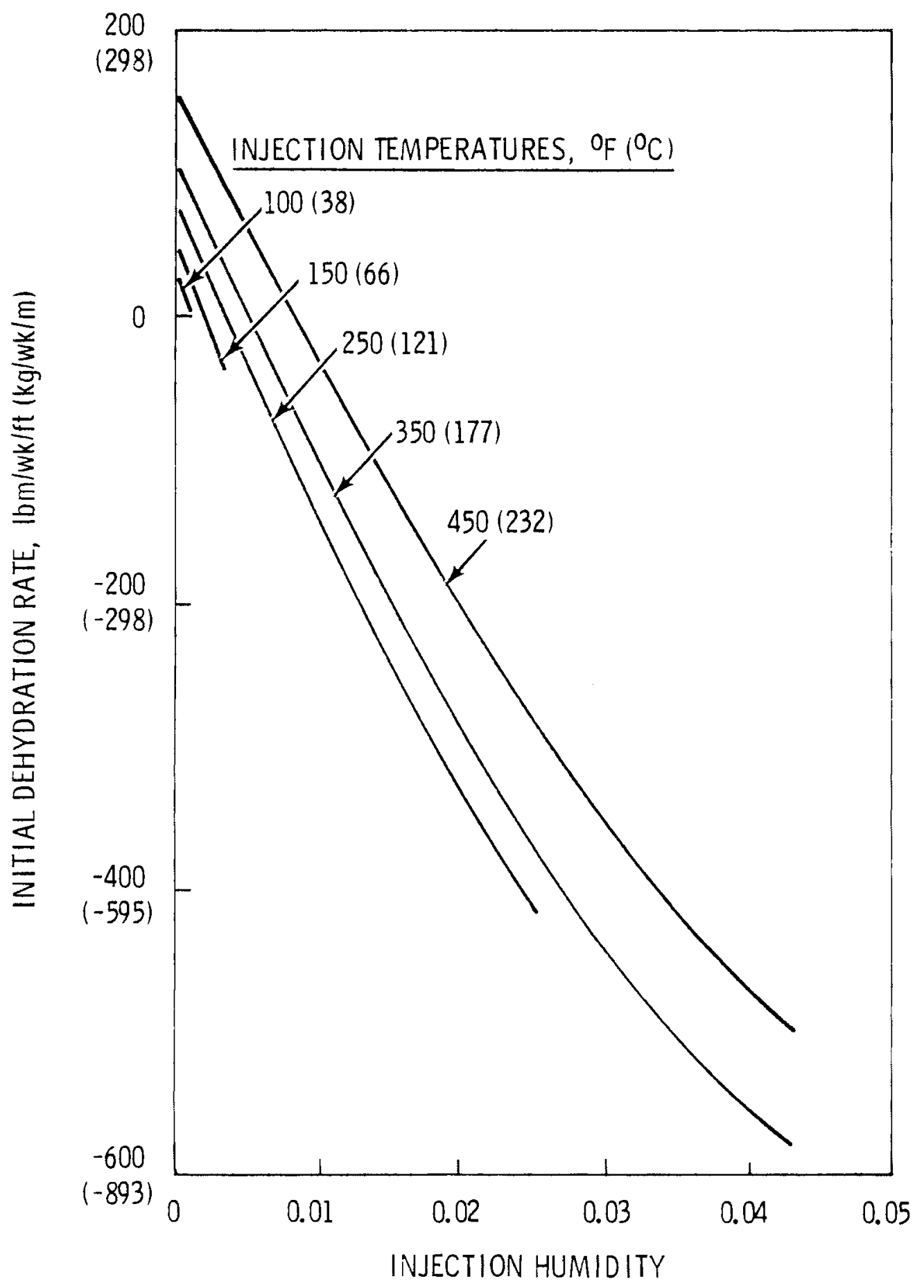

FIGURE 31. Effect of Injection Humidity on Initial Reservoir Dehydration Rates for Various Values of Injection Temperatures 
volume. The case of special interest is that of isothermal injection; $100^{\circ} \mathrm{F}\left(38^{\circ} \mathrm{C}\right)$ air injected into a reservoir initially at the same temperature. The model suggests that injection of fully saturated air at this temperature results in zero change in the water content in the reservoir. For any condition of the injected air that is less than saturated, net dehydration of the reservoir will occur. This behavior would be typical of any isothermal injection. For the other injection temperatures shown in Figure 31, the injection humidity that results in zero net dehydration can be derived. Again, this trade-off value of injection humidity will be affected by long term thermal growth.

The behavior of the long term dehydration rates is shown in Figures 32 through 36 for the five injection temperatures used in this analysis. In Figures 32, 33, and 34 the lower curves are developed for injection humidities that represent a degree of saturation of $50 \%$. For injection temperatures above $100^{\circ} \mathrm{F}\left(38^{\circ} \mathrm{C}\right)$ injecting saturated air results in eventual plugging of the reservoir; i.e., the calculated pore volume water content will reach $100 \%$ of pore volume at an indefinite location and time. Such conditions do not produce meaningful results, al though they do indicate, qualitatively, the potential problem.

For the injection temperatures other than $100^{\circ} \mathrm{F}\left(38^{\circ} \mathrm{C}\right)$ the behavior of each case is similar. The dehydration rate for dry air injection decreases because the dry front moves out of the near well region where thermal cycling is observed. The periodically higher temperatures near the well no longer influence the dehydration. The dehydration rate effectively increases in time (i.e., becomes less negative), for the cases of humid air injection because the thermal pillar has increased in size. Some of the moist air can be stored in the region of the reservoir where the temperature is above the dew point. The air is subsequently extracted without depositing any moisture.

In spite of the observation that the injection of moist air into the reservoir can result in the increase of the mass of liquid water in the reservoir, the region near the wellbore can still be dehydrated. The 


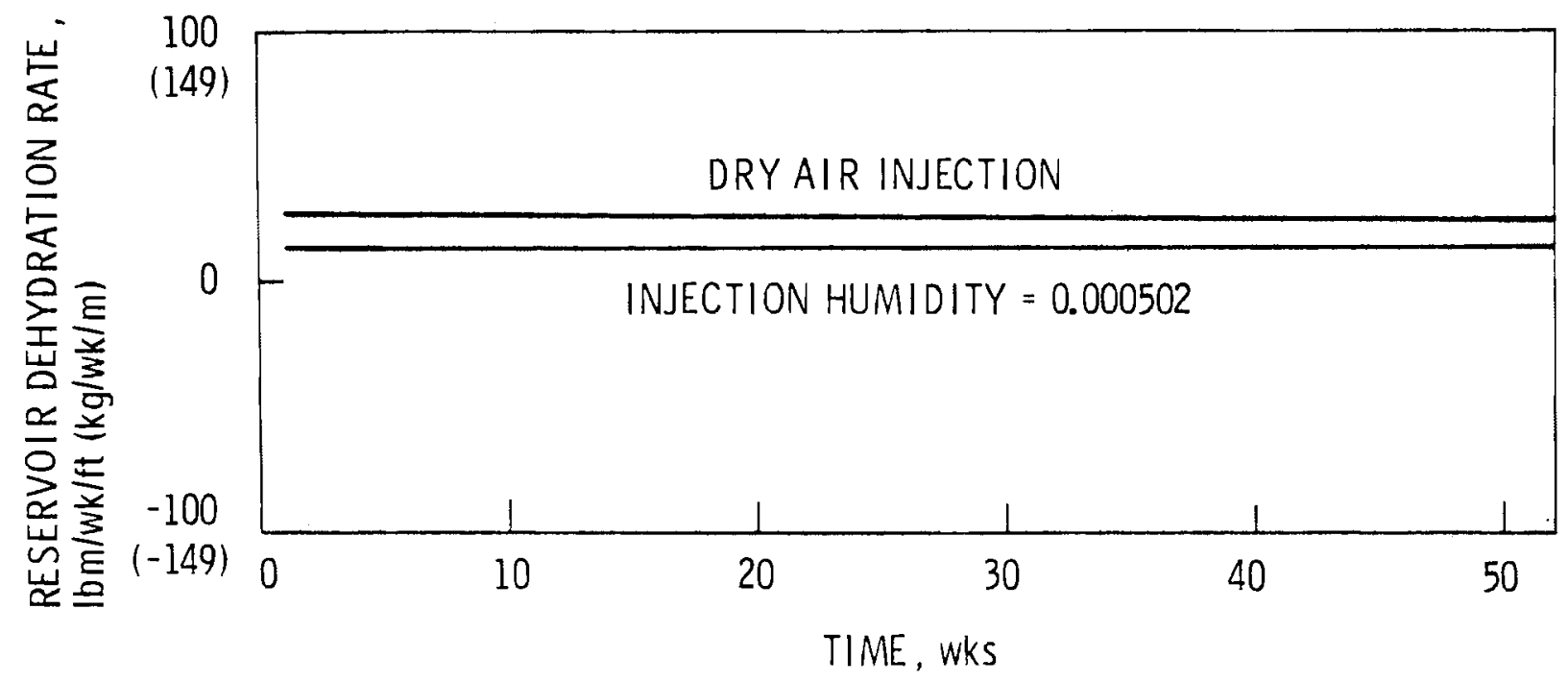

FIGURE 32. Effect of Injection Humidity on Dehydration Rate: $100^{\circ} \mathrm{F}$ $\left(38^{\circ} \mathrm{C}\right)$ Injection Temperature

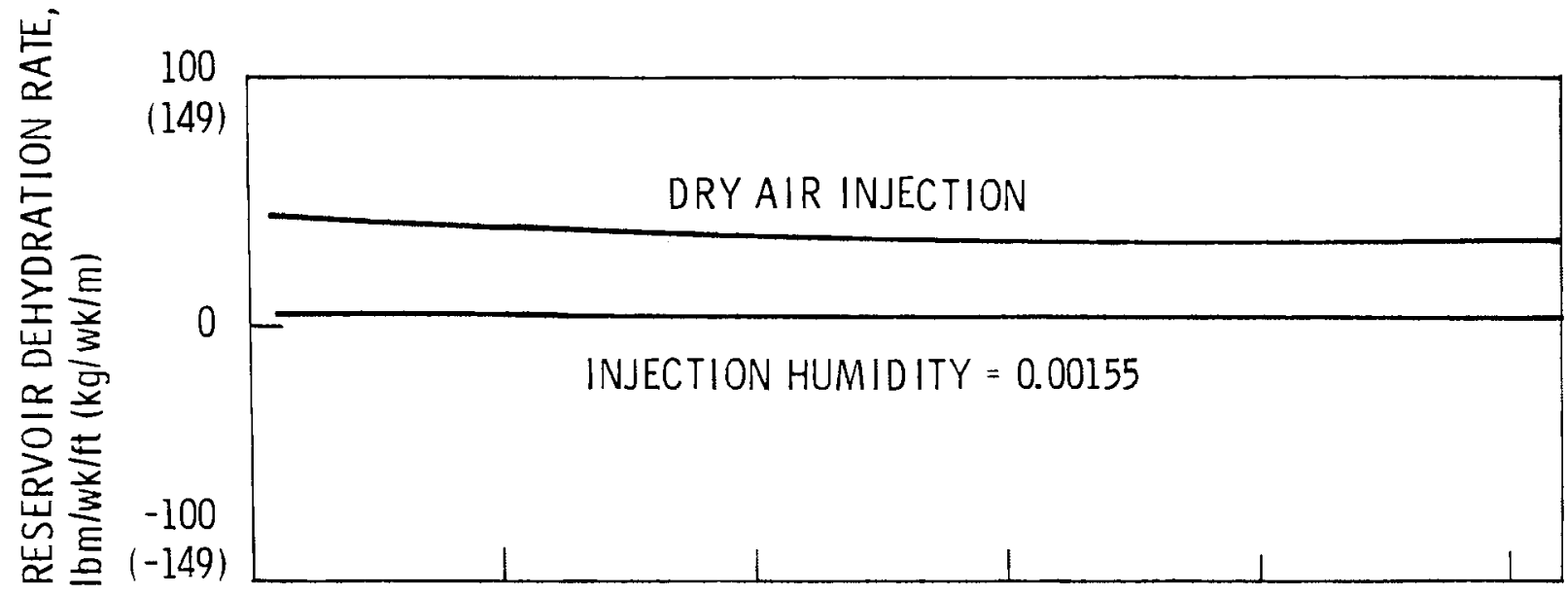

FIGURE 33. Effect of Injection Humidity on Dehydration Rate: $150^{\circ} \mathrm{F}$ $\left(66^{\circ} \mathrm{C}\right)$ Injection Temperature 


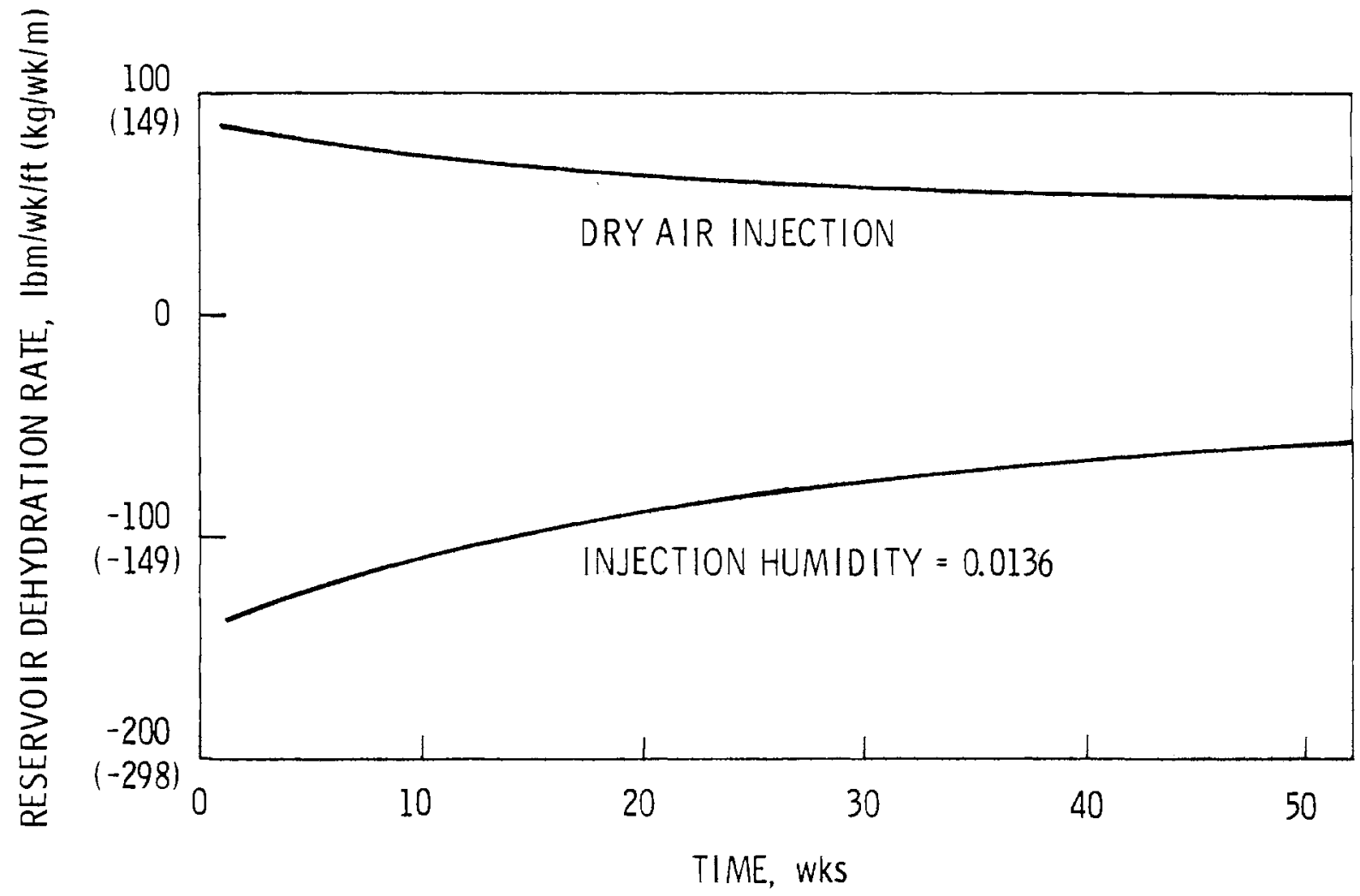

FIGURE 34. Effect of Injection Humidity on Dehydration Rate: $250^{\circ} \mathrm{F}$ $\left(121^{\circ} \mathrm{C}\right)$ Injection Temperature

progression of the dry front with time is shown in Figures 37 to 41 . Although the dry fronts appear to move outward rapidly, conservative reservoir design will likely dictate that considerable effort be given to minimizing the injection humidity.

In the first few weeks of mass cycling in the reservoir, the dry front is within the near well region characterized by thermal cycling. If the temperature is well above the dew point of the injected air stream, significant evaporation can occur. For example, during injection of $450^{\circ} \mathrm{F}\left(232^{\circ} \mathrm{C}\right)$ air, the regions very near the we 11 approach this temperature, as shown in Figure 13. At $50 \mathrm{~atm}(5070 \mathrm{kPa})$ pressure and $450^{\circ} \mathrm{F}\left(232^{\circ} \mathrm{C}\right)$ the absolute humidity of a saturated air-vapor mixture is about 0.850 , well above the 0.0429 maximum injected humidity. Thus, a great deal of 


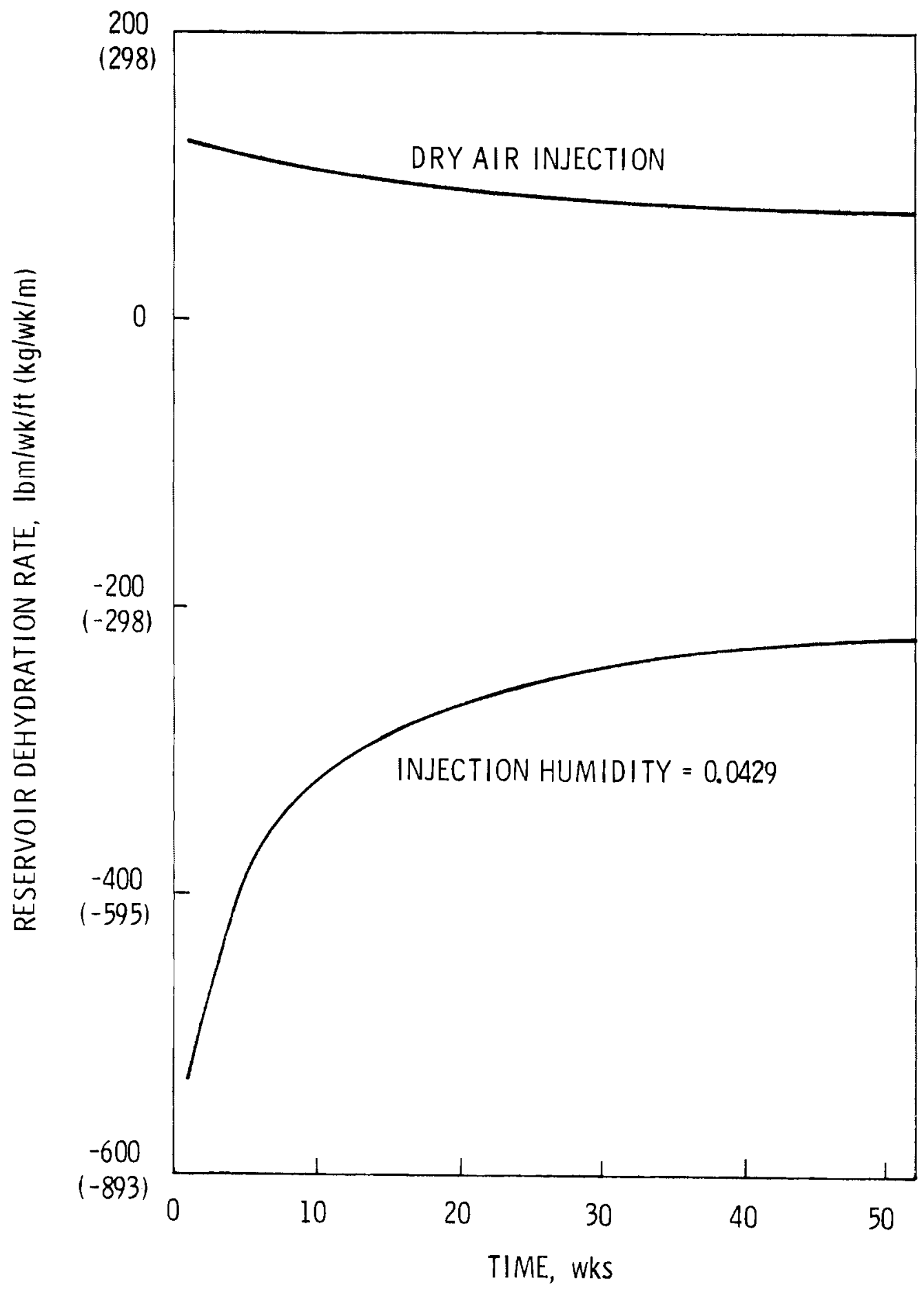

FIGURE 35. Effect of Injection Humidity on Dehydration Rate: $350^{\circ} \mathrm{F}$ $\left(177^{\circ} \mathrm{C}\right)$ Injection Temperature 


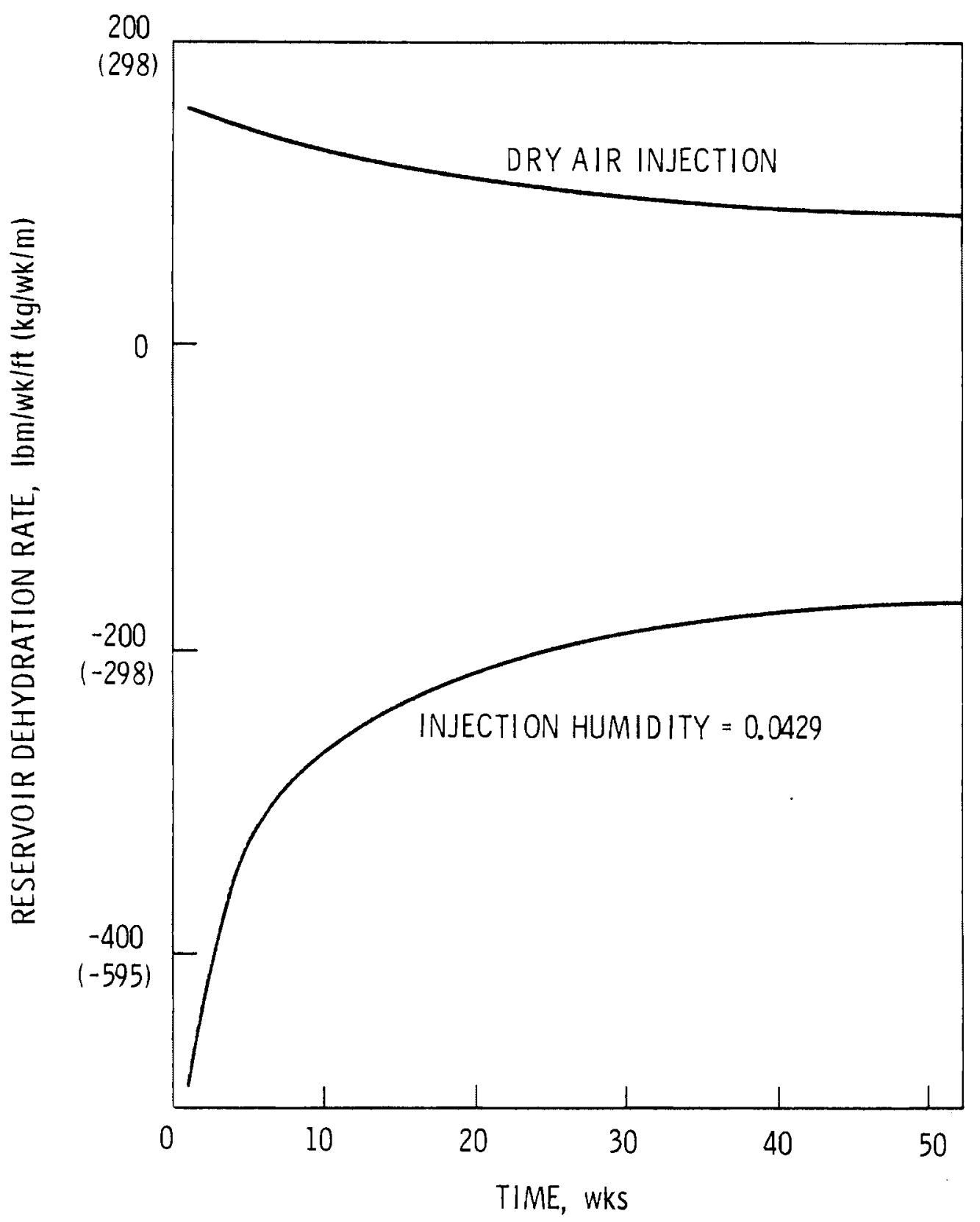

FIGURE 36. Effect of Injection Humidity on Dehydration Rate: $450^{\circ} \mathrm{F}$ $\left(232^{\circ} \mathrm{C}\right)$ Injection Temperature 


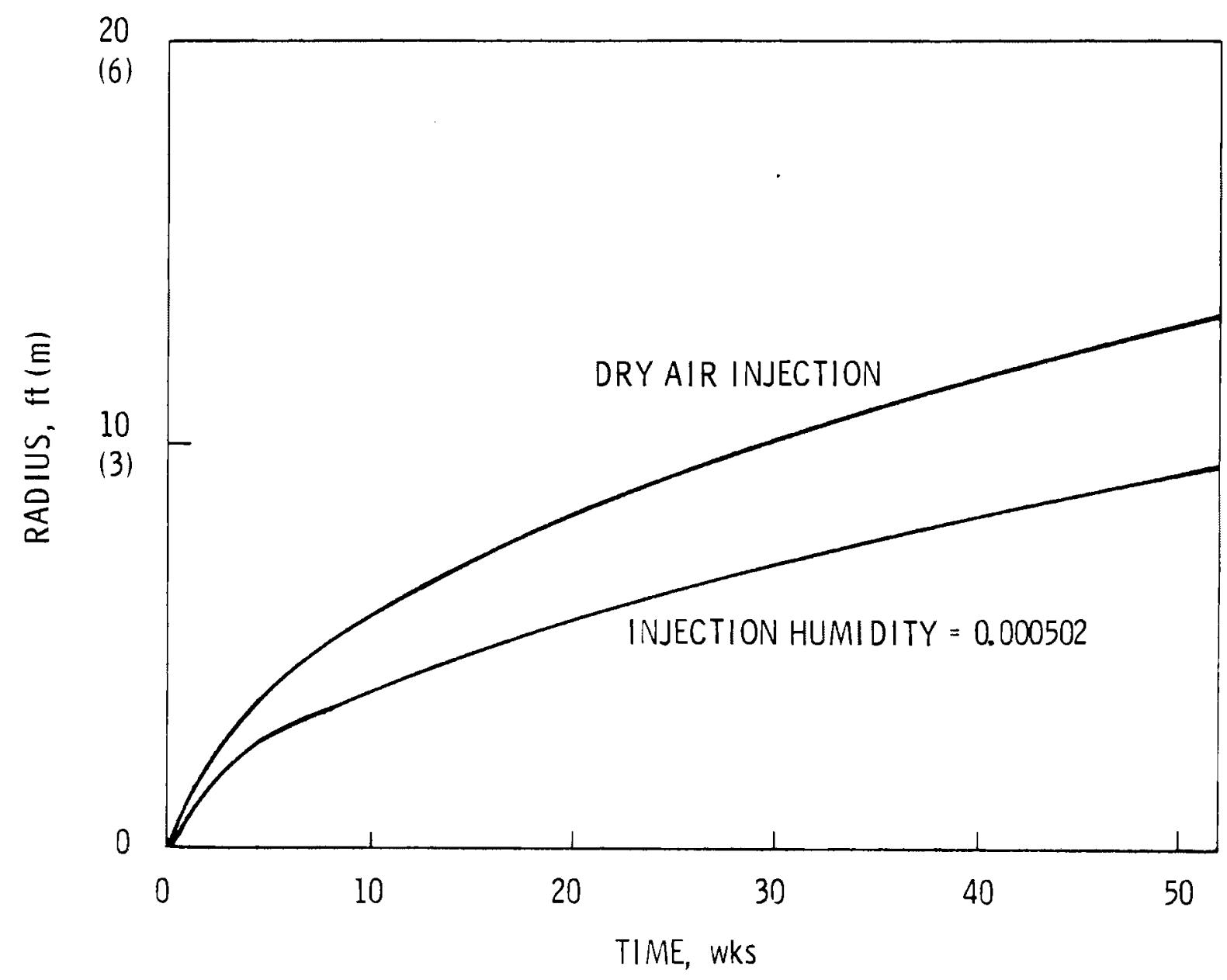

FIGURE 37. Effect of Injection Humidity on Growth of the Dry Front: $1000 \mathrm{~F}(380 \mathrm{C})$ Injection Temperature

liquid water can be evaporated and transported radially outward, regardless of the possible moisture condition of the injected air. For this reason the dry fronts are observed to initially progress outward at about the same rate, independent of the injection humidity.

When the dry front has moved beyond the region characterized by thermal cycling, the behavior changes. In order for evaporation to occur at the dry front, the region must be warmer than the dew point of the injected air stream. Heating of the reservoir beyond the region of thermal cycling occurs primarily by conduction. This is a very slow 


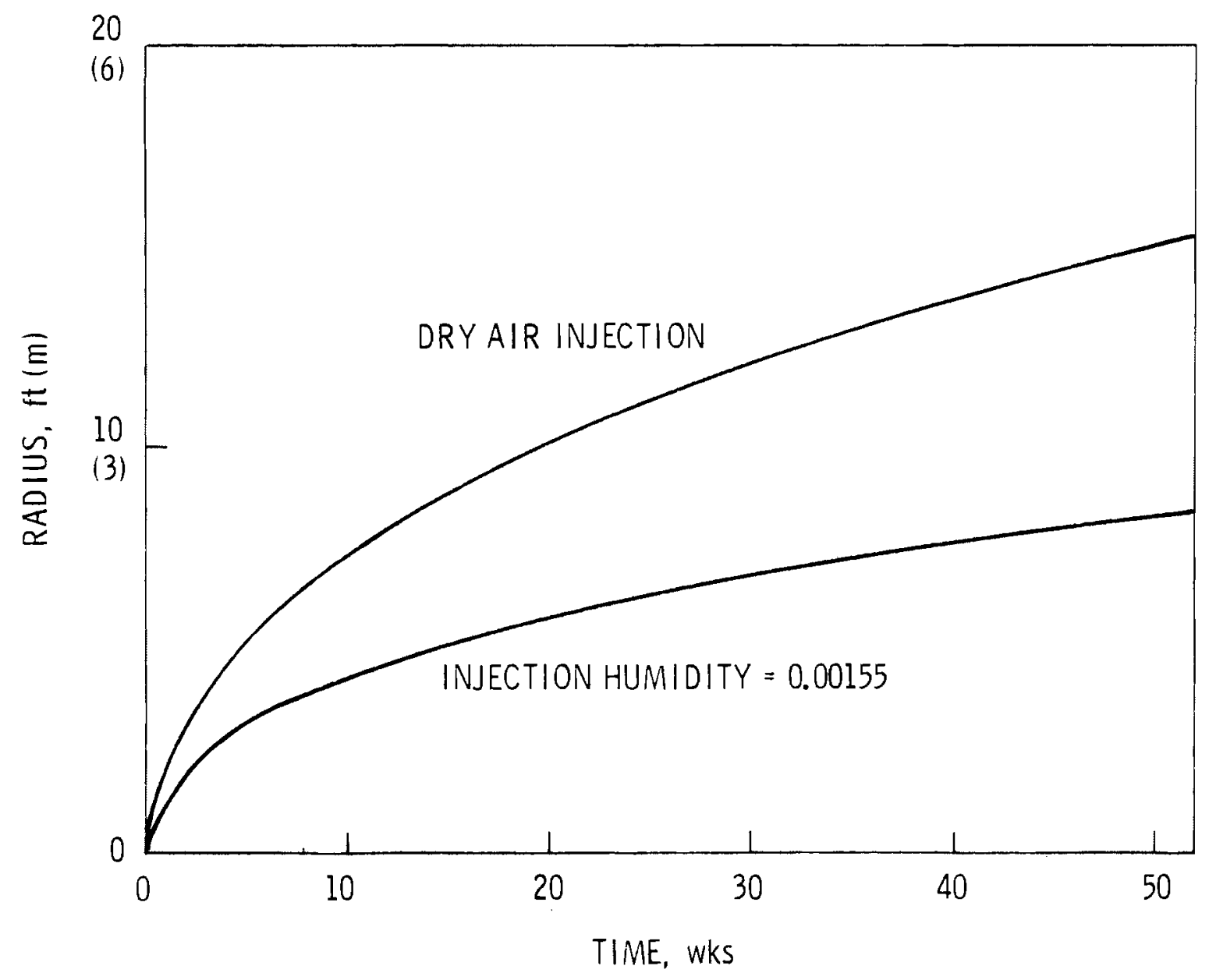

FIGURE 38. Effect of Injection Humidity on Growth of the Dry Front: $150^{\circ} \mathrm{F}\left(66^{\circ} \mathrm{C}\right)$ Injection Temperature

process. For am injection humidity of 0.0429 , evaporation cannot occur until the temperature reaches $276^{\circ} \mathrm{F}\left(136^{\circ} \mathrm{C}\right)$. On the other hand, evaporation can occur immediately for the injection of dry air. The result is that the growth of the dry front slows dramatically for humid air injection once the dry front is beyond the region of thermal cycling. For some cases pore plugging is predicted by the model because condensation occurs at the dry front until the temperature reaches the dew point of the injected air. Thus, to establish criteria for the required size of the dehydrated zone around the we11, the moisture content of the injected air must be considered. 


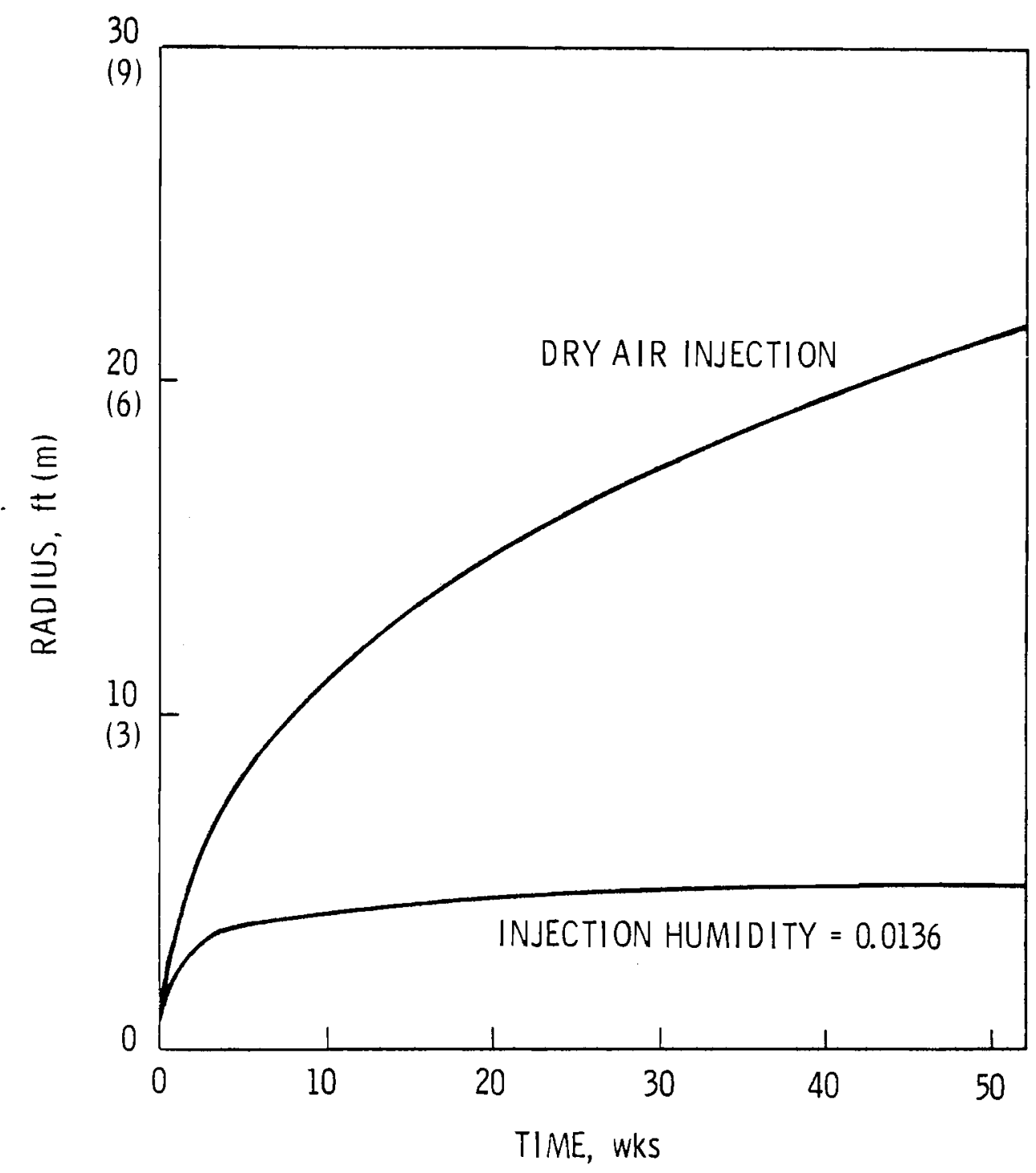

FIGURE 39. Effect of Injection Humidity on Growth of the Dry Front: $250^{\circ} \mathrm{F}\left(121^{\circ} \mathrm{C}\right)$ Injection Temperature

For humid air injection the model indicates that the temperature at the dry front is characterized by the dew point temperature of the injected mixture. For example, consider the results for humid air injection in Figures 28 and 41 . After 1 year of reservoir operation the dry front is at a radius of about $16 \mathrm{ft}(5 \mathrm{~m})$. The temperature at this location is about $270^{\circ} \mathrm{F}$, approximately the dew point of the injection air-vapor mixture. This behavior of the temperature at the dry front 


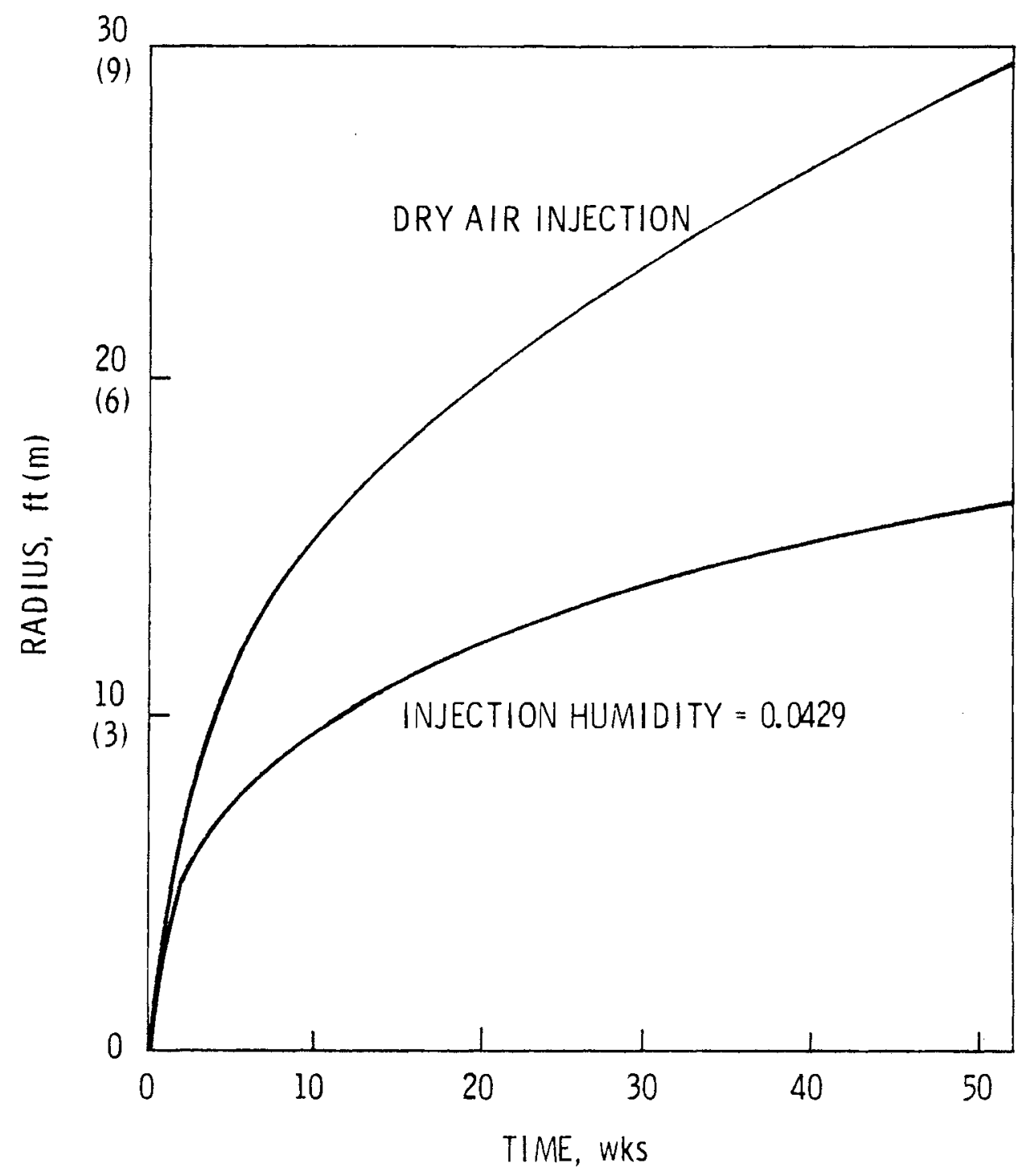

FIGURE 40. Effect of Injection Humidity on Growth of the Dry Front: $350^{\circ} \mathrm{F}\left(177^{\circ} \mathrm{C}\right)$ Injection Temperature

probably holds true for injection humidities above those for which the net dehydration is negative. For lower injection humidities, for which the net dehydration is positive, conductive heating will influence the growth of the dry front because the required amount of heating for evaporation to occur is very sma11. Thus, the behavior of the temperature at the dry front depends on the combined influence of the rate of conduction and the amount of mass being transferred through the dry front. 


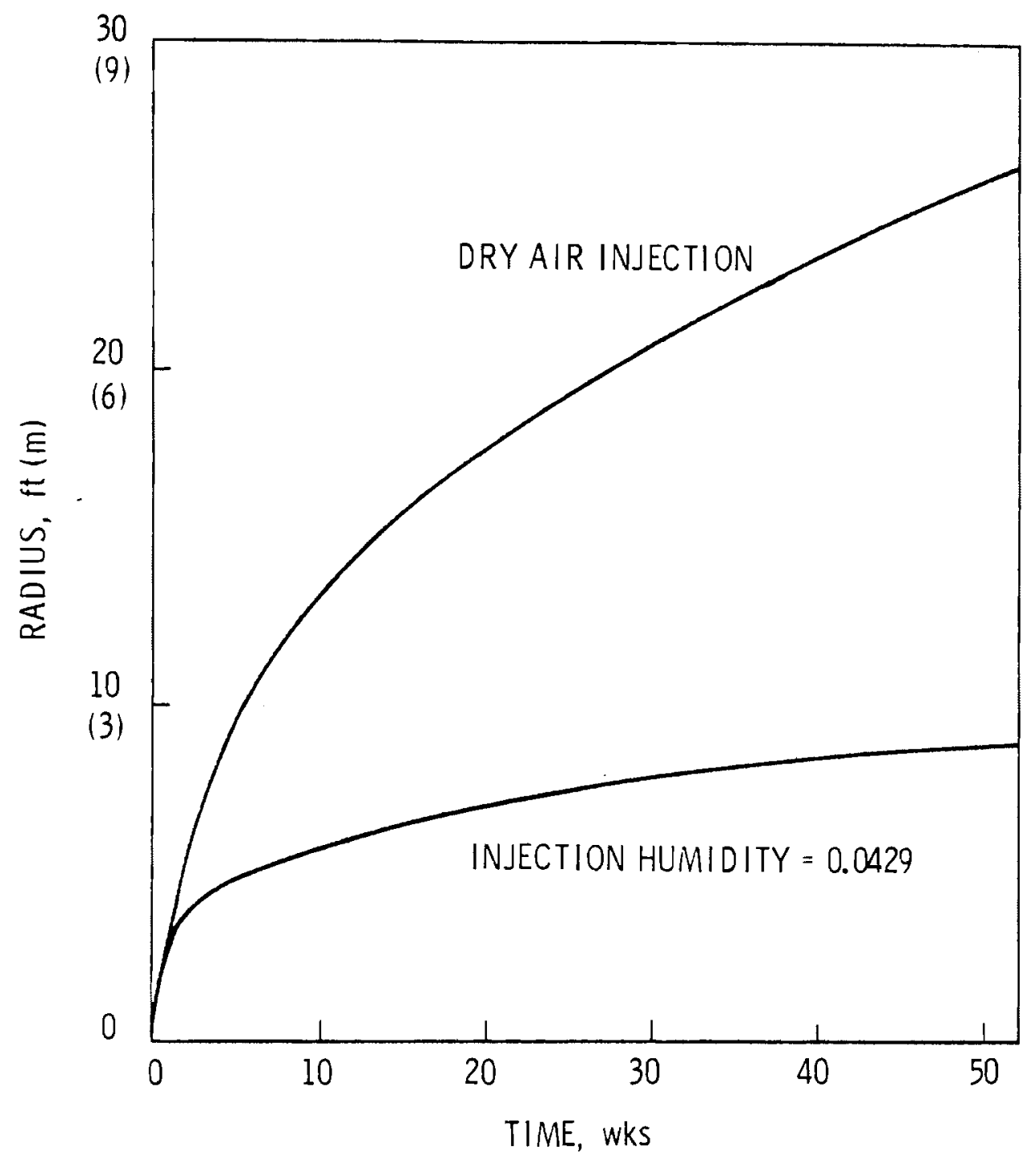

FIGURE 41. Effect of Injection Humidity on Growth of the Dry Front: $450^{\circ} \mathrm{F}\left(232^{\circ} \mathrm{C}\right)$ Injection Temperature

This detail on the temperature of the dry front is important because when air is discharged from the reservoir it will gain moisture until it reaches the dry front. According to the mode1, the mixture is saturated at that temperature and pressure. Therefore, knowing these conditions will allow the humidity of the produced air stream to be predicted. Additionally, the temperature at the dry front is important with respect to potential adverse geochemical reactions. If the temperature 
at the dry front is characterized by the dew point temperature of the injected air-vapor mixture, then reasonable limits can be placed on the allowable humidity of the injected air. With a reservoir pressure of $50 \mathrm{~atm}(5070 \mathrm{kPa})$ an injection humidity of 0.0429 has a dew point at $276^{\circ} \mathrm{F}\left(136^{\circ} \mathrm{C}\right)$. If the existence of liquid water at this temperature were known to produce adverse geochemical reactions, then some dehydration of the injected air stream would be necessary.

\subsection{RESIDUAL WATER}

The effect of residual water on thermal growth, thermal energy recovery and dehydration has been included in the discussion in previous sections. The basic conclusion is that this parameter should not have a large impact on reservoir performance. While a residual water content of $20 \%$ of pore volume in a reservoir of 500 md permeability and $20 \%$ porosity is considered typical, we might anticipate residual water contents as high as $40 \%$ of pore volume for these conditions. However, the thermal capacity of this mass is not so large that it can significantly affect the thermal behavior and dehydration in the reservoir. Its greatest impact would be to reduce the storage volume available in the porous structure of the reservoir. To obtain given mass flow rates to a given size reservoir, a greater percent of pore volume initially filled with water will result in proportionally higher pressure cycling.

The primary effect of residual water on the dehydration can be deduced by considering Figures 42 and 43 . For a given reservoir volume the reservoir having a residual water content of $40 \%$ of pore volume will initially have twice the mass of liquid water as the reservoir having a residual water content of $20 \%$ of pore volume. Although the therma 1 development of both reservoirs occurs at nearly identical rates, the reservoir having more residual water has a higher dehydration rate. Because the dry front moves radially outward at a slower pace for the case having more residual water, the dry front is in a region of the reservoir where the temperature is higher. During reservoir discharge the air gains moisture until it reaches the dry front. The model 


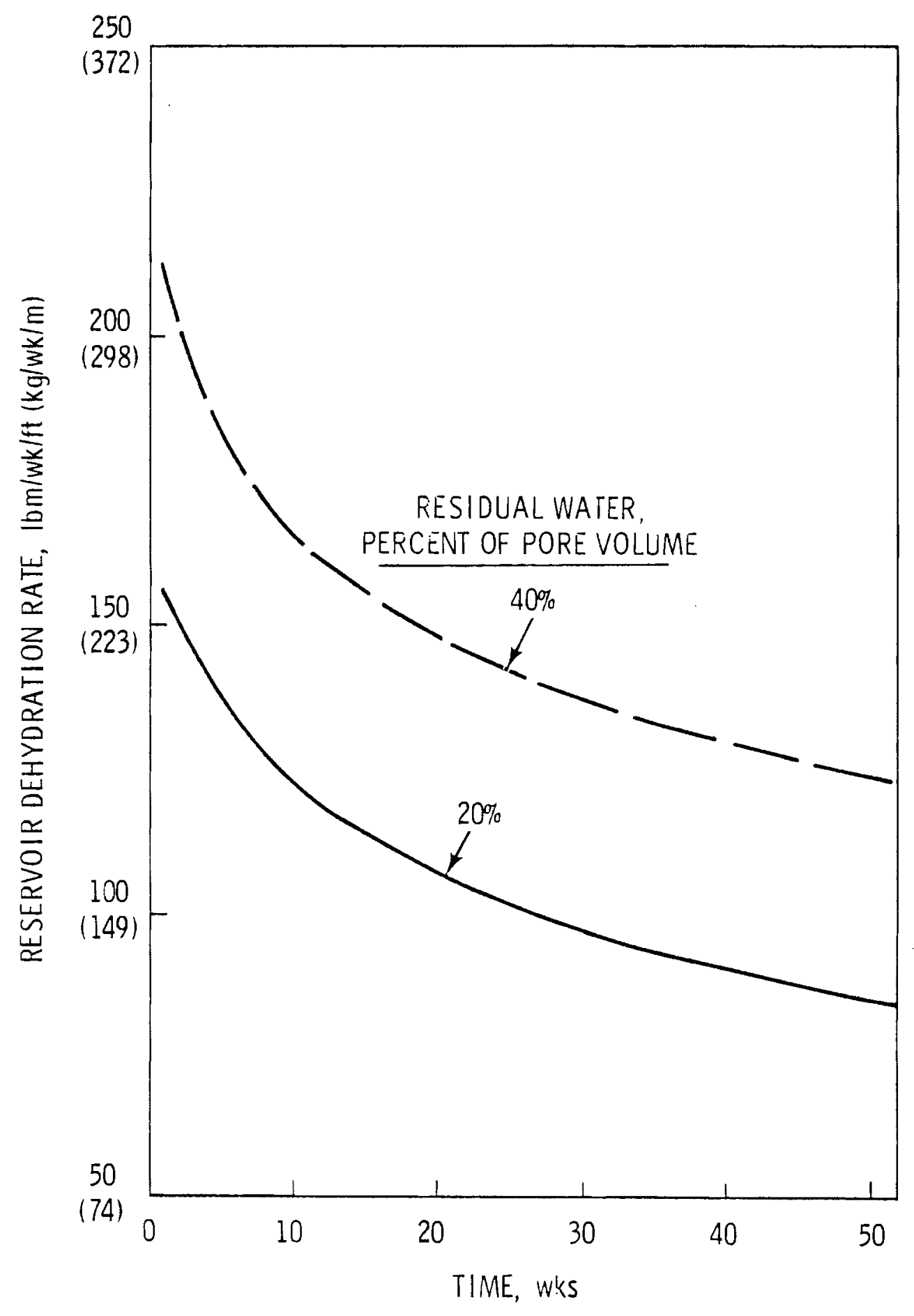

FIGURE 42. Effect of Residual Water on Dehydration Rate 


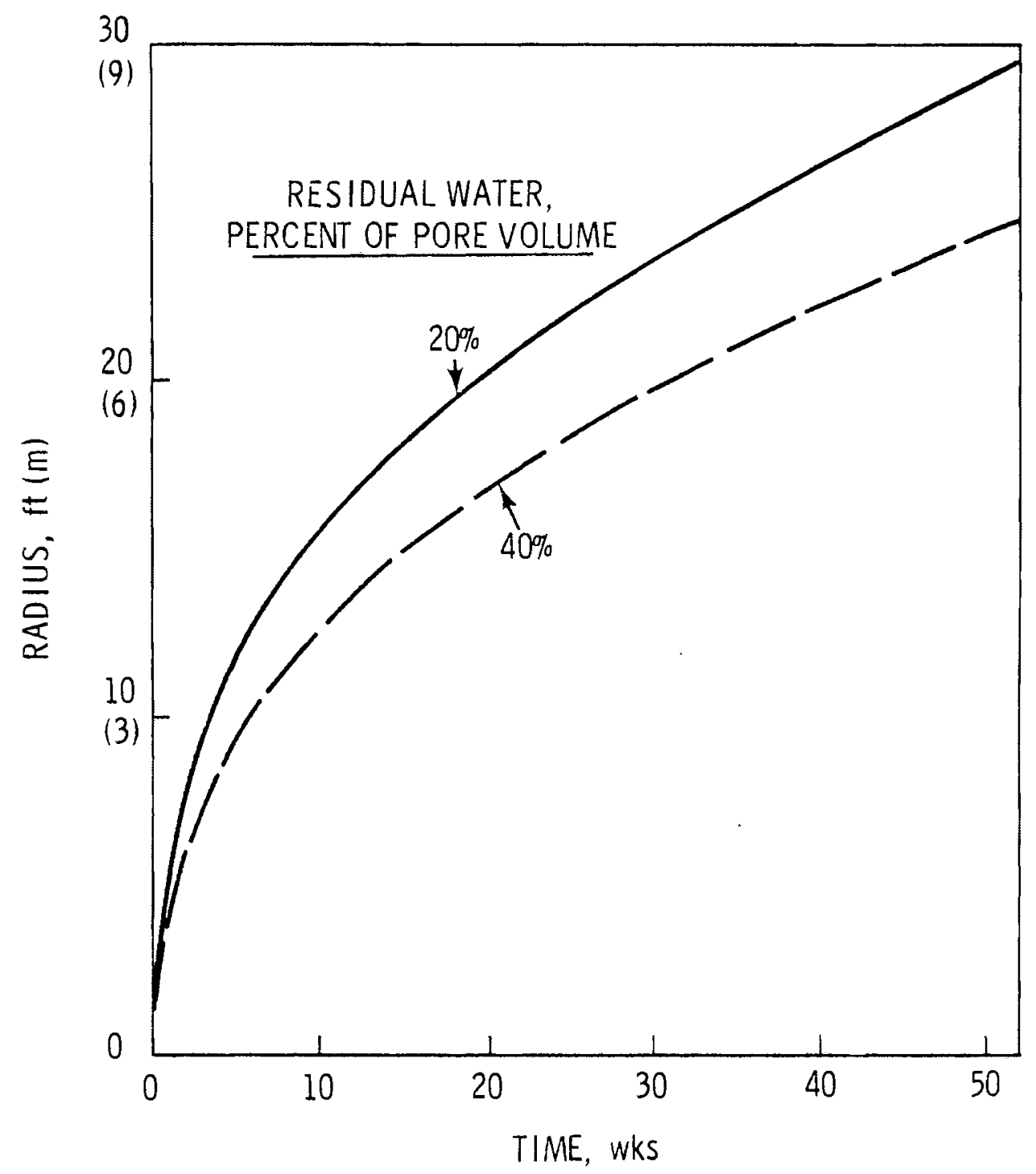

FIGURE 43. Effect of Residual water on Growth of the Dry Front

dictates that the air-vapor mixture will be saturated at the temperature and pressure of the dry front. Since the temperature at the dry front is greater for the case of higher residual water content, the extracted humidity will be greater. Thus, the net reservoir dehydration rate, shown in Figure 43, is greater for the case having more residual water, even though the temperature of the extracted mixtures would be about the same. 


\subsection{SUMMARY, CONCLUSIONS AND RECOMMENDATIONS FOR FURTHER STUDY}

The results of the computer analysis provide insights as to how the presence of residual water in an aquifer CAES reservoir may affect the performance of the reservoir. The results also have provided either new knowledge of the process of dehydration, or verification and quantification of logicaliy expected behavior. More importantly, perhaps, the results can be used to suggest how the presence of the residual water will affect the areas of concern outlined in the problem description.

\subsection{DELIVERABILITY}

It appears that high temperature injection may not be necessary to avoid reduced deliverability due to reduced relative permeability in the vicinity of the wellbore. For a broad range of conditions, the computer mode 1 predicts that comparatively rapid dehydration of the wellbore region is achieved. Reduced deliverability may be more significant for high temperature injection due to the greater viscosity of the air, which would increase the flow resistance.

Injection humidities may prove to be very important to the integrity of reservoir operation. Calculations show that pore plugging can result. Although a liquid mobility model was not included in the analysis, the potential plugging problem is probably quite real. This would certainly have a significant impact on deliverability.

Reduced deliverability related to geochemical reactions was not quantitatively evaluated. However, it was found that a dry zone to a radius of $10 \mathrm{ft}(3 \mathrm{~m})$ could be achieved relatively quickly regardless of the injection temperature. If a dry zone to a radius of $20 \mathrm{ft}(6 \mathrm{~m})$ is required to eliminate concern over long-term geochemical reactions, injection of higher temperature air may be necessary if the dry zone is to be achieved in a reasonable amount of time. Aiso, for dry air injection up to $450^{\circ} \mathrm{F}\left(232^{\circ} \mathrm{C}\right)$, it was shown that the coexistence of high temperatures and liquid water may not be a typical situation but would 
occur only in the initial period of reservoir operation. The potential for geochemical reactions would be significantily reduced by this behavior.

\subsection{THERMAL ENERGY RECOVERY}

In general, the mass of residual liquid water in an aquifer CAES reservoir should be small compared to the total mass of rock in the reservoir. Thus, variations in the residual water content will not have a large effect upon the overall thermal behavior of the reservoir. Thermal energy recovery will be more significantly affected by the humidity of the injected air stream. Dry air injection results in net evaporation which inhibits thermal energy recovery. Condensation resulting from moist air injection adds the latent heat to the thermal energy of the reservoir and, therefore, enhances the thermal energy recovery.

\subsection{WORKING FLUID RECOVERY}

The injection of dry air resulting in net evaporation will increase the working fluid available in the reservoir. Thus, the charging cycle could be shortened somewhat to maintain a constant cushion mass in the reservoir. Condensation of moisture injected into the reservoir reduces the amount of working fluid. In this case, the duration of the charging cycle would have to be increased to maintain a constant cushion mass. Thus, it may be necessary to weigh the importance of thermal energy recovery against working fluid recovery. However, the model suggests that there is relatively little to be gained or lost in the balance between working fluid recovery and thermal energy recovery. It is apparently more important to consider the potential pore plugging problem. Conservative reservoir design would, therefore, require that relatively dry air be injected to the reservoir to decrease the potential for pore plugging. This would cause an expected decrease in thermal energy recovery with a gain in the amount of working fluid. 


\subsection{STORAGE VOLUME}

The presence of residual water in the pore structure of the reservoir rock reduces the potential storage volume. Dehydration should not, in general, be expected to significantly improve this situation. In five years of simulated operation of the reference reservoir, only 17100 $1 \mathrm{bm} / \mathrm{ft}(25400 \mathrm{~kg} / \mathrm{m})$ of water was removed from the air storage zone. This is only $5.5 \%$ of the origina 7 mass of water and represents only a $1.1 \%$ increase in actual storage volume.

\subsection{PRODUCED VAPOR}

In general, the degree of saturation of the produced air stream should be low enough that condensation of vapor should not be a problem. The results of the model indicate that a fairly constant quantity of produced vapor can be expected for a significant portion, if not throughout, the expected life of the CAES facility.

\subsection{FURTHER STUDY}

These conclusions regarding the potential problems associated with residual water are subject to the assumptions made in the numerical mode1. The two most limiting assumptions of the model are zero liquid mobility and instantaneous saturation of the air-vapor mixture. Adjustments of the governing equations can be made to include liquid mobility. Improvements to the evaporation model will not be as direct.

It was initially anticipated that dehydration would occur very slowly, even in the near wellbore region. Since the presence of water in this region may hinder the performance of a reservoir, the model of instantaneous saturation was thought to be conservative because the model would predict the shortest time in which dehydration is achieved. If the existence of liquid water in the wellbore region cannot be tolerated for this length of time, then a realistically slower dehydration rate would be even less satisfactory. In this regard, however, the 
conservativeness of the model has not performed as expected. The computer model predicts that a relatively rapid dehydration of the wellbore region is attained over a very broad range of conditions. Although a computed mass transfer coefficient was found to be comparable to that required by the model, considerable uncertainty exists in the application of a theoretical prediction to this problem. Therefore, to assure realistic dehydration predictions an experimental program must be established to define the rates of evaporation and condensation. This program is part of a larger experimental program scheduled for FY-1979. 


\section{REFERENCES}

1. G.C. Smith, L.E. Wiles and W.V. Loscutoff, Numerical Analysis of Temperature and Flow Effects in a Dry, One-Dimensional Aquifer Used for Compressed Air Energy Storage. PNL-2546, Battelle, Pacific Northwest Laboratory, Richland, WA 99352, February 1979.

2. D. L. Katz et a 1., Handbook of Natural Gas Engineering. McGrawHi11 Book Company, New York, NY, 1959.

3. J. B. Bush, Jr. et al., Economic and Technical Feasibility Study of Compressed Air Storage. ERDA 76-76, General Electric Company, Schenectady, NY 12301, March 1976.

4. D. L. Katz and E. R. Lady, Compressed Air Storage For Electric Power Generation. UTrich Books, Inc., Ann Harbor, MI 48106, 1976. 
PNL-2869

UC-94b

\section{DISTRIBUTION}

No. of

Copies

OFFSITE

A. A. Churm

DOE Chicago Patent Group

Chicago Operations Office 9800 South Cass Avenue

Argonne, IL 60439

3 G. C. Chang

DOE Division of Energy Storage Systems

Advanced Physical Methods Branch

Washington, DC 20545

27 DOE Technical Information Center

B. J. Mueller

Department of Energy

Chicago Operations Office

9800 S. Cass Avenue

Argonne, IL 60439

Chief, APMBR

Division of Energy Storage Systems

U.S. Department of Energy Washington, DC 20545

R. Derby

Division of Energy Storage Systems

U.S. Department of Energy Washington, DC 20545

G. D. Pezdirtz, Director

Division of Energy Storage Systems

U.S. Department of Energy Washington, DC 20545
No. of

Copies

P. A. Thompson

DOE Division of Energy Storage Systems

Advanced Physical Methods Branch

Washington, DC 20545

J. H. Swisher

Division of Energy Storage Systems

U.S. Department of Energy

Washington, DC 20545

D. W. Boehm

Division of Environmenta 1

Control Technology

U.S. Department of Energy

Washington, DC 20545

Assistant Director for Major

Projects

Division of Solar Energy

U.S. Department of Energy

Washington, DC 20545

Assistant Director for Thermal

Power Systems

Division of Solar Energy

U.S. Department of Energy

Washington, DC 20545

DOE Library

U.S. Department of Energy

Mail Station G-043

Washington, DC 20545

R.F. Kimberlin

DOE Library

U.S. Department of Energy

Room 1223

Washington, DC 20545 
No. of

Copies

D. Willett

Acres American, Inc.

Liberty Bank Building

Main at Court

Buffalo, NY 14202

L. A. Wilson

Middle South Services

P.0. Box 61000

New Orleans, LA 70161

G. T. Flynn

Energy Systems Engineer

MIT/Lincoln Laboratory

Lexington, MA 02173

J. E. Calogeras

NASA Lewis Research Center

21000 Brookpark Road

Cleveland, $\mathrm{OH} 44135$

Division of Advanced Energy

Research and Technology

National Science Foundation

Room 1140

1800 G Street, NW

Washington, DC 20550

C. G. Nelson

Manager, Storage Operations

Northern Illinois Gas

Company

P.0. Box 190

Aurora, IL 60507

P. E. Schaub

Potomac Electric Power

Company

1900 Pennsylvania Avenue

Washington, DC 20006

T. McCafferty

Public Service Company

of Indiana

1000 E. Main Street

Plainfield, IN 46168
No. of

Copies

2 Technical Library

Department 3141

Sandia Laboratory

A1buquerque, NM 87115

J. Rasmussen

PEPCO

1900 Pennsylvania Avenue, N.W. Washington, DC 20068

S. Serata

Serata Geomechanics, Inc.

1229 Eighth Street

Berkeley, CA 94710

Energy Research Section

Tennessee Valley Authority

1360 Commerce Union Bank B1dg.

Chattanooga, TN 37401

A. Manaker

Director of Research

Tennessee Valley Authority

Chattanooga, TN 37401

E. Berman

Technical Library

TRW Energy Systems Group

7600 Colshire Drive

McLean, VA 22101

E. H. King

Underground Design Consultants

820 Cascade Bldg.

Portland, OR 97204

A. I. Giramonti

United Technologies Research Center

Silver Lane

East Hartford, CT 06108

H. J. Pincus

University of Wisconsin

Department of Geological

Sciences

Sabin Hall and Greene Museum

P.0. Box 413

Milwaukee, WI 53201 
No. of

Copies

D. Ayers

Manager, Fluid Systems

Laboratory

Westinghouse Electric

Corporation

1291 Cumberland Avenue

West Lafayett, IL 47906

American Public Power

Association

2600 Virginia Avenue, NW

Washington, DC 20037

2 G. T. Kartsounes

Argonne National Laboratory

9700 South Cass Avenue

Argonne, IL 60439

Manager, Research and

Development

Bonneville Power

Administration

P.0. Box 3621

Portland, OR 97208

Research Library, Reference Section

Information Division

Brookhaven Nationa 1

Laboratory

Upton, NY 11973

Stanley Stys

Vice President, American

Brown Boveri Corporation

New Brunswick, NJ 08902

Director of Research

Cincinnati Gas and and Electric Company

139 East Fourth Street

Cincinnati, $\mathrm{OH} 45202$

D. E. DeViney

Commonwealth Edison Company

1319 South First Avenue

Maywood, IL 60153
No. of

Copies

R. A. Bell

Consolidated Edison Company

4 Irving Place

New York, NY 10003

T. Schneider

Electric Power Research

Institute

Box 10412

Palo Alto, CA 94303

D. Anderson

Fenix and Scisson, Inc.

P.0. Box 15609

Tulsa, OK 74115

Director of Research

GPU Service Corporation

260 Cherry Hil1 Road

Parsippany, NJ 07054

A. H. Barber

Director of Marketing

Harza Engineering Company

150 S. Wacker Drive

Chicago, IL 60606

Library

Lawrence Berkeley Laboratory

University of California

Bldg. 50, Room 134

Berkeley, CA 94720

3 Technical Information Department, $L-3$

Lawrence Livermore Laboratory University of California

P.0. Box 808

Livermore, CA 94550

Director of Research Louisiana Power and Light

142 Delaronde Street

New Orleans, LA 70174 
No. of

Copies

I. Glendenning

Head of Long-Term Studies

Marchwood Engineering Labs

Southampton, England

A. Ferreira

Electric Power Research

Institute

NEPLAN

174 Brush Hill Avenue

West Springfield, MA 01089

ONSITE

DOE Richland Operations

Office

D. K. Jones

H. E. Ransom

Pacific Northwest Laboratory

H. J. Bomelburg

D. B. Cearlock

D. W. Dragnich

T. J. Doherty

J. R. Friley

A. J. Haverfield

L. D. Kannberg

W. V. Loscutoff (20)

M. A. McKinnon

L. T. Pedersen

S. J. Phillips

R. P. Smith

J. A. Stottlemyre

A. M. Sutey

D. S. Trent

L. E. Wiles

Technical Information (5)

Publishing Coordination (2)

R. A. Walter 